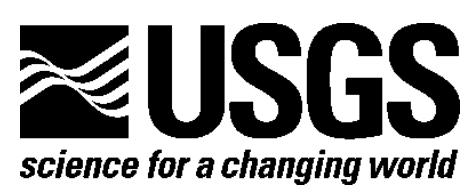

In cooperation with the The Nature Conservancy, National Park Service, and Bureau of Land Management

\title{
Assessment of Rangeland Ecosystem Conditions, Salt Creek Watershed and Dugout Ranch, Southeastern Utah
}

By Matthew A. Bowker, Mark E. Miller, and R. Travis Belote

Open File Report 2012-1061

U.S. Department of the Interior

U.S. Geological Survey 


\section{U.S. Department of the Interior \\ KEN SALAZAR, Secretary}

\section{U.S. Geological Survey \\ Marcia McNutt, Director}

\section{U.S. Geological Survey: Reston, Virginia 2012}

For product and ordering information:

World Wide Web: http://www.usgs.gov/pubprod

Telephone: 1-888-ASK-USGS

For more information on the USGS-the Federal source for science about the Earth, its natural and living resources, natural hazards, and the environment:

World Wide Web: http://www.usgs.gov

Telephone: 1-888-ASK-USGS

\section{Suggested citation:}

Bowker, M.A., Miller, M.E., and Belote, R.T., 2012, Assessment of rangeland ecosystem conditions, Salt Creek watershed and Dugout Ranch, southeastern Utah: U.S. Geological Survey Open-File Report 2012-1061, 56 p.

Any use of trade, product, or firm names is for descriptive purposes only and does not imply endorsement by the U.S. Government.

Although this report is in the public domain, permission must be secured from the individual copyright owners to reproduce any copyrighted material contained within this report. 


\section{Contents}

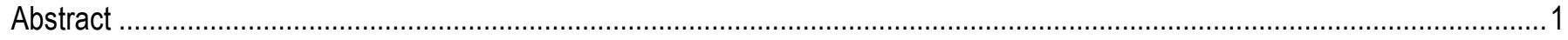

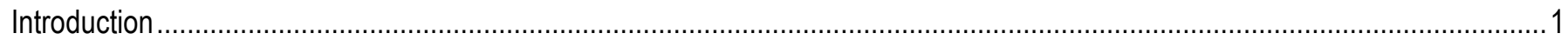

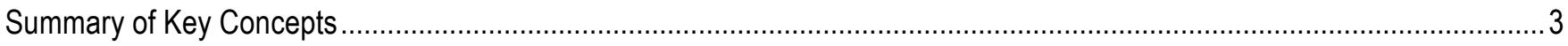

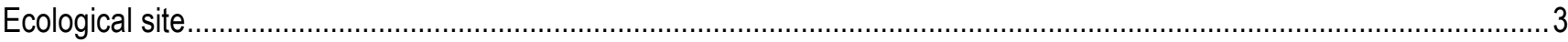

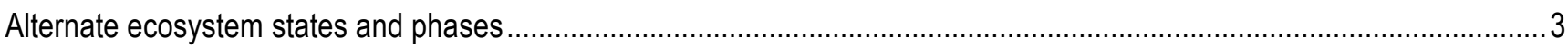

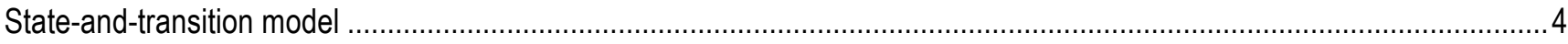

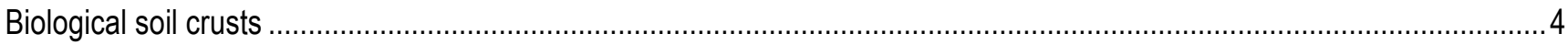

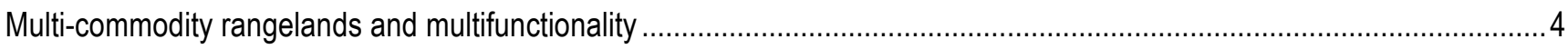

Methods

. .5

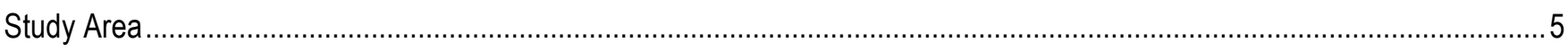

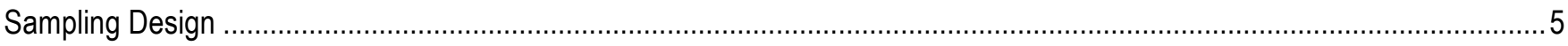

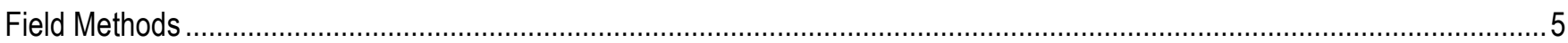

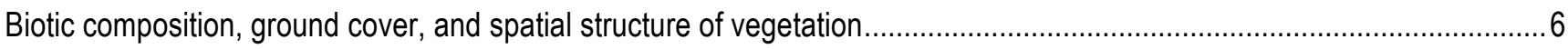

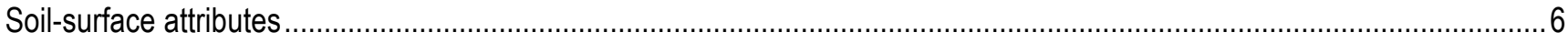

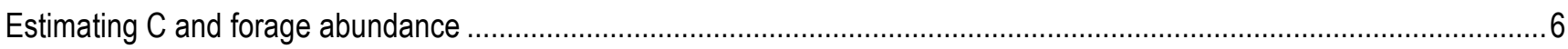

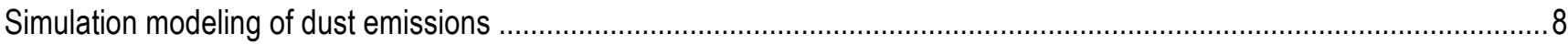

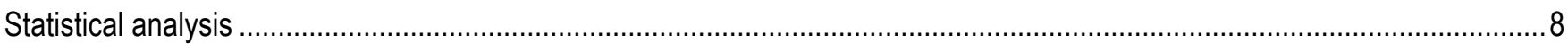

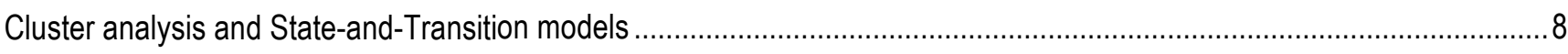

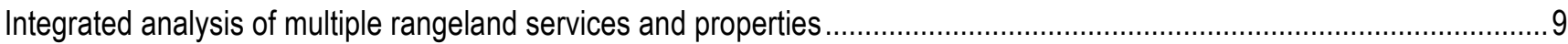

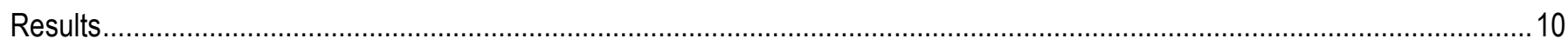

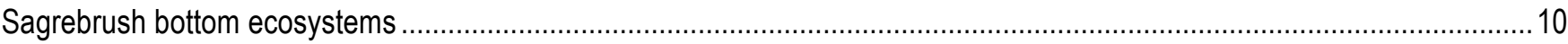

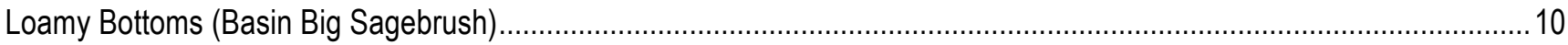

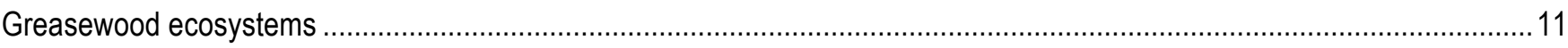

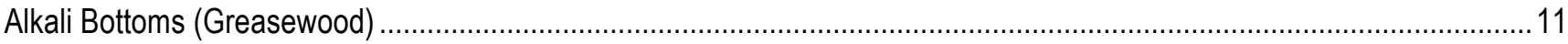

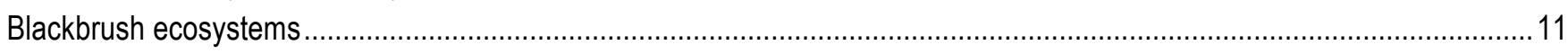

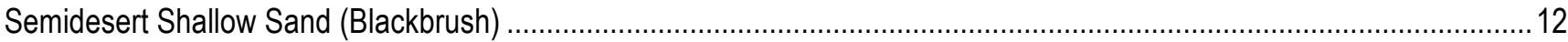

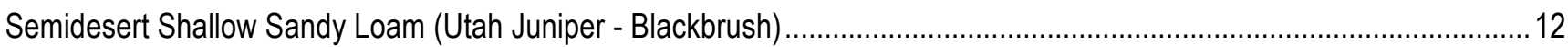

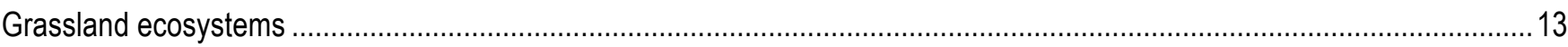

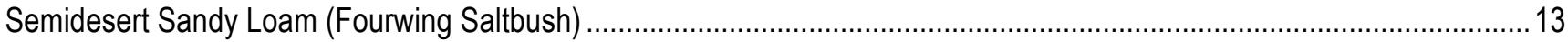

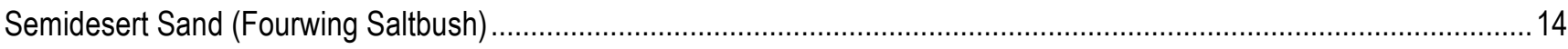

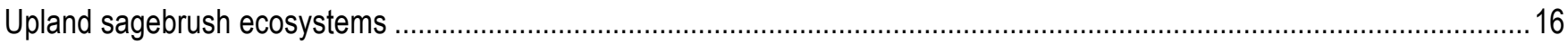

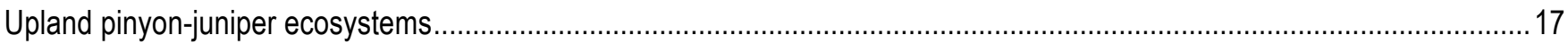

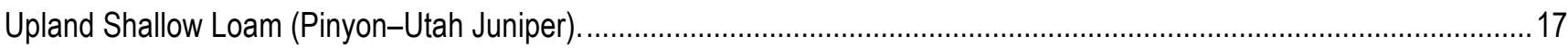

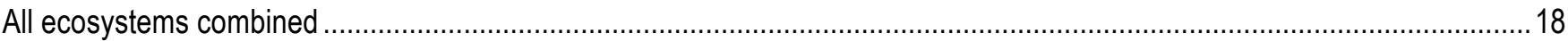

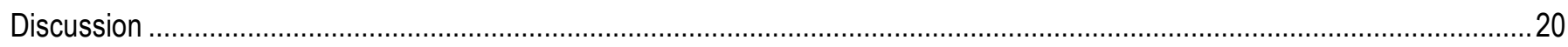

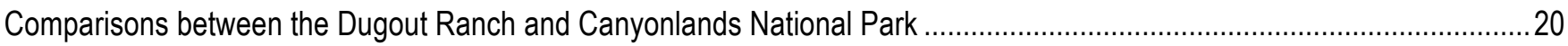

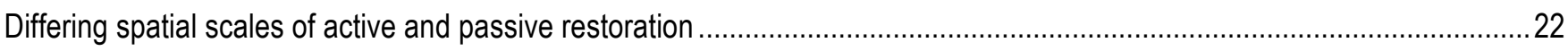

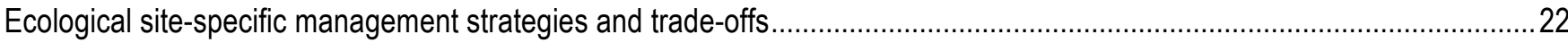

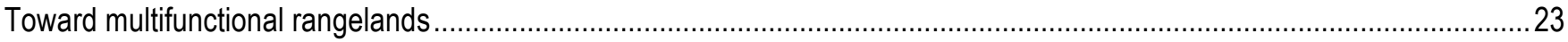

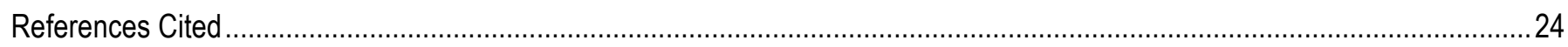




\section{Figures}

Figure 1. Map of the study area in southeastern Utah.

Figure 2. Provisional state-and-transition model illustrating alternate ecosystem states and phases, and hypothesized transitions among them for sagebrush bottom ecosystems.

Figure 3. Provisional state-and-transition model illustrating alternate ecosystem states and phases, and hypothesized transitions among them for greasewood ecosystems.

Figure 4. Provisional state-and-transition model illustrating alternate ecosystem states and phases, and hypothesized transitions among them for blackbrush ecosystems.

Figure 5. Provisional state-and-transition model illustrating alternate ecosystem states and phases, and hypothesized transitions among them for grassland ecosystems. a. Semidesert sandy loam. b. Semidesert sand.

Figure 6. Provisional state-and-transition model illustrating alternate ecosystem states and phases, and hypothesized transitions among them for upland sagebrush ecosystems.

Figure 7. Provisional state-and-transition model illustrating alternate ecosystem states and phases, and hypothesized transitions among them for upland pinyon-juniper ecosystems.

Figure 8. Map of C-storage P-scores applied to hydrological units in Canyonlands National Park and pastures in the Dugout Ranch.

Figure 9. Map of dust P-scores applied to hydrological units in Canyonlands National Park and pastures in the Dugout Ranch.

Figure 10. Map of forage P-scores applied to hydrological units in Canyonlands National Park and pastures in the Dugout Ranch.

Figure 11. Map of nativeness P-scores applied to hydrological units in Canyonlands National Park and pastures in the Dugout Ranch.

Figure 12. Map of multifunctionality (v. 1) P-scores applied to hydrological units in Canyonlands National Park and pastures in the Dugout Ranch.

Figure 13. Map of mutlifunctionality (v. 2) P-scores applied to hydrological units in Canyonlands National Park and pastures in the Dugout Ranch

Figure 14. Map of study sites across the study area with points scaled proportionally to absolute values of carbon storage $\left(\mathrm{kg} \mathrm{plot}^{-1}\right)$.

Figure 15. Map of study sites across the study area with points scaled proportionally to absolute values of modeled dust emission $\left(\mathrm{g} \mathrm{cm}^{-1} \mathrm{~d}-1\right.$ at $\left.3500 \mathrm{~cm} \mathrm{~s}^{-1}\right)$.

Figure 16. Map of study sites across the study area with points scaled proportionally to absolute values of preferred forage biomass $\left(\mathrm{kg} \mathrm{plot}^{-1}\right)$

Figure 17. Map of study sites across the study area with points scaled proportionally to absolute values of relative exotic

cover (percent)

\section{Tables}

Table 1. Ecosystem services and properties estimated, and data sources and models used to estimate them.

Table 2. Plots sampled in this study by land ownership, ecosystem type, and year sampled.

Table 3. Mean values and coefficient of variation $(\times 100)$ describing key attributes of clusters in Loamy Bottoms. Variables underlined in bold indicate those used in cluster analysis.

Table 4. Mean values and coefficient of variation ( $\times 100)$ describing key attributes of clusters in Alkali Bottoms. Variables underlined in bold indicate those used in cluster analysis.

Table 5. Mean values and coefficient of variation (x 100) describing key attributes of clusters in Semidesert Shallow Sand. Variables underlined in bold indicate those used in cluster analysis. 
Table 6. Mean values and coefficient of variation (x 100) describing key attributes of clusters in Semidesert Shallow Sandy Loam. Variables underlined in bold indicate those used in cluster analysis.

Table 7. Mean values and coefficient of variation $(\times 100)$ describing key attributes of clusters in Semidesert Sandy Loam. Variables underlined in bold indicate those used in cluster analysis.

Table 8. Mean values and coefficient of variation ( $\times 100)$ describing key attributes of clusters in Semidesert Sand. Variables underlined in bold indicate those used in cluster analysis.

Table 9. Mean values and coefficient of variation $(\times 100)$ describing key attributes of clusters in Upland Loam. Variables underlined in bold indicate those used in cluster analysis.

Table 10. Mean values and coefficient of variation ( $\times 100)$ describing key attributes of clusters in Upland Shallow Loam. Variables underlined in bold indicate those used in cluster analysis.

Table 11. Summary of P-scores for hydrological units of the Needles District of Canyonlands, and pastures of the Indian Creek Allotment of the Dugout Ranch..

Table 12. Summary of E-scores for major ecological sites within hydrological units of the Needles District of Canyonlands, and pastures of the Indian Creek Allotment of the Dugout Ranch. 
This page intentionally left blank 


\title{
Assessment of Rangeland Ecosystem Conditions, Salt Creek Watershed and Dugout Ranch, Southeastern Utah
}

\author{
By Matthew A. Bowker, Mark E. Miller, and R. Travis Belote
}

\begin{abstract}
Increasingly, dry rangelands are being valued for multiple services beyond their traditional value as a forage production system. Additional ecosystem services include the potential to store carbon in the soil and plant biomass. In addition, dust emissions from rangelands might be considered an ecosystem detriment, the opposite of an ecosystem service. Dust emitted may have far-reaching impacts, for example, reduction of local air quality, as well as altering regional water supplies through effects on snowpack. Using an extensive rangeland monitoring dataset in the greater Canyonlands region (Utah, USA), we developed a method to estimate indices of the provisioning of three ecosystem services (forage production, dust retention, $\mathrm{C}$ storage) and one ecosystem property (nativeness), taking into account both ecosystem type and alternative states within that ecosystem type. We also integrated these four indices into a multifunctionality index. Comparing the currently ungrazed Canyonlands National Park watersheds to the adjacent Dugout Ranch pastures, we found clearly higher multifunctionality was attained in the Park, and that this was primarily driven by greater C-storage and better dust retention. It is unlikely to maximize all benefits and minimize all detriments at the same time. Some goods and services may have synergistic interactions; for example, managing for carbon storage will increase plant and biocrust cover likely lowering dust emission. Likewise, some may have antagonistic interactions. For instance, if carbon is consumed as biomass for livestock production, then carbon storage may be reduced. Ultimately our goal should be to quantify the monetary consequences of specific land use practices for multiple ecosystem services and determine the best land use and adaptive management practices for attaining multiple ecosystem services, minimizing economic detriments, and maximizing economic benefits from multi-commodity rangelands. Our technique is the first step toward this goal, allowing the simultaneous consideration of multiple targeted ecosystem services and properties.
\end{abstract}

\section{Introduction}

Traditional range management and assessment methods in the United States originally rested upon a belief in a successional climax which offered the best livestock forage (Pendelton, 1989). Similarity indices were used to quantitatively compare forage conditions on the ground to those of this climax state (Dyksterhuis, 1949). After Clementsian successional ideas began to fall out of favor in range science, a desired vegetation state became the frame of reference (Moir, 1989). A strong departure from the desired range conditions might have resulted in a prescription for reduced stocking or rest to allow the buildup of forage. Even early on, it was recognized that this focus only on forage was an incomplete assessment of range condition (Ellison, 1949), and that other elements such as the rate of soil erosion were also quite important; nonetheless, the cattle forage emphasis continued until recently. More recent developments have sought to greatly broaden the way in which rangelands are assessed. Multiindicator ecologically based assessments of site and soil condition were developed in arid and semiarid 
Australian rangelands (Landscape Function Analysis; Tongway and Smith, 1989; Tongway and Hindley, 1995). This approach took into account the gap size distribution of interspaces between plants, and integrated characteristics of the soil surface to develop stability, infiltration and nutrient cycling indices. Rangeland Health Assessment followed in a similar vein, integrating numerous qualitative indicators of 3 key ecological attributes: soil/site stability, hydrologic function, and integrity of the biotic community (Pellant and others, 2005; Pyke and others, 2002), in some cases integrated with quantitative indicators (Miller, 2008). Associated monitoring techniques introduced a related but quantitative approach based on measurement of multiple indicators (Herrick and others, 2005).

In this report, we use a large field sampling effort to quantitatively and comprehensively measure the condition of a variety of rangelands in the vicinity of Canyonlands National Park (CANY, recognized abbreviation for the Park), Utah, USA, encompassing portions of the currently ungrazed National Park and the surrounding Dugout Ranch which supports an active cattle ranching operation. In this study area livestock grazing, climate, and invasive annual plants have contributed to persistent changes in ecosystem properties and resulted in various transitions among alternative states on the landscape (Miller and others, 2011). The area has been grazed since around the turn of the century, and the Indian Creek Cattle Company in 1914, a precursor to the modern Dugout Ranch, acquired grazing rights. With the establishment of CANY in 1964, the Needles District of the Park encompassed a portion of the long-grazed Dugout Ranch operation. Permitted grazing continued in portions of the Needles District until phased out in 1975 (Schmieding, 2008). Despite the relatively long period of recovery from grazing, it has not been immune to vegetation change, as it has experienced invasion by Bromus tectorum, an exotic annual grass, even in portions of the park that are believed to have been never grazed (Belnap and Phillips, 2001; Evans and others, 2001). Some areas that were heavily impacted by past grazing practices remain persistently degraded today (Miller and others, 2011). The remainder of the Dugout Ranch is still a working ranch with federal grazing leases on lands managed by the Bureau of Land Management (BLM; Indian Creek Allotment) and U.S. Department of Agriculture Forest Service (USDA FS; Cottonwood Allotment). In response to vegetation changes, the Dugout Ranch is stocked at less than 50 percent of the rates that it was stocked in the 1970's (Fahys, 2010). In the late 1990s, The Nature Conservancy acquired the ranch in 1996 and recently took over the grazing lease in 2009 (The Nature Conservancy, 2011). The explicit goal of The Nature Conservancy with this property is to develop practical solutions to aid ranchers, communities, agencies and policy makers in efforts to sustain the lands and waters of the Colorado Plateau.

Increasingly, rangelands are being valued for multiple services beyond their traditional value as a forage production system (Brown and MacLeod, 2011; Havstad and others, 2007). Additional ecosystem services include the potential to store carbon in the soil and aboveground biomass (Schlesinger and others, 2009; Wohlfahrt and others, 2008). Carbon markets are considered by many to be one option by which to allow a flexible compliance with emissions targets, and have been experimented with in Europe, and are being hotly debated in Australia (Bernstein and others, 2010). These could eventually strongly alter ranching practices because there may be monetary value to be gained from reducing stocking in some ecosystems if ranchers had a means to "sell" the carbon they could store by doing so. Another aspect of rangelands, which has not been considered in traditional rangeland valuation systems, is the emission of eolian dust. Dust emissions from rangelands might be considered an ecosystem detriment, the opposite of an ecosystem service and a cost of the surface disturbance that comes along with livestock ranching. Due to radiative forcing, dust over snowpack is expected to reduce total runoff from the Rocky Mountains by $7-20$ percent in the next century due to a drying climate (Painter and others, 2010). The sustainability of many western U.S. cities hinges strongly on future water security. Munson and others (2011a) make a strong case that increasing prevalence of drought in the future coupled with surface disturbances such as grazing will create the greatest dust emissions. This is likely 
to occur because of physical disruption of the soil surface and increasing space between drought-stricken plants (Neff and others, 2008; Field and others, 2010). It is likely impossible to devise a rangeland management scheme which maximizes all benefits and minimizes all detriments at the same time. Some goods and services may have synergistic interactions; for example, managing for carbon storage will increase plant and biocrust cover likely lowering dust emission, and sometimes may also allow the buildup of forage and option for future grazing. Likewise, some may have antagonistic interactions. For instance, if carbon is consumed as biomass for livestock production, then carbon storage would be reduced.

Our ultimate goal is to develop an analysis tool for quantitatively assessing rangelands in terms of their ability to provision multiple ecosystem services simultaneously, and apply the tool to determine the best land use and adaptive management practices, minimizing economic detriments, and maximizing economic benefits from multi-commodity rangelands. Our immediate objectives in the present study were to (1) characterize the variation in ecosystem structure and properties in several key ecosystem types which account for some of the most important forage-production in rangelands of the Colorado Plateau; (2) using this analysis and known or hypothesized site history, develop provisional state-andtransition models as a first step in understanding ecosystem dynamics in this region; (3) evaluate the functional outcome of hypothesized state changes, focusing on modeled potential wind erosion, carbon storage, forage production, and exotic species invasion; (4) conduct an integrative analysis at pasture and watershed levels to evaluate the spatial distribution of various forms of degradation, and provision of multiple ecosystem services; and (5) make publicly available a large data resource for the use of scientists and resource managers. To our knowledge, no previous efforts have attempted to explicitly assess rangelands with regards to sustaining multiple ecosystem goods and services.

\section{Summary of Key Concepts}

\section{Ecological site}

An ecological "site" is not a physical location; rather it is a unit in a land classification system developed by the USDA Natural Resource Conservation Service (USDA NRCS, 1991). The system encompasses potential vegetation, soil type, climate, and geomorphic setting. We use the system here as a delineation of ecosystem type (Bestelmeyer and others, 2009; Brown and MacLeod, 2011; Herrick and others, 2006; Karl and Herrick, 2010,).

\section{Alternate ecosystem states and phases}

Ecosystems can shift between alternative states or dynamic regimes that are characterized by persistent differences in structure and function (Beisner and others, 2003; Mayer and Rietkerk, 2004;Scheffer and Carpenter, 2003). Such shifts are caused by factors that independently or interactively trigger relatively major changes in functional group structure, disturbance regimes, and/or resource regimes (Chapin and others, 1996). In the context of ecosystem management, alternative states are of concern for two primary reasons. First, shifts between alternative states may occur as relatively abrupt, nonlinear responses to factors such as climate and human land use (Briske, 2006; Scheffer and Carpenter 2003). The potential for abrupt changes in ecosystem properties generates a high degree of uncertainty and unpredictability in management (Holling, 1996). Second, alternative states invariably differ from one another in their capacity to provide ecosystem services and support different management objectives. Once a state shift has occurred, restoration of previous conditions and management options may be difficult, costly, or effectively impossible (Suding and Hobbs, 2009; Whisenant, 1999). Alternative states have been described for many types of ecosystems (Folke and 
others, 2004; Mayer and Rietkerk, 2004), but drylands are among the most susceptible to this phenomenon due to low and variable amounts of precipitation in combination with effects of human land-use activities (Reynolds and others, 2007; Schlesinger and others, 1990; van de Koppel and others, 1997).

Phases can be envisioned as alternate states within alternate states. They may differ compositionally, and functionally from other phases within a state. In contrast to states, phases can freely shift to another phase within a given state, and back (termed "pathways" rather than "transitions" by Bestelmeyer and others, 2003). They represent clustering around a common set of forms in the natural variability that exists within an ecosystem state. We adopted these concepts to help understand variability in form and function within ecological sites.

\section{State-and-transition model}

A state-and-transition model is a heuristic model of the above alternative state dynamics, often specific to a particular ecosystem type. Alternative ecosystem states and phases are generally represented as boxes. Possible transitions among states or phases are denoted by arrows; the arrows are directional, indicating a transition from one state or phase to another and is associated with a specific hypothesized or known mechanism. A catalog of transitions along with the triggering mechanism is often presented (Westoby and others, 1989). Often they are simply a visualization of the processes and dynamics which are thought to occur in a particular ecosystem, and may be empirically validated in monitoring or other data, or derived solely from expert opinion and ecological theory (Bestelmeyer and others, 2003). Nevertheless they provide a useful model of successional dynamics that follow multiple pathways, depending on the type of perturbation. We adopt this tool as a visualization of alternative states and the dynamics of the studied ecosystems (Bestelmeyer and others, 2009), and in our assessment of different ecosystem services (Brown and MacLeod, 2011).

\section{Biological soil crusts}

A notable characteristic of most of these ecosystems which figures prominently in our work is that they have the potential to support biological soil crusts (biocrusts, hereafter), which are soil-surface assemblages of cyanobacteria, mosses, and lichens that are functionally significant for soil stabilization (Belnap, 1995; Warren, 2003), nutrient cycling (Evans and Lange, 2003), hydrologic processes (Eldridge and others, 2002; Warren, 2003), and mediation of vascular plant establishment (Belnap and others, 2003; Escudero and others, 2007). The functional significance of biocrusts is countered by their high vulnerability to surface disturbances that can result in long-term reductions in their structure and

functionality (Belnap and Eldridge, 2003). In sparsely vegetated drylands, disturbance-induced declines in biocrusts often are accompanied by accelerated soil erosion and persistent changes in soil physical and biogeochemical properties (Barger and others, 2006; Neff and others, 2005), thus they become a secondary change agent when grazing, climate, or invasive plants alter their abundance. In many of our state-and-transition models, prevalence of biocrusts is a defining property of states and phases (Miller and others, 2011), and the loss or recovery of biocrusts may be a trigger leading to a transition (Bowker, 2007).

\section{Multi-commodity rangelands and multifunctionality}

We acknowledge that US rangelands provide a market commodity, usually in the form of beef (Brown and MacLeod, 2001). In addition, they also provide other commodities and services which are more difficult to value economically. For example, they maintain carbon stocks. In highly functional condition, they minimize dust emissions. Multifunctionality is the simultaneous provision of more than 
one such ecosystem good or service (Zavaleta and others, 2010). This concept is still quite new and a variety of methods have been proposed to quantify it (Bowker and others, 2011). We develop an assessment method in this work.

\section{Methods}

\section{Study Area}

Field studies were conducted in a 1,500-km2 area located on the central Colorado Plateau approximately $50 \mathrm{~km}$ northwest of the town of Monticello in southeastern Utah, U.S.A. Approximately 25 percent of the study area is located within CNP, with the remainder on the Indian Creek Allotment associated with the Dugout Ranch (fig. 1). Plots sampled for this study range in elevation from 1,400 m to 2,400 m. Mean annual precipitation (MAP) ranges from about 210 to $390 \mathrm{~mm}$ across this elevation gradient with approximately 39 percent occurring during Oct-Feb, 25 percent during Mar-May, and 37 percent during Jun-Sep (Western Region Climate Center, http://www.wrcc.dri.edu/). The ratio of MAP to potential evapotranspiration ranges from 0.17 to 0.51 (Flint and Flint, 2007), with 0.20 being the division between arid and semiarid zones and 0.50 the division between semiarid and dry subhumid zones in drylands (Reynolds and Stafford Smith, 2002).

Plant communities are varied in this landscape and may be summarized as 8 categories: Sagebrush bottom, Greasewood, Shadscale, Blackbrush, Blackbrush-Juniper, Grassland, Upland Sagebrush, Pinyon-Juniper. At a finer resolution, the study area has been classified into 15 types of ecological land units (ecological sites) by the U.S. Department of Agriculture Natural Resources Conservation Service (USDA NRCS, 1991). Ecological sites are differentiated by (1) physical attributes including inherent soil properties (texture, depth, and horizonation), geomorphic setting, and climate; and (2) the potential (rather than current) vegetation associated with these physical attributes within a specific ecoregion (Bestelmeyer and others, 2009; Herrick and others, 2006).

\section{Sampling Design}

We sampled 352 plots to characterize ranges of variability in structural attributes of the 15 dominant ecological sites found in the study area. Sampling locations were determined primarily on the basis of a spatially balanced stratified random sampling design using digital spatial data in GIS. Strata consisted of soil map units (excluding units dominated by rock outcrops) and fenced pastures used to manage livestock in the Indian Creek Allotment. For CANY where no fenced pastures exist, spatial balance in the distribution of sampling locations was achieved using a general randomized tessellation stratification procedure (Stevens and Olsen, 2004). In selecting random points for sampling in the Indian Creek Allotment, points that fell in soil map units supporting grassland, upland sagebrush, and treated upland pinyon-juniper vegetation (i.e., woodlands treated to reduce tree cover and increase cover of palatable grasses) were assigned a higher selection probability ( 3 percent) than points that fell in other map units ( 1 percent) because the former vegetation types typically produce more forage and thus receive preferred use by livestock. In addition to random sampling locations, some plot locations were selected subjectively to sample unique conditions or environmental settings that were important for characterizing the full range of variability associated with particular ecological sites.

\section{Field Methods}

At each plot, sampling was conducted along three parallel $50-\mathrm{m}$ transects separated by $25 \mathrm{~m}$ and oriented parallel to the hillslope contour. Some plot locations were adjusted by up to $50 \mathrm{~m}$ to avoid the 
placement of transects across significant soil - ecological site boundaries. Sampling was conducted from late May through October over the course of three field seasons in 2006-2008.

\section{Biotic composition, ground cover, and spatial structure of vegetation}

At each plot, live fractional cover of vascular plants (foliar and basal cover, differentiated as live or dead by species), biological crust (differentiated as dark cyanobacteria, moss, or lichen), and litter, rocks, and bare ground were estimated by line-point intercept sampling with 1-m sampling intervals (150 points per plot; Herrick and others, 2005). As an indicator of vegetation structure in relation to wind erosion (Okin and Gillette, 2001; Okin and others, 2006), gaps between perennial plant canopies were measured using line-intercept sampling and a standard rule set (Herrick and others, 2005). We also measured gaps between perennial plant bases (standard rule set) as an indicator of vegetative resistance to overland water flow (Herrick and others, 2005). The frequency of livestock dung was measured by dung presence or absence in square $1-\mathrm{m}^{2}$ quadrats placed along each transect at 5-m intervals (30 quadrats per plot). Dung frequency provides an index of recent livestock use but not past livestock use. The frequency of exotic plants also was measured by exotic species' presence or absence in the same quadrat. Richness of the vascular plant community was estimated on the basis of a list of all plant species observed at each plot during sampling.

\section{Soil-surface attributes}

Surface soil aggregate stability was measured using a field kit (Herrick and others, 2001), with plot-level averages based on measurements made at six random points per transect (18 subsamples per plot). Fine-scale soil-surface roughness facilitates the retention of overland water flow (Ward and Trimble, 2004), the capture and retention of litter and seeds (Kinloch and Friedel, 2005), and the creation of safe sites for seed germination and establishment (Harper and others, 1965). We measured fine-scale soil-surface roughness in plant interspaces by draping a 20-cm jewelry chain with 2-mm chain links across surface micro topographic features and measuring the horizontal distance between the two ends of the chain. Average horizontal distance was calculated on the basis of five subsample measurements made at 10-m intervals along each transect (15 subsamples per plot). A soil roughness index (SRI) was calculated for each plot as

$$
\mathrm{SRI}=\left(1-\mathrm{L}_{2} / \mathrm{L}_{1}\right) * 100
$$

where L2 is average horizontal distance and L1 is the length $(20 \mathrm{~cm})$ of the chain (Saleh, 1993). In sandstone-derived soils in our study area, magnetic minerals in soil are attributable to deposits of fartravelled aeolian dust that contribute significant amounts of silt, clay, and rock-derived nutrients (Reynolds and others, 2001; Reynolds and others, 2006). As an indicator of dust and rock-derived nutrient content in soils of our plots, we measured the magnetic susceptibility (MS) of the soil surface with a MS-20 magnetic susceptibility meter (GF Instruments, s.f.o. Czech Republic) with sensitivity of 10-6 SI units. For each plot, average MS was calculated on the basis of five subsample measurements made at $10-\mathrm{m}$ intervals along each transect (15 subsamples per plot).

\section{Estimating $\mathrm{C}$ and forage abundance}

For our study area, no comprehensive set of tools exists for estimating vegetation biomass based on common range monitoring data such as that used here. However there are abundant published equations for converting percent cover data to biomass estimates, mostly based on linear or polynomial regression. Our approach hinged first upon seeking different equations for different pools of C: soil surface $\mathrm{C}$, litter $\mathrm{C}$, rhizomatous grass $\mathrm{C}$, bunchgrass $\mathrm{C}$, shrub $\mathrm{C}$, and tree $\mathrm{C}$. Estimating belowground $\mathrm{C}$ 
is the most challenging aspect of C-stock estimation. Since all data represented above ground properties of the ecosystems, we did not attempt to integrate belowground $\mathrm{C}$. We searched available literature for appropriate equations favoring the following characteristics, in descending order: (1) Equations were developed in the Colorado Plateau ecoregion, (2) Equations were developed using plants found in the Colorado Plateau ecoregions in adjacent ecosystems, and (3) When 1 and 2 could not be satisfied, we used equations based upon multiple species.

Soil surface $\mathrm{C}$ was estimated using an equation developed from data in Bowker and others (2006). This study measured soil organic matter, litter cover, biocrust cover, and plant cover in over 100 samples sites on a variety of soils and spanning a $1000-\mathrm{m}$ elevation gradient in Grand Staircase Escalante National Monument (GSENM). GSENM contains many of the same ecological sites found in the CANY region. We used a multiple regression model with the predictors litter cover, biocrust cover, and total plant cover, to model percent organic matter with and without transformations. Litter cover was the best predictor, followed by biocrust cover. Plant cover explained no additional variance, so it was excluded. The version of the equation which log transformed organic matter content (percent on a soil weight basis), and square root transformed the predictors performed slightly better $\left(R^{2}=0.37\right)$. The final equation used was $\log _{10}($ Percent organic matter $)=0.0938525+0.0424773 \sqrt{ }$ percent litter + 0.0149296 Vpercent biocrust. Based on rough bulk density estimates (1.2 for loam soils, 1.5 for sandy loam, and 1.8 for sand), and soil surface volume of the sites (to a depth of $1 \mathrm{~cm}$ ) we consverted this value into $\mathrm{kg}$ per $\mathrm{plot}^{2}$. Finally we converted to $\mathrm{kg} \mathrm{C}$ based on the presumption that about 58 percent of the organic matter is carbon (Nelson and Sommers 1996).

Litter C was estimated based on an equation found in Clark and others (2008). This technique was based upon a 3-dimensional point intercept method that relates to area and volume of plants and litter. Since litter was only intercepted once at the base, the litter equation reduces to percent cover and is therefore compatible with our dataset. The equation predicted $\mathrm{g} \mathrm{m}^{-2}$ litter biomass as a polynomial function of the following form: litter biomass $=12.314$ (percent cover litter) -0.022 (percent cover litter $)^{2}$. No intercept term is used, because when litter cover is 0 , litter biomass is also 0 . We converted biomass to $\mathrm{C}$ based on the presumption that about 47.5 percent of the litter is carbon (Schlesinger, 1991)

Rhizomatous grass biomass was estimated based on a study by Williamson and others (1987) in which the biomass of Bouteloua gracilis, one of the most common rhizomatous grasses in the CANY region, was related to its percent cover. The simple equation is as follows: rhizomatous grass biomass $=$ 4.4 (percent cover rhizomatous grass). Again no y-intercept was used. Despite its simplicity, this model explained 62 percent of the variation in biomass. We converted biomass to $\mathrm{C}$ based on the presumption that about 47.5 percent of the grass biomass is carbon.

Equations for both bunchgrass and shrub biomass came from an Argentinian study which developed equations pooling multiple species (Flombaum and Sala, 2007). The plants used are of a similar stature to many bunchgrasses and shrubs of the Colorado Plateau. Although equations were given for individual species, we used the multi-species equations, which performed very well for bunchgrasses $\left(R^{2}=0.74\right)$ and shrubs $\left(R^{2}=0.86\right)$. The equations are: 1 . Bunchgrass biomass $=596.3$ (percent cover bunchgrass), and 2. Shrub biomass $=1225.4$ (percent cover shrubs). No y-intercepts were used. We converted biomass to $\mathrm{C}$ based on the presumption that about 47.5 percent of the plant biomass is carbon.

An equation for tree biomass was obtained from Huang and others (2009). In the western Colorado Plateau, these authors used a proxy for biomass based on allometric equations using root collar diameter of Pinus and Juniperus, the two genera which constitute nearly all the tree biomass in the CANY region, and related this biomass estimate to canopy cover measured in the field (Huang and others 2009). The equation was as follows: $\log 10$ (tree biomass $)=-4.66+1.32 \log _{10}($ tree cover). In this equation biomass was expressed as $\mathrm{kg}$, and canopy cover was expressed as area $\left(\mathrm{cm}^{2}\right)$ rather than as a 
percentage. This equation explains 69 percent of the variation in biomass. We converted biomass to C based on the presumption that about 47.5 percent of the tree biomass is carbon.

All equations were applied to each sample, and where needed, the estimates were converted to $\mathrm{kg}$. The resulting estimates, in $\mathrm{kg} \mathrm{C}$, were summed for each site. To estimate forage biomass, we applied an identical protocol, except that we did so using only palatable shrubs and perennial grasses.

\section{Simulation modeling of dust emissions}

We used a model of wind erosion (WEMO hereafter) to investigate effects of measured biophysical attributes on predicted rates of wind-driven soil movement at our plots (Okin, 2008). WEMO predicts horizontal dust flux $\left(\mathrm{g} \mathrm{cm}^{-1} \mathrm{~d}^{-1}\right)$ on the basis of wind velocity, plant height, the sizeclass distribution of gaps between plant canopies, total plant cover, threshold shear velocity (TSV; (Gillette and others 1982), and a suite of other variables. TSV is the surface wind velocity required to initiate soil movement and thus is a measure of soil erodibility. Direct measurement of TSV requires a wind tunnel or similar apparatus. To derive estimates of TSV for WEMO, we used an empirical relationship between soil aggregate stability and TSV from wind tunnel observations on soils similar to those in our study area (J. Belnap, unpubl. data). In the wind tunnel data, TSV variability increased with increasing soil aggregate stability, and residuals were not normally distributed around a least-squares model. Therefore, we used quantile regression to fit separate linear models through the 10th, 50th, and 90th percentiles of the empirical TSV data (Cade and Noon, 2003). Here we report WEMO predictions based on the 10th percentile model because fluxes predicted on the basis of this quantile model were most consistent with measured fluxes at two of our plots where wind erosion has been monitored continuously since 1999 (Virginia Park and Needles Residence in Belnap and others, 2009). The rate of wind erosion is proportional to the cube of wind velocity above TSV (Blanco and Lal, 2008), so we used a range of wind velocities $\left(1750,2625\right.$, and $3500 \mathrm{~cm} \mathrm{~s}^{-1}$, measured at $10 \mathrm{~m}$ above the surface) in WEMO to examine relative increases in predicted dust fluxes with increasing wind velocity. The maximum velocity we used in WEMO corresponds with the maximum wind velocity reported in the region surrounding our study area (Williams and others, 1995). Production and cover of annual plants are highly responsive to precipitation variability, thus annuals typically contribute little to erosion resistance during periods of drought (for example, Belnap and others, 2009). To account for this, we used perennial plants only as the basis for WEMO inputs for canopy gaps, plant cover, and plant height. Thus predicted dust fluxes represent relative measures of vulnerability to wind erosion during drought conditions.

\section{Statistical analysis}

\section{Cluster analysis and State-and-Transition models}

When sample size permitted $(\mathrm{n} \geq 12)$, we used hierarchical cluster analyses to detect groupings of samples (clusters) within ecological sites represented in our data. We used Ward's method with a flexible beta. Distance among samples was defined as Euclidean distance. Cluster analyses were based upon a common set of attributes primarily describing the abundance of plant functional groups, bare ground cover and biocrust cover. We slightly adjusted the variables used in the cluster analyses as appropriate to include important information, or exclude unimportant information. For example, we excluded plant functional groups that were very minor components from the analysis, or in some cases included particular species in ecological sites that were dominated by that species. We selected the number of clusters partially based on information remaining and partially based on subjective interpretation of multiple scenarios of n clusters (McCune and Grace, 2002). All cluster analyses were conducted in PC-ORD 4.0 (MJM Software Design). 
Clusters are interpreted as either alternative ecosystems states, or alternative phases within those states. We used them to assist us in developing provisional state-and-transition models. Transitions in the models were hypothesized based on known site history (for example, grazing status, land treatment history), field observations, past literature, and general principles. Transitions are not validated by data here; rather they remain hypothetical because this topic was outside of the scope of the research.

\section{Integrated analysis of multiple rangeland services and properties}

Within each pasture, multiple ecological sites may occur. We developed a 4-step method for determining the status of pastures, the typical management unit based on a hierarchical weighted averaging procedure. "Status" refers to that pasture's ability to sustain key ecosystem services (table 1) and properties, and for that pasture to sustain multiple ecosystem services and properties simultaneously.

Step 1. Determine appropriate upper bound of status. Four key attributes (total forage, C-storage score, maximal dust emissions, and nativeness) are rescaled from $0-1$, within ecological sites. For example in Upland Shallow loam, total forage cover ranges up to an observed maximum of 24.6 for samples in cluster 5 . The values of all clusters are rescaled from $0-1$, so that the new value for cluster 5 is $1(=24.6 / 24.6)$, meaning that if a sample falls into this cluster, the value of this key attribute is as high as it can reasonably be expected to be. Likewise, if a sample falls in cluster three it receives a forage score of $0.14(=3.5 / 24.6)$. The maximal dust emissions score is treated slightly differently because it is the opposite of an ecosystem service, an "ecosystem detriment". After it is rescaled, the resultant value is reflected by subtracting it from 1 ; thus a value of 1 becomes $0,0.3$ becomes $0.7,0$ becomes 1 , and so on.

Step 2. Calculating the E-score. These values are used in a weighted average based upon the proportional abundance of samples in a given ecological site within a given pasture (termed "E score"). Thus, if in Pasture A, the samples representing Upland Shallow Loam are 20 percent Cluster 6 (Forage score $=1)$, and 80 percent Cluster 3 (Forage score $=0.14)$ a value of .31 is calculated $(=[0.2 \times 1]+[0.8$ $\times 0.14])$. This procedure is repeated for all sampled ecological sites within the pasture. Prior to this calculation, we corrected for the greater sampling probability of treated areas.

Step 3. Calculating the P-score. To create a composite score for a given functional attribute (e.g. forage score) across a pasture (termed "P score"), E scores are used in a weighted average, which uses proportional abundance of ecological sites within pastures as weights. We used the relative abundance of samples representing different ecological sites on a per-pasture basis, as an estimate of their relative abundance in the field. For example if Pasture A is 50 percent Upland Shallow Loam (with an E score of 0.31, as derived above), and the remainder is Semidesert Sand (with an E score of 0.90), then the P score will be $0.61(=[0.50 \times 0.31]+[0.8 \times 0.14])$. Prior to this calculation, we corrected for differential sampling probability of grassland and upland sagebrush ecological sites in the Indian Creek Allotment. $\mathrm{P}$ scores are calculated for each key attribute of status under consideration, thus in this case for each pasture there will be $4 \mathrm{P}$ scores, which can be analyzed independently.

Step 4. Integrating multiple $P$ scores. We adapted the multiplicative function index (MFI; Bowker and others, 2011) to integrate multiple P scores. Central to our index is its multiplicative nature, if any single P score is measured and found to be minimal, MFI must also be minimal. High P scores for one service (for example, forage) cannot compensate for low values in another (for example, dust emissions). Maximal MFI can only be obtained when all P scores are maximized simultaneously. To satisfy the above requirements, our index must be based on multiplication. In the case that all $\mathrm{P}$ scores are to be weighted equally, they are simply all multiplied together. For comparison within a single dataset, the above steps may be adequate. However, because this value gets smaller with each multiplication, standardization is needed to allow comparisons among different datasets for which a different number of functions may have been measured. We propose that taking the root value satisfies 
this goal. If two P-scores have been multiplied, the square root is taken. In the case of three functional indicators, the cube root is taken, and so on. Taking the root value also helps to preserve central tendency and control increasing positive skew in the distribution of the index, therefore it is advised even when comparison are constrained to a single dataset.

\section{Results}

Our sampling spanned 15 different ecological sites, 8 different general vegetation types, and multiple land ownership boundaries (table 2). Four ecological sites represented about 70 percent of all samples: Semidesert Sandy Loam (Fourwing Saltbush), Upland Loam (Basin Big Sagebrush), Upland Shallow Loam (Pinyon-Utah Juniper), and Semidesert Sand (Fourwing saltbush).

\section{Sagrebrush bottom ecosystems}

Our dataset included one sagebrush bottom ecological site, Loamy Bottoms (Basin Big Sagebrush) that was sufficiently well represented on the landscape to perform cluster analyses. Description of soils, climate and geomorphic setting can be found at ftp://ftpfc.sc.egov.usda.gov/UT/Range/D35XY/035XY011UT.pdf

\section{Loamy Bottoms (Basin Big Sagebrush)}

A hierarchical cluster analysis found 4 clusters of samples. Cluster 1 is the only cluster represented by $>5$ samples, otherwise clusters ought to be interpreted cautiously. Cluster 3 consists of a single highly unique sample. The clusters can be grouped as states or phases in a provisional state and transition model to assist interpretation (fig. 2, table 3).

Biocrust: Cluster 1 represents a distinct state due to its dominance by biocrust cover (nearly 40 percent). This cluster also has the highest coverage of Artemisia tridentata. Functionally, this cluster is characterized by low forage cover for this ecological site, and is not prone to emitting dust. Though not a true reference state due to the presence of exotic species, this state probably represents the current site potential.

Shrub-bare: Clusters 2 and 3 can be grouped together as phases of the Shrub-bare state. Both of these clusters are characterized by at least some biocrust cover in interspaces, although considerably less than the Biocrust state. Cluster 2 has less than a third of the biocrust cover of cluster 1, and also less Artemisia cover. Exotic annual forbs and grasses are represented in cluster 2 about equally, together accounting for over a third of the total plant cover. Cluster 3 is the most difficult to interpret, because it is represented by only 1 sample, and because it is so unique. It does have some biocrust cover, albeit, only a fraction of that seen in cluster 1. Artemisia and all perennial vegetation is much less abundant here than in other clusters. The sample is notable in its very high cover of native forbs. Both of these clusters have low forage cover for this ecological site, and neither of them is prone to emitting dust. Dust emissions are possible only at the highest wind speed modeled, and fluxes are minor.

Annualized-bare: Presumably arising from cluster 2, cluster 4 is actually dominated by Bromus tectorum, which accounts for two thirds of the community. Artemisia is a sub-dominant in this community, which also contains perennial grasses and palatable shrubs. Consequently, forage cover is about twice as high as the values seen in the biocrust state. Dust emissions are possible at all windspeeds, and at the highest windspeed, are almost 20 -fold greater than the highest emitting cluster in the biocrust state.

Distribution of putative states: This ecological site is primarily found in CANY. In CANY, 85 percent of samples are in biocrust-dominated states, whereas the remainder, are in an annualized-bare state. On the Dugout Ranch, 50 percent of samples are in the biocust state, and 50 percent are in the 
annualized-bare state, although this is based on only two samples. Because samples were primarily selected according to a spatially balanced random sampling scheme within the ecological site, these proportions provide a reasonable estimate of their proportional areal coverage as well. Unless otherwise noted, this applies to all following ecological sites as well.

\section{Greasewood ecosystems}

Our dataset included one greasewood ecological site, Alkali Bottoms (Greasewood) that was sufficiently well represented on the landscape to perform cluster analyses. Description of soils, climate and geomorphic setting can be found at $\mathrm{ftp}: / / \mathrm{ftp}$ fc.sc.egov.usda.gov/UT/Range/D35XY/035XY003UT.pdf.

\section{Alkali Bottoms (Greasewood)}

We used a hierarchical cluster analysis to group species into three clusters. Cluster 1 was well represented, but Clusters 2 and 3 each consisted of fewer than 5 samples. The clusters can be grouped as states or phases in a provisional state and transition model to assist interpretation (fig. 3, table 4).

Biocrust: Cluster 1 is interpreted to belong to a state characterized by high cover and dominance by Sarcobatus vermiculatus, among other shrubs. Interspaces among shrubs are biocrusted, attaining over 35 percent cover and exceeding cover of vascular plants, consequently bare ground is relatively low at $\sim 30$ percent. Grasses in general are very minor components of this cluster, and invasive grasses are totally absent. Exotic forbs may be present but constitute $<1$ percent cover. Preferred forage cover is also minor, and primarily accounted for by palatable shrubs. Dust emissions are not plausible, likely due to high biocrust cover, and tall plant heights. Though not a true reference state due to the presence of exotic species, this state probably represents the current site potential.

Shrub-Bare: Cluster 2 is notable in having only about a third of the total plant cover of the biocrust state. Biocrusts are reducued to only about one fifth of their cover in the biocrust state. Perhaps most conspicuous is that bare ground increases to over two thirds of the plot area. Grasses again are minor community components, and shrub cover is sharply reduced. The one community component that is increased is the exotic forb, Salsola, which composes about one third of the community. At high wind speeds, modeled dust emissions are many-fold higher than any other cluster.

Annualized: Cluster 3 does not exhibit the low overall cover of cluster 2. Bare ground coverage is less than a third that on cluster 2, and is actually less than cluster 1 as well. Regarding biocrust and perennial plant cover, cluster 3 is approximately equidistant between clusters 1 and 2 . Owing to relatively high grass cover and palatable shrubs, this cluster also has the highest coverage of preferred forage. The exceptional characteristic of this site is that is is dominated by Bromus tectorum, which accounts for two thirds of the community. The presence of Bromus greatly increases the live plant cover to about three time that of the other clusters. Dust emissions are possible at the highest wind speed modeled; however the fluxes are $<5$ percent of those modeled for cluster 2 .

Distribution of putative states: This ecological site is primarily found in CANY. In CANY, 75 percent of samples are in biocrust-dominated states, whereas the 12.5 percent each of samples belonged to the shrub-bare state and the annualized state. On the Dugout Ranch, no samples belonged to the biocrust state. 40 percent and 60 percent are in the shrub-bare and annualized state, respectively.

\section{Blackbrush ecosystems}

Our dataset included four blackbrush-dominated ecological sites: Semidesert Sand (Blackbrush), Semidesert Sandy Loam (Blackbrush), Semidesert Shallow Sand (Blackbrush), Semidesert Shallow Sandy Loam (Utah Juniper - Blackbrush). Of these, two were sufficiently well represented on the 
landscape to perform cluster analyses. Description of soils, climate and geomorphic setting can be found at ftp://ftp-fc.sc.egov.usda.gov/UT/Range/D35XY/035XY224UT.pdf for Semidesert Shallow Sand, and at ftp://ftp-fc.sc.egov.usda.gov/UT/Range/D35XY/035XY227UT.pdf for Semidesert Shallow Sandy Loam.

\section{Semidesert Shallow Sand (Blackbrush)}

A hierarchical cluster analysis found 3 clusters of samples. Sample size in general is low. Clusters 2 and 3 are comprised of 6 samples each, but cluster 1 is represented only by a single sample. The clusters can be grouped as states or phases in a provisional state and transition model to assist interpretation (fig. 4a; table 5).

Biocrust: Clusters 1 and 2 can be characterized as biocrust-dominated Coleogyne shrublands. Coleogyne represents at least two thirds of the vegetation. It is not clear if cluster 1 is truly a rare representative of a different phase or simply an unusual example of cluster 2. Cluster 1 has exceptionally high bicorust cover, at 34 percent, and low bare gound at 26 percent. In contrast these figures for cluster 2 are 20 percent and 49 percent, respectively. Another difference is that there is at least twice the cover of annuals, exclusively natives, in Cluster 1 compared to other clusters. Exotic annuals colonize cluster 2 , but they are a minor community component ( $<3$ percent relative cover). Modeled dust emissions are non-exisitent for cluster 1, but dust may be emitted from cluster 2 at the two highest wind speeds. Though not a true reference state due to the presence of exotic species, this state probably represents the current site potential.

Shrub-Bare: Cluster 3 is characterized by the replacement of all but about 4 percent of the BSC cover with bare ground. The vegetative community is essentially the same as clusters 1 and 2, being highly dominated by Coloegyne. Like cluster 2, exotic annuals are present but not a major community component. Functionally, this cluster stands out as a major potential dust emitter. Dust emissions are possible at all simulated wind speeds, and $\sim 5 \times$ greater than cluster 2 at the highest wind speed.

Distribution of putative states: The portfolios of CANY and the Dugout Ranch starkly contrast. In CANY, 86 percent of samples are in biocrust-dominated states, whereas the remainder is examples of the shrub-bare state. On the Dugout Ranch, about 83 percent of sites are representative of the shrubbare, and 17 percent represent the biocrust state.

\section{Semidesert Shallow Sandy Loam (Utah Juniper - Blackbrush)}

A hierarchical cluster analysis found 4 clusters of samples. Clusters 1,2,and 4 were relatively well represented in the data (each $n>5$ ), whereas cluster 3 was less common and thus should be interpreted somewhat cautiously. The clusters can be grouped as the following states or phases in a provisional state and transition model to assist interpretation (fig. 4b; table 6).

Biocrust: Clusters 1 and 2 compose this provisional state, and are interpreted here as two spatial variants. Both are notable in supporting at least 24 percent biocrust cover. Also, both lack exotic annuals, and both support $<3$ percent of perennial grasses. The plant community is clearly dominated by woody plants. The primary difference between the two clusters is the relative abundance of Coleogyne shrubs compared to trees such as Pinus or Juniperus. This may indicate that this ecological site should be split in two, unless all of the Coleogyne-dominated samples have the potential to be colonized by trees. Cluster 1 is depauperate in Coleogyne, but supports a moderate cover of trees ( $\sim 6$ percent) in additional to a mix of other shrubs. Cluster 2 has somewhat lower cover overall, and supports $<2$ percent cover of trees, and is dominated by shrubs, primarily Coleogyne. Functionally, neither potentially emits a major amount of dust. Cluster 1 emits no dust in any of the three simulated wind speeds. Cluster 2, possibly owing to its lower canopy cover and shorter plant height, emits some dust at 
the highest wind speed but is about 20 -fold lower than the most erodible cluster (below). Though not a true reference state due to the presence of exotic species, this state probably represents the current site potential.

Invaded: Cluster 3 is the most difficult to interpret because it is represented by only two samples. On one hand it is the most productive of all the clusters, supporting both the highest cover of Coleogyne and trees. Total live plants are $2-3 \times$ more abundant than in clusters 1 and 2 . Biocrusts are also well represented, attaining cover comparable to cluster 1 . In additional to these differences in overall productivity, the feature that most distinguishes this cluster is the relatively high prevalence of exotic annuals. Exotic annuals comprise over 13 percent of the community. The grass Bromus tectorum attains a $>40$ percent frequency. Due to the high living cover and low amounts of bare ground, modeled dust emissions are nil at all wind speeds considered.

Shrub-Bare: Cluster 4 is floristically similar to clusters 1 and 2, being dominated by Coloegyne, trees, or both. Exotic annuals are present, but less abundant and frequent than cluster 3 . The primary outstanding characteristic is the low biocrust cover, and high bare gound cover. Owing to this degraded soil surface, dust emissions are possible at all three wind speeds. At the highest wind speed, modeled emissions are $20 \mathrm{x}$ greater than the next highest emitting cluster (2).

Distribution of putative states: In CANY, 88 percent of samples are in biocrust dominated shrubland-woodland states. Another 12 percent are in the invaded state. The Dugout Ranch samples are exclusively in the shrub-bare state.

\section{Grassland ecosystems}

Our dataset included five grassland ecological sites: Sandy Bottom (Fourwing Saltbush), Semidesert Sand (Fourwing Saltbush), Semidesert Sandy Loam (Fourwing Saltbush), Semidesert Shallow Sandy Loam (Shadscale), Upland Shallow Loam (Black Sagebrush). Of these, two were sufficiently well represented on the landscape to perform cluster analyses. Description of soils, climate and geomorphic setting can be found at ftp://ftp-

fc.sc.egov.usda.gov/UT/Range/D35XY/035XY215UT.pdf for Semidesert Sandy Loam, and at ftp://ftpfc.sc.egov.usda.gov/UT/Range/D35XY/035XY212UT.pdf for Semidesert Sand.

\section{Semidesert Sandy Loam (Fourwing Saltbush)}

A hierarchical cluster analysis found 5 clusters of samples. All clusters are well replicated; this ecological site was the best sampled. The clusters can be grouped as states or phases in a provisional state and transition model to assist interpretation (fig. 5a; table 7).

Biocrust: Cluster 1 consists of perennial grasslands, with interspaces containing at least three times as much biocrust cover as any other cluster. Owing to the high biocrust cover, surface roughness and soil aggregate stability are also the highest among all clusters. Although perennial grass cover is somewhat lower than some clusters, this cluster is also notable in that it contains more than twice as much palatable shrub cover compared to the other clusters. Exotic species, annual grasses and/or forbs, are generally present but constitute only about 12 percent of the community that is fairly low for this ecological site. Functionally, this cluster maintains the second highest coverage of perennial forage. Modeled dust emissions occur only at the highest wind speeds, and are several times lower than any other cluster. Though not a true reference state due to the presence of exotic species, this state probably represents the current site potential.

Grass-Bare: We identified two clusters, cluster 2 and 3, which share much affinity in being dominated by perennial grasses but lacking the high biocrust cover of cluster 1 . Both clusters exhibit a high areal coverage of bare ground. Both clusters also appear to have diminished amounts of palatable 
shrubs. Total forage cover is comparable to the biocrust state. Modeled dust emissions are similar among the tow clusters, and are about $4-5 \times$ greater than the less-disturbed biocrust state. The primary difference in the clusters involves the level of invasion by exotic species.

Cluster 2 contains $>1$ percent each of exotic annual forbs and exotic annual grasses. Together these constitute only 3.9 percent of the community. In contrast, Cluster 3 contains almost as much exotic annual grass cover as it does perennial grass cover. Exotics account for about one third of the community in this cluster.

Annualized-Bare: There are two variations on annualized-bare ecosystem states, represented by clusters 4 and 5. Both are notable in that more than 64 percent of the plant community is composed of exotic species. Whether these clusters are linked by a transition, or whether they simply differ because cluster 4 tends to be higher is unknown. The exotic annual grass, Bromus tectorum, dominates cluster 4. This contributes to a high total live coverage of about 60 percent, hence there is farily little bare ground exposed when Bromus is flourishing; this however can change in drought years. Despite the invasion, perennial forage value is actually the highest in this cluster. Modeled dust emissions, however, are $11 \times$ higher than the biocrust state and $2-4 \times$ higher than the grass-bare state.

Cluster 5 is dominated by the exotic annual forb Salsola, which constitutes about three quarters of the community on average. Bare ground coverage is higher in this cluster than in any other, and biocrust cover the lowest. There is very little perennial forage value, as forage is $4-5 \times$ lower than the other clusters. Perhaps the most important functional characteristic of this cluster is its potential to emit dust. It is by far the greatest dust emitter, $2 \times$ the next highest cluster (4), and $27 \times$ higher than the biocrust state.

Distribution of putative states: In CANY, 43 percent of samples are in grass-bare states. Another 36 percent are in biocrust states, and 21 percent in persistent annualized states. The Dugout Ranch is dominated even more extensively by grass-bare states, at 71 percent. Another 25 percent are annualized, and only 5 percent exist in a biocrust state.

\section{Semidesert Sand (Fourwing Saltbush)}

A hierarchical cluster analysis found 7 clusters of samples. Clusters 2, 3, and 4 were relatively well represented in the data (each $n>5$ ), whereas the other 4 were less common and thus should be interpreted somewhat cautiously. The clusters can be grouped as states or phases in a provisional state and transition model to assist interpretation (fig. 5b; table 8).

Biocrust: Clusters 1,2 and 3 are primarily located within CANY, and thus protected from grazing for decades and share high biocrust cover, an indicator of low soil disturbance. Biocrusts are a notable component of this ecosystem (Kleiner and Harper 1972). Simulated dust emissions in all three clusters are all zero at the lowest wind speed, and in general at least 3.7 times lower at other winds speeds compared to other clusters not dominated by biocrusts (the exception is a cluster dominated by Bromus tectorum, for which cover and therefore resistance to wind erosion is confined to only a portion of the year). All have some degree of exotic annual invasion, but cluster means are low (total exotic cover $\leq 6.3$ percent, exotic relative cover $\leq 11.9$ percent). They primarily vary in the relative abundance of different native plant functional groups, and may simply be small-scale spatial variants.

The highest mean biocrust cover characterizes cluster 1, nearly double that of clusters 2 and 3 . It also stands out from the other clusters in its large proportion of native annual forbs, high dominance of grasses relative to shrubs, and among the grasses a high dominance of $\mathrm{C} 3$ bunchgrasses. From a functional standpoint, this cluster is notable in that simulated dust emissions are zero even at the highest windspeeds considered.

At the opposite end of the spectrum in these biocrust-dominated grassland clusters, cluster 3 is notable in that bare ground is more than 3 times higher compared to cluster 1, partially owing to its 50 
percent lower biocrust cover in addition to having about 45 percent less total plant cover. Annuals, exotic and native are only about one third as abundant as in cluster 1. Like Cluster 1, perennial grasses dominate over shrubs, though this dominance is less extreme. Dominance of C4 grasses, with both bunchgrasses and rhizomatous grasses both well represented, are another distinguishing characteristic of this cluster. This cluster emits dust according to models, however emissions are relatively low.

In many ways, cluster 2 is intermediate between clusters 1 and 3 . This cluster has intermediate levels of bare ground, an intermediate $\mathrm{C} 3: \mathrm{C} 4$ grass ratio, and intermediate exotic annual cover. It is similar to cluster 3 in biocrust cover, total shrub cover, modeled dust emissions and total annual cover. Functionally, it is unique from both clusters 1 and 3 in that its high perennial bunchgrass cover and relatively high palatable shrub cover lend it $>50$ percent more forage.

Though not a true reference state due to the presence of exotic species, this state probably represents the current site potential.

Grass-Bare: Cluster 4 is twice as likely to occur outside of CANY relative to inside the park. It is simply distinguished from other clusters because it has low cover. This includes the second lowest biocrust cover values ( $\sim 4$ percent), and the lowest total live plants ( $\sim 18$ percent). Bare ground accounts for over half of cover. Sites in this cluster may have exotics but cannot be considered annualized, as exotic relative cover is only about 6.7 percent. Modeled dust emissions are quite high, even at low wind speeds where this cluster is the only one that emits dust. At higher wind speeds, emissions are among the highest.

Annualized-Bare: Clusters 5, 6 can clearly be considered annualized, with exotic annuals representing about to thirds or more of total vegetation cover. Exotic annual grasses, such as Bromus tectorum, and exotic annual forbs such as Salsola are represented in both clusters.

Cluster 5 occurs exclusively outside of CANY in currently grazed pastures. It is considerably different from cluster 6 in that total plant cover is about two thirds less, possibly due to recent grazing. This cluster lacks palatable shrubs entirely, though does have more $\mathrm{C} 4$ bunchgrasses than any other cluster ( $\sim 5$ percent). Simulated dust emissions at low wind speed are nil, but are extreme at higher windspeeds, in some scenarios emitting hundreds of times more sediment than other clusters.

Cluster 6 occurs exclusively in within CANY, indicating that if annualization was due to disturbance, this state has persisted in the absence of grazing. It has the highest plant cover of all clusters (nearly 90 percent), though it should be stressed that this cover is seasonal, and also subject to high interannual variation. This cluster has the highest shrub cover of all clusters, most of which are palatable. Perennial grass cover is trivial ( $\sim 2$ percent). Functionally, this cluster emits no dust.

Cluster 7 consists of only 3 samples, all within CANY. These have some similarity to the Annualized clusters 5 and 6 On the other hand, they appear to retain some characteristics of biocrustdominated grasslands, but since they have not been disturbed in decades a degradation transition scenario is less plausible than a recovery scenario. Exotic relative cover is moderately high, less than half that of exotic annualized clusters, and double that of most biocrust-dominated clusters. Biocrust cover, at $\sim 15$ percent, is closer to biocrust-dominated grasslands than either denuded or exotic annualized clusters. High annual cover, rather than being composed primarily of Bromus tectorum (in fact this cluster has the least $B$. tectorum of any cluster), is mostly native annual forbs, with the exotic forb Salsola being the primary exotic invader. Perennial vegetation cover is low, although most perennial functional groups are represented. Modeled dust flux is nil at the lowest two wind speeds, but moderate at the highest wind speed modeled. Some Bromus tectorum-dominated sites were observed to shift to Salsola dominance during the 2001-2002 drought. This type of transition may explain this cluster.

Distribution of putative states: In CANY, 62 percent of samples are in biocrust states. Another 17 percent are in grass-bare states, and 10 percent in persistent annualized states. The Dugout Ranch 
exhibits a very different portfolio, with 65 percent of samples in a grass-bare state, 24 percent in a biocrust state, and 12 percent in an annualized state.

\section{Upland sagebrush ecosystems}

Our dataset included one upland sagebrush ecological site: Upland Loam (Basin Big Sagebrush). Description of soils, climate and geomorphic setting can be found at ftp://ftpfc.sc.egov.usda.gov/UT/Range/D35XY/035XY306UT.pdf.

Upland Loam (Basin Big Sagebrush)

A hierarchical cluster analysis found 6 clusters of samples, all of which are reasonably well represented in the dataset. The clusters can be grouped as states or phases in a provisional state and transition model to assist interpretation (fig. 6; table 9).

Biocrust: Cluster 1 may represent the closest extant analogs to a reference state, though it is unclear how high the biocrust cover would be in the absence of grazing. This cluster has both the highest abundance of $A$. tridentata, the indicator species of this ecological site, and biocrust cover. Consequently, aggregate stability and surface roughness are higher than any other clusters, and simulated dust emissions are negligible. Although invasion by exotic annual grasses, for example, Bromus tectorum, is likely, the species accounts for less than 3 percent of total cover.

Grass - Invaded: Cluster 2 is clearly dominated by native perennial grasses, primarily C3 species, and has about half the cover of sagebrush of Cluster 1, and less than half of the cover of biocrusts. The ecological integrity of this cluster is compromised by a substantial presence of Agropyron cristatum (composing 17 percent of the community), an exotic perennial grass, which may have been seeded or may have dispersed on its own. Exotic annual grasses are likely present, but compose only about $\sim 2$ percent of the community. Compared to cluster 1, simulated dust emissions are higher, but still relatively low compared to some other clusters.

Cluster 3 is floristically similar to cluster 2 , but differs in total live vegetation cover, which is reduced by about 40 percent. Conversely, bare ground is more than doubled compared to cluster 2 . The two vegetative functional groups to change the most are native $\mathrm{C} 3$ perennial grasses, which decline, and exotic annual grasses, which increase to account for about 10 percent of the community. Simulated dust flux increases at all wind speeds compared to cluster 2, nearly doubling at the highest wind speed.

Annualized: Clusters 4 and 5 represent communities dominated to different degrees by exotic annual grasses. Both clusters are dominated by slightly over 20 percent cover of perennial native grasses, and have Artemisia and other shrubs, biocrusts, and trees as minor components. Cluster 4, possibly in the process of annualization has a major component of Bromus tectorum constituting 16 percent of total cover. Cluster 5 may represent a later stage of the annualization process as Bromus tectorum is the single most abundant species and composes 44 percent of the total cover. WEMO model runs suggest these clusters emit the most dust in this ecological site, orders of magnitude greater than the sagebrush-biocrust state, and 5-25 times greater than invaded perennial grasslands. Of the two, cluster 5 is this greater dust emitter, about 30 percent higher than cluster 4.

Tree-Bare: Cluster 6 is unique in that it is dominated by a substantial coverage of trees $(\sim 30$ percent). This may be partially due to the overall high elevation of this cluster or may be brought about by a history of grazing and fire suppression (Archer and others, 1995). The remainder of the community is composed of a mixture of native perennial grasses (mostly C3), and shrubs including Artemisia. This community exhibits a moderate degree of invasion by exotics with annuals and perennials about equally represented. Biocrust cover is intermediate between annualized states and biocrust states. Possibly owing to the greater height of the vegetation, simulated dust flux is low and only occurs at the highest wind speed - only the sagebrush-biocrust state is lower. 
Distribution of putative states: This ecological site is almost completely distributed outside of CANY on the Dugout Ranch, thus estimates of areal coverage of ecosystem states should be interpreted with care.

In CANY, 33 percent of samples are in a biocrust state, with the other 67 percent in the grassinvaded state (Cluster 2 type). On the Dugout Ranch, the grass-invaded state (split nearly evenly between clusters 2 and 3), accounts for the largest proportion of samples (44 percent). Annualized ecosystems are a close second, accounting for 39 percent. The biocrust state and tree-bare state each comprise 11 percent of the Dugout samples.

\section{Upland pinyon-juniper ecosystems}

Our dataset included one upland pinyon-juniper ecological site: Upland Shallow Loam (PinyonUtah Juniper). Description of soils, climate and geomorphic setting can be found at ftp://ftpfc.sc.egov.usda.gov/UT/Range/D35XY/035XY315UT.pdf.

\section{Upland Shallow Loam (Pinyon-Utah Juniper).}

A hierarchical cluster analysis found 6 clusters of samples, all of which are reasonably well represented in the dataset except for cluster 3 , which was represented by only 3 samples, and should be interpreted cautiously. The clusters can be grouped as states or phases in a provisional state and transition model to assist interpretation (fig. 7; table 10).

Biocrust: Clusters 1, 2 and 3 may simply be elevational variants of one another. Cluster 1 occurs at a mean elevation of $1850 \mathrm{~m}$, cluster 2 occurs at a mean elevation of $2170 \mathrm{~m}$, and cluster 3 occurs at a mean elevation of $2310 \mathrm{~m}$. All three are clearly dominated by trees, primarily Pinus and Juniperus. All three have minor herbaceous and shrub components, and none have more than 3 percent exotic annual grasses. The primary difference is that plant cover increases with elevation, decreasing both biocrusts and bare ground. Total cover increased from 11 percent at the lowest elevation to 32.7 at the medium elevation to 52.7 percent at the higher elevation; trees, which rise from 6 percent to 23 percent to 34 percent, largely account this for. Concomitantly, bare ground decreases from 44 percent to 28 percent to 23 percent, and biocrust cover declines from 19 percent at low elevation to $\sim 6-8$ percent at higher elevations. Functionally, forage production rises from negligible in cluster 1 to a moderate - low value compared to manipulated sites within this ecological site (see below). In cluster 1 at the lowest elevation, models predict that emissions are not possible until wind speeds of $3500 \mathrm{~m} \mathrm{~s}^{-1}$ are attained at which point fluxes fairly high for this ecosite are observed. In clusters 3 and 4, at medium and high elevation respectively, these emissions drop to trivial values. Though not a true reference state due to the presence of exotic species, this state probably represents the current site potential.

Tree-bare: Cluster 4 is floristically similar to Cluster 1, and was found in the present dataset at similar low elevations. These two clusters also are similar in that they are both relatively low in total plant cover for this ecological site, although cluster 4 is slightly higer than cluster 1 . The single largest difference between the two clusters is that about two thirds of the biocrust cover in cluster 1 is replaced by bare ground in cluster 4 . Forage availability remains extremely low, and is essentially identical to that of cluster 1 . Dust emissions are also similar; nil at the lowest wind speed, $>0$ but still relatively low at moderate wind speed, and moderate at the highest wind speed.

Perennial Grass Exotic: Cluster 5 consists of 80 percent plots which have undergone chaining and seeding, and are mostly at higher elevation than other samples in the dataset. The Pinus-Juniperus tree component is one-third that of cluster 3 due to intentional removal. The trees are largely replaced by Artemisia tridentata and by the seeded exotic perennial grass Agropyron cristatum. Exotic annuals are 
absent. Potential dust flux is near the median for this ecological site, but is much increased compared to cluster 4, which has negiligible-modeled emissions.

Cluster 6 is 91 percent composed of samples, which have undergone similar chaining and seeding treatment in the past, but have subsequently burned. These are mostly at moderate elevations. The largest difference compared to cluster 5 is that the tree and shrub components are essentially eliminated, and are largely replaced by the exotic perennial bunchgrass, $A$. cristatum, which increases its dominance to two thirds of the entire plant cover. Exotic annual grasses compose $<5$ percent of the community. Functionally, this cluster exhibits the highest forage availability in the ecosite, about 8 times higher than cluster 2, the closest analog to the reference state. However, this cluster also potentially emits the greatest amount of dust in the ecological site, several hundred-fold greater than cluster 2.

Distribution of putative states: This ecological site is completely distributed outside of CANY

on the Dugout Ranch. After accounted for higher sampling probability of treated plots, the biocrust state accounts for the highest proportion of samples and areal coverage (53 percent). Another 20 percent is accounted for by the tree-bare state, and 21 percent is accounted for by the exotic state.

\section{All ecosystems combined}

P-scores in CANY: Because pastures in CANY no longer exist, P-scores were calculated for 12th order Hydrological Units (tabulated in table 11). A rating of 1 is the maximum, indicating that for a given ecosystem service or property, all samplings sites of all ecological sites belong to the state or phase which maximizes that service or property. Likewise, a rating of 0.5 would indicate that samples on average are attaining about half the values of that service or property that is possible. Ratings of 0 are possible but not probable for most ecosystem services and properties. A 0 rating is more probable for dust and for multifunction, it indicates that all sample sites are in a state or phase, which has the maximal dust emissions.

In the case of the carbon storage P-score, Davis Canyon attained a near perfect rating (.976), followed closely by Lavender Creek (0.926). Butler Wash and Lower Middle Salt Creek also attained strong ratings at 0.787 and 0.74 . The remaining hydrological units received middling ratings, with Lower Salt Creek rating lowest (Elephant Canyon $=0.668$, Upper Salt Creek $=0.637$, Lower Salt Creek $=0.592$ ).

The P-score for dust emissions also was near perfect in Lavender Creek (0.988) and Davis Canyon (0.970). Elephant Canyon (0.883), Upper Salt Creek (0.832), Butler Wash (0.819), and Middle Salt Creek (0.740) were rated highly. Again Lower Salt Creek was rated lowest among the watershed in the National Park (0.682).

P-scores for preferred forage in CANY watersheds ranged from medium to high. Butler Wash was rated highest (0.803) with Davis Canyon (0.775) close behind. Moderate scores were obtained for Upper Salt Creek (0.691), Middle Salt Creek (0.663), and Lavender Creek (0.603). The worst scores were obtained in Lower Salt Creek (0.506) and Elephant Canyon (0.488).

All CANY watersheds received good P-scores for nativeness. Davis Canyon (0.907) was rated the highest. The lowest score obtained was in Lavender Creek (0.751). The remaining scores span this range and are, in decreasing order: Butler Wash (0.885), Lower Salt Creek (0.873), Elephant Canyon (0.842), Upper Salt Creek (0.842).

We calculated a multifunctionality index in two ways: inclusive of all four ecosystem services and properties, and including all but forage, which is tangential to current management practices. Both methods yielded almost identical results so they are presented together (with the index including forage listed first, followed by the index lacking forage). In general, CANY hydrological units are rated very well. The highest performing units overall are Davis Canyon (0.895/0.874), Butler Wash (0.817/0.818), and Lavender Creek (0.772/0.717). The next highest cluster includes Upper Salt Creek (0.730/0.701), 
and Middle Salt Creek (0.722/0.721). Finally the lowest rated hydrologic units were Elephant Canyon (0.687/0.636), and Lower Salt Creek (0.642/0.630).

E-scores in Canyonlands National Park: E-scores may be useful for pinpointing which ecological site likely accounts for low P-scores. E-scores are tabulated in Table 12. The P-score analysis revealed that Lower Salt Creek was the most poorly rated hydrological unit with regards to C-storage, forage, and both versions of the multifunction index. More than half of this hydrological unit is represented by Semidesert Sandy Loam (four wing saltbush), which received middling to moderately high scores for most ecosystem services and properties. The reason for the low scores may be the low E-scores for carbon storage in Semidesert Sand (Fourwing saltbush) and Semidesert Shallow Sand (Blackbrush) which together account for a sizable minority of the hydrologic unit. The middling forage scores do not seem to reflect any particular ecological site, but rather seem relatively similar in 5 of the 6 ecological sites. Elephant Canyon received the lowest P score for dust within the National Park. Three of the four ecological sites exhibit E scores less than 0.5 in this watershed including the dominant one, Semidesert Sand (Fourwing saltbush). Lavender Creek received the lowest nativeness P-score, although the rating was still good. This rating is almost certainly depressed by abhorrently low E-scores in Semidesert Sand (Fourwing saltbush), because the other ecological sites are very highly rated.

P-scores in the Dugout Ranch: We calculated P-scores for 25 pastures of varying size in the Indian Creek Allotment of the Dugout Ranch (table 11). A rating of 1 is the maximum, indicating that for a given ecosystem service or property, all sampling sites of all ecological sites belong to the state or phase which maximizes that service or property. Likewise, a rating of 0.5 would indicate that samples on average are attaining about half the values of that service or property that is possible. Ratings of 0 are possible but not probable for most ecosystem services and properties. A 0 rating is more probable for dust and for multifunction, it indicates that all sample sites are in a state or phase, which has the maximal dust emissions.

In the case of the carbon storage P-score, the Ranch, Bull 1, and Upper Ranch 2 pastures received perfect scores, albeit all of these pastures were represented by only a single sample. Similarly, Cottonwood, Wilson Ranch, and Glen Canyon all scored over 0.9 , but were represented by only $1-3$ samples. The highest score for which a better sample size exists were observed in Davis Canyon (0.632), Wild Cow (0.584), Middle Pasture (0.578), Corral Pocket (0.548), and Lavender (0.517). The majority of the remainder ranged from 0.3-0.4. The lowest well replicated values were observed in Beef Basin (0.245) and Salt Creek (0.253).

The best rated pastures in dust P-scores with sufficient sample size were in the $0.8-0.9$ range, and included Wild Cow and Bridger Jack Mesa. The majority of ratings were middling values of 0.45 0.55. Although a few poorly replicated pastures received lower scores ( 2 being 0.0 ), Beef Basin and Dark Canyon Bench were both well -replicated and scored below 0.45.

As with carbon storage and dust P-scores, most of the very high and very low P-score values for preferred forage were observed in pastures with $<3$ samples. The majority of ratings were middling values of $0.4-0.6$. Of those with a larger sample size, Lavender and Ruin Park each attained scores above 0.7. Of the well-replicated pastures, Bridger Jack Mesa and Middle Pasture had the lowest scores at $<0.3$. The next lowest group $(0.3-0.4)$ included Dark Canyon Plateau and Corral Pocket.

Unlike the other P-scores, the nativeness P-score generally attained higher values, averaging 0.696. Also unlike the other P-scores, in the case of the nativeness P-score several well-replicated pastures attained very high values ( $>0.9$ ): Park Pasture, Middle Pasture, Corral Pocket, Wild Cow, Dark Canyon Plateau, Bridger Jack Mesa, and Beef Basin. Pastures with low values $(0.3-0.4)$ were numerous but also were represented by less than 3 samples: Cottonwood, Upper Ranch, Upper Cottonwood, Slick Bench, Salt Creek, Ruin Park, and Bull 1. The majority of the remaining samples received scores $>0.5$. 
Davis and Wild Cow received the highest multifunctionality P-scores at 0.610 and 0.602 (Bull 1, Bull 3, Ranch, Upper Ranch, Wilson Ranch attained similar or higher scores with fewer replicates). Middle Pasture (0.178) was rated lowest among the well-replicated pastures. Other notable moderately low values (0.3-0.45) were observed in Park Pasture, Dark Canyon, Beef Basin and Corral Pocket. The second application of the multifunctionality index yielded nearly identical results, except in a few cases where the pasture was represented by only 1 or 2 samples.

E-scores in the Dugout Ranch: E-scores for the Dugout Ranch are summarized in Table 12. The poor multifunctionality ratings for Middle Pasture are likely driven by low E-scores for both dust and forage in semidesert shallow sand ecosystems. Low E scores for dust and forage in semidesert shallow sandy loam ecosystems, and low forage scores for upland shallow loam ecosystems probably resulted in poor multifunctionality P-scores for Dark Canyon Plateau. Park Pasture's low multifunctionality seems to be related to weak E-scores for C-storage and forage in semidesert sand, the majority ecological site; in addition zero $\mathrm{E}$ scores for dust in minority ecological sites probably also lowered scores. The most notable E-scores in Beef Basin are for C-storage in Upland loam ecosystems. These ecosystems dominate the pasture. Corral Pocket seems to have been rated low due to weak E-scores for forage and dust in both semidesert sand and semidesert shallow sand ecological sites.

\section{Discussion}

\section{Comparisons between the Dugout Ranch and Canyonlands National Park}

Canyonlands National Park attained higher scores and more favorable portfolios of ecosystem state distribution than the Dugout Ranch in most of the ecosystem services and properties considered. The contrast is most obvious in a map of C-storage P-score results, wherein the CANY boundary signifies a profound shift in values (fig. 8). Grazing not only consumes forage directly, but consumption diminishes buildup of organic residues, and disrupts the photosynthetic biocrust on the soil surface which is also C-rich (Warren and Eldridge 2003). Thus maximization of stocking levels and C-storage very likely interact antagonistically. High stocking levels at least temporarily reduce C-storage. On the surface, the fact that CANY recieved high scores may suggest that the ability to store $\mathrm{C}$ is not permanently degraded since CANY was stocked at similar or greater levels in the past (Neff and others 2005). If this is true, it should be noted that this recovery encompassed the 1980's which was a very wet period (Hereford and others 2002), and that the last decade and likely the future have been marked by prolonged droughts (Allen and others 2010, Breshears and others 2005, Gitlin and others 2006). An alternative explanation is that the relatively high scores in CANY may simply reflect a high preponderance of areas that were never grazed heavily due to inaccessibility or lack of forage.

Dust P-scores tell a similar story, with the CANY boundary delineating a shift from midling to low P-scores in the Dugout Ranch to high ones within the park (fig. 9). Park-Middle-Creek-Drill-Lower Ranch 2-Corral Pocket pastures and Steven's Mesa-Salt Creek 2-Slick Bench-Upper Cottonwood pastures on the Dugout Ranch form two especially problematic spatial clusters. Like C-storage, this suggests that in most cases maximimizing stocking degrades an ecosystems ability to retain sediment. Grazing disrupts stabilizing biocrusts, reduces height of palatable forage and may increase the spacing among plant patches - all of which are parameters or directly influence parameters in dust emission models (Okin 2008). The high values observed in CANY seem to suggest that this degradation is not permanent, but again we stress: (1) High values may simply reflect a high preponderance of sites which were never grazed heavily, a (2) If indeed recovery did occur, the climate of the recovery period from 1975 to the time of sampling is likely very different from the current regime of climate change linked droughts. Thus the permanence of the degration of this ecosystem service is unknown. Projections of future climates largely suggest a drying climate, possibly featuring multi-decadal droughts (Christensen 
and others, 2007; Seager and others, 2007). Given the dependence of dust emissions on droughts (Munson and others, 2010a) we can expect dust emissions to increase, and the ability of degraded ecosystems to recover their former dust retention capacity is questionable.

Whether the antagonistic effects of stocking on C-storage and dust retention are reciprocal is less straightforward. Cattle stocking rates are based on availability of preferred forage. Grazers consume a portion of the standing crop of forage, and may induce vegetation changes that either diminish (Schlesinger and others, 1990) or enhance forage value (McNaughton, 1976). The creation of CANY and subsequent phase out of grazing can be viewed as an experiment. Although not explicit goals of the creation of the Park, it can be said that the management strategy maximizes C-storage and dust retention. What effect did this experiment have on the forage stock at the level of hydrological units? The one clear result is that there is a homogenization of forage P-scores to medium - high values within CANY (fig. 10). There remains heterogeneity within hydrological units, but the scores for the entire units are similar. Thus we can say that the cessation of grazing did not have a generally negative effect on forage; the effect appears to be mostly positive although we note that a no-grazing scenario does not necessarily maximize forage stocks. In contrast, The Dugout Ranch is much more variable with some pastures attaining very high scores and some attaining very low scores (fig. 10). There are also fewer spatial clusters of similar values, except the Park-Middle-Creek-Drill-Lower Ranch2-Corral Pocket pastures which all received medium to low scores. This heterogeneity may reflect normal rotation schemes of the few years prior to sampling, but may also be indicative of more persistent vegetation changes. These results suggest that a management scheme, which maximizes dust control and C-storage, does not have a strong antagonistic relationship on forage stocks or potential for future grazing should management objectives change. Again, there is much uncertainty regarding present and future climates, as even in the absence of grazing, cool season grasses (a preferred forage item) are declining in abundance (Munson and others, $2011 \mathrm{a}, \mathrm{b})$.

In addition to these ecosystem services, we also considered nativeness as an ecosystem property. Maintaining biotic integrity of native plant communities is a stated goal of the National Park Service. It has long been asserted that grazing enhances or speeds invasion of exotics into previously uninvaded landscapes. On the other hand, seasonally cattle consume some of these exotics such as Bromus tectorum in spring. After invasion or annualization has occurred, the effect of grazing on controlling or enhancing the degree of invasion is unknown. To a large degree the Bromus invasion of CANY occurred before the creation of the park and cessation of grazing, although some localities only experienced invasion in the late 1990's in response to wet Spring climates (Belnap and Phillips, 2001). In this case, the cessation of grazing may have created a homogenization of the landscape at the resolution of the hydrological unit. This is supported by the fact that CANY hydrological units all attain fairly similar nativeness P-scores, which are neither low nor very high; all are at least modestly invaded (fig. 11). We should point out that this result may mask variation at the site-level as some highly degraded individual sites occur. The Dugout Ranch is again extremely variable among pastures, with most pastures receiving midling values but some scoring very high or low (fig. 11). Two spatial clusters emerge. Despite being a problem area in some other ecosystem properties, the cluster formed by Park-Middle-Creek-Drill-Corral Pocket-Davis pastures, all have fairly high nativeness scores. Pastures nearby the ranch headquarters and the canyons contiguous with this area, Lavender Canyon and Cottonwood Canyon, form another cluster of very low nativeness scores.

Combining all of these services and properties into one number was attained using a multifunctionality index (Bowker and others, 2011). The first application of the multifunctionity index was based on all four services and properties. The second application used two subset of services or properties: 1. In CANY, those which might be relevant to National Park management goals (Dust, Nativeness) or might become relevant (C-storage), 2. On the Dugout Ranch, those directly relevant 
(Forage) or with potential to become relevant (Dust and C-storage) to ranchers. In the first application, there is again a clear demarcation between CANY and the Dugout Ranch, with all CANY hydrological units attaining high scores (fig. 12). On the Dugout Ranch, the previously mentioned northern cluster (Park-Middle-Creek-Drill-Corral Pocket-Lower Ranch 2) emerges as an area of low multifunctionality. The upper Cottonwood Canyon cluster of Steven's Mesa-Salt Creek 2-Slick Bench-Upper Cottonwood and Dark Canyon Plateau also emerge as problem areas. Despite being an area of low nativeness scores, the area surrounding the ranch headquarters and lower Cottonwood Canyon did not score low owing to better scores for other services and properties. Although our second application of the multifunction index assumed that forage was irrelevant to the National Park, and that nativeness was irrelevant to ranching goals, the two indices produced almost identical results across the landscape (fig. 13).

\section{Differing spatial scales of active and passive restoration}

The pasture-level P-score analysis method is perhaps only informative when the spatial scale of management activities is large. We suggest there is a spatial scale disconnect between decisions related to range utilization and passive restoration, compared to active restoration. A pasture is generally a fenced unit in which a grazing regime is applied for a specific period of time. Pastures are grazed or rested based upon season, standing crop of forage and other factors.

In a landscape where the primary disturbance agent is grazing, recovery from grazing impacts largely defines restoration success. Restoration activities may be passive or active. Passive restoration simply involves the removal of the stressor or disturbance agent. The most practical scale at which to remove, reduce, or otherwise modify stocking rates, is at the scale of the pasture.

Utilization and disturbance legacy is heterogenous within pastures however. If passive restoration is insufficient to attain management goals, specific sites within pastures may be the targets of active restoration. This is especially so within CANY, where a multi-decadal passive-restoration experiment has already occurred. Pasture-level metrics are not useful for locating candidate locations for active restoration. We suggest that a complementary approach would involve the plotting of key variables across the landscape to identify "problem spots". Figures 14-17 plot all sampling points, scaling each point based on values for stored carbon, dust emission rates, forage, and relative cover of exotic species. Perhaps most instructive is Figure 15 which identifies multiple dust "hotspots" where potential dust emissions can be multiple orders of magnitude greater than the surrounding matrix. Likewise, Figure 17 identifies annualized plots both isolated and in clear clusters which may be restoration targets. Figure 14 is instrumental in illustrating both the potential and heterogeneity in carbon storages of the higher, wetter portions of the study area (for example, Wild Cow, Sweet Alice, Dark Canyon Plateau Pastures).

\section{Ecological site-specific management strategies and trade-offs}

Some ecological sites are inherently better than others in provisioning a particular service or maintaining nativeness. Because utilization of forage directly consumes $\mathrm{C}$, creates surface disturbance, and is thought to assist or hasten exotic invasion, some ecological sites will present trade-offs that must be accounted for in management strategies (Rodríguez and others 2006). There are few clear-cut cases where management for one service or property can be conducted without tradeoffs for another.

The Upland loam ecological site has both the best potential for forage production and the second best potential for $\mathrm{C}$ storage. This ecological site could represent a rare synergy in that the best forage production is found in the hypothetical least disturbed states (fig. 6; cluster 1 and 2) and consumption of that forage via grazing may lead to two divergent outcomes: invasion of trees or invasion of annual exotics. If invasion of trees is the outcome, then $\mathrm{C}$-storage is enhanced. The risk is that grazing will 
promote invasion by exotic annuals and enhance total dust production from very low levels to moderate levels.

Semidesert Shallow Sandy Loam (Utah Juniper-Blackbrush) is one of the ecological sites with a modest potential for C-storage. Consumption of the forage does not seem to be very costly because potential dust emissions are relatively low, and this ecological site seems to be resistant to exotic species. However, because this ecological site is one of the worst forage producers, it simply may not be worth grazing and may serve the greatest benefit to society due to the aggregate value of controlling dust emissions, storing $\mathrm{C}$, and maintaining resistance to exotic species. This may be generally true of blackbrush ecosystems.

Greasewood ecosystems, represented by the Alkali Flat ecological site, may be the most clearcut case. These ecosystems are very poor in terms of forage production and C-storage (note: because Sarcobatus vermiculatus is a large shrub, and $\mathrm{C}$ equations are not always Colorado Plateau specific, the potential C-storage may be underestimated). Utilization of this meager forage creates a risk for moderate dust emissions, or dominance by exotic species, which may outweigh the benefits.

Many of the significant forage producing ecological sites (mostly sagebrush and grassland ecosystems) carry considerable trade-offs with the utilization of that forage. Loamy Bottoms, Semidesert Sand, and Semidesert Sandy Loam all invoke major tradeoffs with dust emissions, and in some cases with exotic invasion. In almost all cases, the clusters, which emit the most dust, are those, which have undergone the most transformation due to grazing and have become annualized to some degree.

The Upland Shallow Loam ecological site represents a true pinyon-juniper ecosystem. It is notable in that it can be made into one of the better forage-producing ecological sites using brush clearing and seeding with exotic perennial grasses. However, in addition to the costs of implementing these treatements, this practice has other costs in terms of alternative ecosystem services and properties. Upland shallow loam also has the greatest potential for $\mathrm{C}$ storage, largely due to trees. Furthermore, maximizing forage production degrades nativeness to the point that exotics strongly dominate the community. These exotic communities can, in turn, enhance invasion into adjacent areas.

\section{Toward multifunctional rangelands}

Our analysis is a necessary first attempt at broadening the way that rangeland utilization is viewed. Even in the absence of a monetary value, our analysis enables other ecosystem services to be evaluated alongside forage. There are additional ecosystem goods and services not considered here, such as habitat provisioning for wild game, pollination services, biomass fuels and building materials, and recreational value (Costanza and others, 1997). There are also alternative livestock, which may use different preferred forage (for example, goats; Eldridge and others, 2011). A view of rangelands encompassing all of these values would likely lead to different and more varied usages of the landscape to best suit the needs of human society.

Currently there is no established monetization of alternative rangeland goods and services that has been applied to semi-arid rangelands of the Colorado Plateau. We view this as a key next step, but it is by no means trivial. Pricing and trading of $\mathrm{C}$ would depend on the establishment of a $\mathrm{C}$ market in the United States and probably a legislatively set price for $\mathrm{C}$ stored. An example of how this might work can be found in the proposed Carbon tax in Australia where a price of \$23 AUS ( $\$ 24$ US) per metric ton of C stored is likely to pass (Siegel, 2011). A trading scheme is to follow within three years. Such a tax would be likely to affect certain practices such as woody brush removal to improve forage. Without the $\mathrm{C}$ tax and a trading system, a rancher can only convert rangelands into income via forage, thus even if such woody plant removal strategies are prone to failure they still occur often. In essence, a $\mathrm{C}$ tax could completely change the equation. Under this scenario, a rancher would have to make the decision to forego one type of value ( $\mathrm{C}$ stored as woody brush), in order to attempt to promote a different value 
(forage for livestock). This would very likely reduce the total amount of woody brush cleared in situations where the first value was sizeable enough. As we learn more about dust emissions and their impacts we can imagine a similar system developing around capture and retention of dust. If dust is indeed modifying water supplies to the already over-allocated Colorado River Basin (Painter and others 2010), then there may be a real drive to value dust based upon the cost of water in this arid region. If all or many of these ecosystem services were translated into dollar values, and the antagonistic and synergistic relationships among different goods and services were better understood, a single numbernet monetary gain both for the individual rancher and for society as a whole, could be available for decision making.

\section{Acknowledgments}

Funding support was provided by the U.S. Geological Survey (Southwest Biological Science Center, Status and Trends of Biological Resources Program, and Global Change Program), The Nature Conservancy of Utah, and the National Park Service. Additional logistical support was provided by the Bureau of Land Management. We thank Rebecca Mann, Mary Moran, Hillary Hudson, Ralph Ferrara, and Ole Bye for assistance with fieldwork and data management. Jayne Belnap provided wind-tunnel data. Barry Baker and Mike Duniway provided comments that improved the quality of the manuscript.

\section{References Cited}

Allen, C.D., Macalady, A.K., Chenchouni, H., Bachelet ,D., McDowell, N., Vennetier, M., Kitzberger, T., Rigling A., Breshears D.D., Hog, E.H., Gonzalez, P., Fensham, R., Zhang, Z., Castro, J., Demidova, N., Lim, J-L., Allard, G., Running, S.W., Semerci, A., Cobb, N., 2010, A global overview of drought and heat-induced tree mortality reveals emerging climate change risks for forests: Forest Ecology and Management, v. 259, p.6606-84.

Barger, N.N, Herrick, J.E, Van Zee, J.W., Belnap J., 2006, Impacts of biological soil crust disturbance and composition on $\mathrm{C}$ and $\mathrm{N}$ loss from water erosion: Biogeochemistry, v. 77, p.247-263.

Beisner, B., Haydon, D., Cuddington, K.,2003, Alternative stable states in ecology: Frontiers in Ecology and the Environment, v. 1, p. 376-382.

Belnap, J., 1995, Surface disturbances: their role in accelerating desertification: Environmental Monitoring and Assessment, v. 37, p.39-57.

Belnap, J., Phillips, S.L., 2001, Soil biota in an ungrazed grassland: response to annual grass (Bromus tectorum) invasion: Ecological Applications, v. 11, p.1261-1275.

Belnap, J., Eldridge, D.J., 2003, Disturbance and recovery of biological soil crusts in Belnap, J, Lange, O.L., (eds.) Biological soil crusts: Structure, function, and management. Second edition. Berlin: Springer-Verlag, p. 363-383.

Belnap, J., Prasse, R., Harper, K.T., 2003, Influence of biological soil crusts on soil environments and vascular plants in Belnap, J., Lange, O.L., (eds.) Biological soil crusts: Structure, function, and management. Second edition. Berlin: Springer-Verlag, p. 281-300

Belnap, J., Reynolds, R.L., Reheis, M.C., Phillips, S.L., Urban, F.E., Goldstein, H.L., 2009, Sediment losses and gains across a gradient of livestock grazing and plant invasion in a cool, semi-arid grassland, Colorado Plateau, USA: Aeolian Research, v. 1, p. 27-43.

Bernstein, S., Betsill, M., Hoffman, M., Paterson, M., 2010, A tale of two Copenhagens: carbon markets and climate governance: Millenium - Journal of International Studies, v. 39, p. 161-173. 
Bestelmeyer, B.T., Brown, J.R., Havstad, K.M., Alexander, R., Chavez, G., Herrick, J.E., 2003, Development and use of state-and-transition models for rangelands: Journal of Range Management, v. 56, p. 114-126.

Bestelmeyer, B.T., Tugel, A.J., Peacock, G.L., Robinett, D.G., Shaver, P.L., Brown, J.R., Herrick, J.E., Sanchez, H., Havstad, K.M., 2009, State-and-transition models for heterogeneous landscapes: A strategy for development and application: Rangeland Ecology and Management, v. 62, p. 1-12.

Blanco, H., Lal, R., 2008, Principles of soil conservation and management. Dordrect: Springer.

Bowker, M.A., 2007, Biological soil crust rehabilitation in theory and practice: an underexploited opportunity: Restoration Ecology, v. 15, p. 13-23.

Bowker, M.A., Belnap, J., and M.E. Miller., 2006, Spatial modeling of biological soil crusts to support rangeland assessment and monitoring: Rangeland Ecology and Management, v. 59, p. 519-529.

Bowker, MA, Maestre, FT, Mau, RL., 2011, What determines semi-arid ecosystem multifunctionality? Biodiversity and patch size distribution of biological crusts: Ecological Monographs in review.

Breshears, D.D., Cobb, N.S., Rich, P.S., Price, K.P., Allen, C.D., Balice, R.G., Romme, W.H., Kastens, J.H., Floyd, M.L., Belnap, J., Anderson, J.J., Myers, O.B., Meyer, C.W., 2005, Regional vegetation die-off in response to global-change-type drought: Proceedings of the National Academy of Sciences, v. 102, p.15144-15148

Briske, D.D., 2006, A unified framework for assessment and application of ecological thresholds: Rangeland Ecology and Management, v. 59, p. 225-236.

Brown, J., MacLeod, N., 2011, A site-based approach to delivering rangeland ecosystem services: The Rangeland Journal, v. 33, p. 99-108.

Cade, B.S, Noon, B.R., 2003, A gentle introduction to quantile regression for ecologists: Frontiers in Ecology and the Environment, v. 1, p. 412-420.

Chapin, F.S., III, Torn, M.S., Tateno, M., 1996, Principles of ecosystem sustainability: American Naturalist, v. 148, p. 1016-1037.

Christensen, J.H., Hewitson B., Busuioc A., Chen A., Gao X., Held I., Jones R., Koli R.K., Kwon W.-T., Laprise R., Rueda V.M., Mearns L., Menéndez C.G., Räisänen J., Rinke A., Sarr A., Whetton P., 2007, Regional climate projections in Solomon, S., Qin, D., Manning, M., Chen, Z., Marquis, M., Averyt, K.B., Tignor, M., Miller, H.L., (eds.) Climate Change 2007: The Report of the IPCC. Cambridge: Cambridge University Press, p. 847-940

Clark, P.E., Hardegree, S.P., Moffet, C.A., Pierson, F.B., 2008, Point sampling to stratify biomass variability in sagebrush steppe vegetation: Rangeland Ecology and Management, v. 61, p. 614-622.

Costanza, R., d'Arge, R., de Groot, R., Farber, S., Grasso, M., Hannon, B., Naeem, S., Limburg, K., Paruelo, J., O'Neill, R.V., Raskin, R., Sutton, P., van den Belt, M., 1997, The value of the world's ecosystem services and natural capital: Nature, v. 387, p. 253-260.

Dyksterhuis, E.J., 1949, Condition and management of rangeland based on quantitative ecology: Journal of Range Management, v. 2, p. 104-115.

Eldridge, D.J., Zaady, E., Shachak, M., 2002, Microphytic crusts, shrub patches and water harvesting in the Negev Desert: the Shikim system: Landscape Ecology, v. 17, p. 587-597.

Eldridge, D.J., Bowker, M.A., Maestre, F.T., Reynolds, J.F., Roger, E., Whitford, W.G., 2011, Impacts of shrub encroachment on ecosystem structure and functioning: toward a global synthesis: Ecology Letters, v. 14, p. 709-722.

Ellison, L., 1949, The ecological basis for judging condition and trend on mountain rangeland: Journal of Forestry, v. 47, p.786-795. 
Escudero, A., Martinez, I., de la Cruz, A., Otalora, M.A.G., Maestre, F.T., 2007, Soil lichens have species-specific effects on the seedling emergence of three gypsophile plant species: Journal of Arid Environments, v. 70, p. 18-28.

Evans, R.D., Lange, O.L., 2003, Biological soil crusts and ecosystem nitrogen and carbon dynamics in Belnap, J., Lange, O., (eds.) Biological soil crusts: Structure, function, and management. Second edition. Berlin: Springer-Verlag, p. 263-279.

Evans, R.D., Rimer, R., Sperry, L., Belnap, J., 2001, Exotic plant invasion alters nitrogen dynamics in an arid grassland: Ecological Applications, v. 11, p. 1301-1310

Fahys, J., 2010, Dugout Ranch: finding a future that fits. Salt Lake Tribune 7 November 2010.

Field, J.P., Belnap, J., Breshears, D.D., Neff, J.C., Okin, G.S., Whicker, J.J., Painter, T.H., Ravi, S., Reheis, M.C., Reynolds, R.L., 2010, The ecology of dust: Frontiers in Ecology and the Environment, v. 8 , p. $423-430$

Flint, L.E., Flint, A.L., 2007, Regional analysis of ground-water recharge in Stonestrom, D.A., Constantz, J., Ty, P.A., Leake, S.A., (eds.) Ground-water recharge in the arid and semiarid southwestern United States: U.S. Geological Survey Professional Paper 1703-B, p. 29-60

Flombaum, P., Sala, O., 2007, A non-destructive and rapid method to estimate biomass and aboveground net primary production in arid environments: Journal of Arid Environments, v. 69, p. $352-358$.

Folke, C., Carpenter, S.R., Walker, B., Scheffer, M., Elmqvist, T., Gunderson, L., Holling, C.S., 2004, Regime shifts, resilience, and biodiversity in ecosystem management: Annual Reviews in Ecology, Evolution, and Systematics, v. 35, p. 557-581.

Gillette, D.A., Adams, J., Muhs, D., Kihl, R., 1982, Threshold friction velocities and rupture moduli for crusted desert soils for the input of soil particles into the air: Journal of Geophysical Research, v. 87, p. 9003-9015.

Gitlin, A.R., Stulz, C.M., Bowker, M.A., Stumpf ,S., Ecton, K., Kennedy, K., Munoz, A., Bailey, J.K., Whitham, T.G., 2006, Dominant plants as "barometers" of change during record droughts: local and landscape patterns of mortality: Conservation Biology, v. 20, p. 1477-1486.

Harper, J.L., Williams, J.T., Sagar, G.R., 1965, The behaviour of seeds in soil. I. The heterogeneity of soil surfaces and its role in determining the establishment of plants from seed: Journal of Ecology, v. 53, p. 273-286.

Havstad, K.M., Peters, D.P.C., Skaggs, R., Brown, J., Bestelmeyer, B., Fredrickson, E., Herrick, J., Wright, J., 2007, Ecological services to and from rangelands of the United States: Ecological Economics, v. 64, p. 261-268.

Hereford, R., Webb, R.H., Graham, S., 2002, Precipitation history of the Colorado Plateau region, 1900 - 2000. US Geological Survey Fact Sheet 119-02.

Herrick, J.E., Whitford, W.G., Walton, M., 2001, Field soil aggregate stability kit for soil quality and rangeland health evaluations: Catena, v. 44, p. 27-35.

Herrick, J.E., Van Zee, J.W., Havstad, K.M., Burkett, L.M., Whitford, W.G., 2005, Monitoring manual for grassland, shrubland and savanna ecosystems. Volume I: Quick start. Las Cruces, NM: USDAARS Jornada Experimental Range.

Herrick, J.E., Bestelmeyer, B.T., Archer, S., Tugel, A.J., and Brown, J.R., 2006, An integrated framework for science-based arid land management: Journal of Arid Environments, v. 65, p. 319-335.

Holling, C.S., 1996, Surprise for science, resilience for ecosystems, and incentives for people:

Ecological Applications, v. 6, p. 733-735. 
Huang, C.-Y., Asner, G.P., Martin, R.E., Barger, N.N., and Neff, J.C., 2009, Multi-scale analysis of tree cover and abovegreound carbon stocks for pinyon-juniper woodland: Ecological Applications, v. 19, p. 668-681.

Karl, J.W., Herrick, J.E., 2010, Monitoring and assessment based on ecological sites: Rangelands, v. 32, p. 60-64.

Kinloch, J.E., Friedel, M.H., 2005, Soil seed reserves in arid grazing lands of central Australia 2: Availability of 'safe sites': Journal of Arid Environments, v. 60, p. 163-185.

Kleiner, E.F., Harper, K.T., 1972, Environment and community organization in grasslands of Canyonlands National Park: Ecology, v. 53, p. 299-309.

Mayer, A.L., Rietkerk, M., 2004, The dynamic regime concept for ecosystem management and restoration: BioScience, v. 54, p. 1013-1020.

McCune, B.P., Grace, J.B., 2002, Analysis of ecological communities. Gleneden Beach, Oregon: MJM Software Design.

McNaughton, S.J., 1976, Serengeti migrating wildebeest: facilitation of energy flow by grazing: Science, v. 191, p. 92-94.

Miller, M.E., 2008, Broad-scale assessment of rangeland health, Grand Staircase-Escalante National Monument, USA: Range Ecology and Management, v. 63, p. 249-262.

Miller, M.E., Belote, R.T., Bowker, M.A., Garman, S.L., 2011, Alternative states of a semiarid grassland ecosystem: implications for ecosystem services: Ecosphere, v. 2, art. 55.

Moir, W.H., 1989, History of development of site and condition criteria for range condition within the U.S. Forest Services in Lauenroth, W.K., Laycock, W.A., (eds.) Secondary succession and the evaluation of rangeland condition. Boulder, Colorado: Westview Press, p. 49-73

Munson, S.M., Belnap, J., Okin, G.S., 2011a, Responses of wind erosion to climate-induced vegetation changes on the Colorado Plateau: Proceedings of the National Academy of Sciences of the United States of America, v. 108, p. 3854-9.

Munson, S.M., Belnap, J., Schelz, C., Moran, M., Carolin, T.W., 2011b, On the brink of change: plant responses to climate on the Colorado Plateau: Ecosphere, v. 2, art. 68.

Neff, J.C., Reynolds, R.L., Belnap, J., Lamothe, P., 2005, Multi-decadal impacts of grazing on soil physical and biogeochemical properties in southeast Utah: Ecological Applications, v. 15, p. 87-95.

Neff, J.C., Ballantyne, A.P., Farmer, G.L., Mahowald, N.M., Conroy, J.L., Landry, C.C., Overpeck, J.T., Painter, T.H., Lawrence, C.R., Reynolds, R.L., 2008, Increasing eolian dust deposition in the western United States linked to human activity: Nature Geosciences, v. 1, p. 189-195.

Nelson, D.W., Sommers, L.E., 1996, Total carbon, organic carbon, and organic matter in Page, A.L. and others, (eds.) Methods of Soil Analysis, Part 2, 2nd eds. Am. Soc. of Agron., Inc. Madison, WI, p. $961-1010$.

Okin, G.S., 2008, A new model of wind erosion in the presence of vegetation: Journal of Geophysical Research, v. 113, art. F02S10.

Okin, G.S., Gillette, D.A., 2001, Distribution of vegetation in wind-dominated landscapes: implications for wind erosion modeling and landscape processes: Journal of Geophysical Research, v. 106, p. 9673-9684.

Okin, G.S., Gillette, D., Herrick, J.E., 2006, Multiscale controls on and consequences of aeolian processes in landscape change in arid and semi-arid environments: Journal of Arid Environments, $\mathrm{v}$. 65, p. 253-275. 
Painter, T.H., Deems, J.S., Belnap, J., Hamlet, A.F., Landry, C.C., Udall, B., 2010, Response of Colorado River runoff to dust radiative forcing in snow: Proceedings of the National Academy of Sciences, v. 107, p. 17125-17130.

Pellant, M., Shaver, P.L., Pyke, D.A., Herrick, J.E., 2005, Interpreting indicators of rangeland health. Version 4. Interagency technical reference TR-1734-6. U.S. Department of Interior, Bureau of Land Management, National Science and Technology Center, Denver, CO.

Pendelton, D.T., 1989, Range condition as used in the Soil Conservation Service in Lauenroth, W.F., Laycock, W.A., (eds.) Secondary succession and the evaluation of rangeland condition. Boulder, Colorado: Westview Press, p. 17-34

Pyke, D.A., Herrick, J.W., Shaver, P., Pellant, M., 2002, Rangeland health attributes and indicators for qualitative assessment: Journal of Range Management, v. 55, p. 584-597.

Reynolds, J.F., Stafford Smith, D.M., 2002, Do humans cause deserts? in Reynolds, J.F., Stafford Smith, D.M., (eds.) Global desertification: Do humans cause deserts. Berlin: Dahlem University Press, p. 125

Reynolds, J.F., Stafford Smith, D.M., Lambin, E.F., Turner, B.F, II, Mortimore, M., Batterbury, S.P.J., Downing, T.E., Dowlatabadi, H., Fernández, R.J., Herrick, J.E., Huber-Sannwald, E., Leemans, R., Lynam, T., Maestre, F.T., Ayarza, M., Walker, B., 2007, Global desertification: Building a science for dryland development: Science, v. 316, p. 847-851.

Reynolds, R.L., Belnap, J., Reheis, M.C., Lamothe, P., Luiszer, F., 2001, Aeolian dust in Colorado Plateau soils: Nutrient inputs and recent change in source: Proceedings of the National Academy of Sciences, v. 98, p. 7123-7127.

Reynolds, R.L., Reheis, M.C., Neff, J.C., Goldstein, H., Yount, J.D., 2006, Late Quaternary eolian dust in surficial deposits of a Colorado Plateau grassland: Controls on distribution and ecologic effects: Catena, v. 66, p. 251-266.

Rodríguez, J.P., Beard, T.D., Jr., Bennett, E.M., Cumming, G.S., Cork, S., Agard, J., Dobson, A.P., Peterson, G.D., 2006, Trade-offs across space, time, and ecosystem services: Ecology and Socity, v. 11, p. 28.

Saleh, A., 1993, Soil roughness measurement: chain method: Journal of Soil and Water Conservation, v. 48, p. 527-530.

Scheffer, M., Carpenter, S.R., 2003, Catastrophic regime shifts in ecosystems: Linking theory to observation: Trends in Ecology and Evolution, v. 18, p. 648-656.

Schlesinger, WH., 1991, Biogeochemistry: An analysis of global change. Academic Press, San Diego.

Schlesinger, W.H., Reynolds, J.F., Cunningham, G.L., Huenneke, L.F., Jarrell, W.M., Virginia, R.A., Whitford, W.G., 1990, Biological feedbacks in global desertification: Science, v. 247, p. 1043-1048.

Schlesinger, W.H., Belnap, J., Marion, G., 2009, On carbon sequestration in desert ecosystems: Global Change Biology, v. 15, p. 1488-1490.

Schmieding, S.J., 2008, From controversy to compromise to cooperation: The administrative history of Canyonlands National Park. National Park Service, Moab, UT.

Seager, R, M., Held, I., Kushnir, Y., Lu, J.,Vecchi, G., Huang, H.-P., Harnik, N., Leetmaa, A., Lau, N.C., Li, C., Velez, J., and N. Naik., 2007, Model projections of an imminent transition to a more arid climate in southwestern North America: Science, v. 316, p. 1181-1184.

Seigel, M., 2011, Australia's Lower House narrowly passes carbon tax. New York Times: 12 October 2011.

Stevens, Jr. D.L., Olsen, A.R., 2004, Spatially-balanced sampling of natural resources: Journal of the American Statistical Association, v. 99, p. 262-278. 
Suding, K.N., Hobbs, R.J., 2009, Threshold models in restoration and conservation: A developing framework: Trends in Ecology and Evolution, v. 24, p. 271-279.

Tongway, D.J., Hindley, N., 1995, Manual for assessment of soil condition of tropical grasslands. Canberra, Australia: CSIRO.

Tongway, D.J., Smith, E.L., 1989, Soil surface features as indicators of rangeland site productivity: Australian Rangeland Journal, v. 11, p. 15-20.

The Nature Conservancy., 2011, http://www.nature.org/ourinitiatives/urgentissues/climatechange/ placesweprotect/utah-dugout-ranch.xml

USDA NRCS., 1991, Soil Survey of Canyonlands Area, Utah: Parts of Grand and San Juan Counties. Salt Lake City, UT: U.S. Department of Agriculture, Natural Resources Conservation Service.

van de Koppel, J., Rietkerk, M., Weissing, F.J., 1997, Catastrophic vegetation shifts and soil degradation in terrestrial grazing systems: Trends in Ecology and Evolution, v. 12, p. 352-356.

Ward, A.D., Trimble S.W., 2004, Environmental hydrology. Second edition. Boca Raton, FL: Lewis Publishers.

Warren, S.D., 2003, Synopsis: Influence of biological soil crusts on arid land hydrology and soil stability in Belnap, J., Lange, O., (eds.) Biological soil crusts: Structure, function, and management. Second edition. Berlin: Springer-Verlag, p. 349-360

Warren, S.D., Eldridge, D.J., 2003, Biological soil crusts and livestock in ardi ecosystems: are they compatible? in Belnap, J., Lange, O., (eds.) Biological soil crusts: Structure, function, and management. Second edition. Berlin: Springer-Verlag, p. 401-416

Westoby, M., Walker, B., Noy-Meir, I., 1989, Opportunistic management for rangelands not at equilibrium: Journal of Range Management, v. 42, p. 266-274.

Whisenant, S.G., 1999, Repairing damaged wildlands: A process-oriented, landscape-scale approach. Cambridge: Cambridge University Press.

Williams, J.D., Dobrowolski, J.P., Gillette, D.A., West, N.E., 1995, Microphytic crust influence on wind erosion: Transactions of the American Society of Agricultural Engineers, v. 38, p. 131-137.

Williamson, S.C., Detling, J.K., Dodd, J.L., Dyer, M.I., 1987, Nondestructive estimation of shortgrass aerial biomass: Journal of Range Management, v. 40, p. 254-256.

Wohlfahrt, G., Fenstermaker, L.F., Arnone, I.J., 2008, Large annual net ecosystem CO2 uptake of a Mojave Desert ecosystem: Global Change Biology, v. 14, p. 1475-1487.

Zavaleta, E.S., Pasari, J.R., Hulvey, K.H., Tilman, G.D., 2010,Sustaining multiple ecosystem functions in real assemblages requires higher biodiversity: Proceedings of the National Academy of Sciences $\mathrm{V}$. 107, p. 1443-1446. 


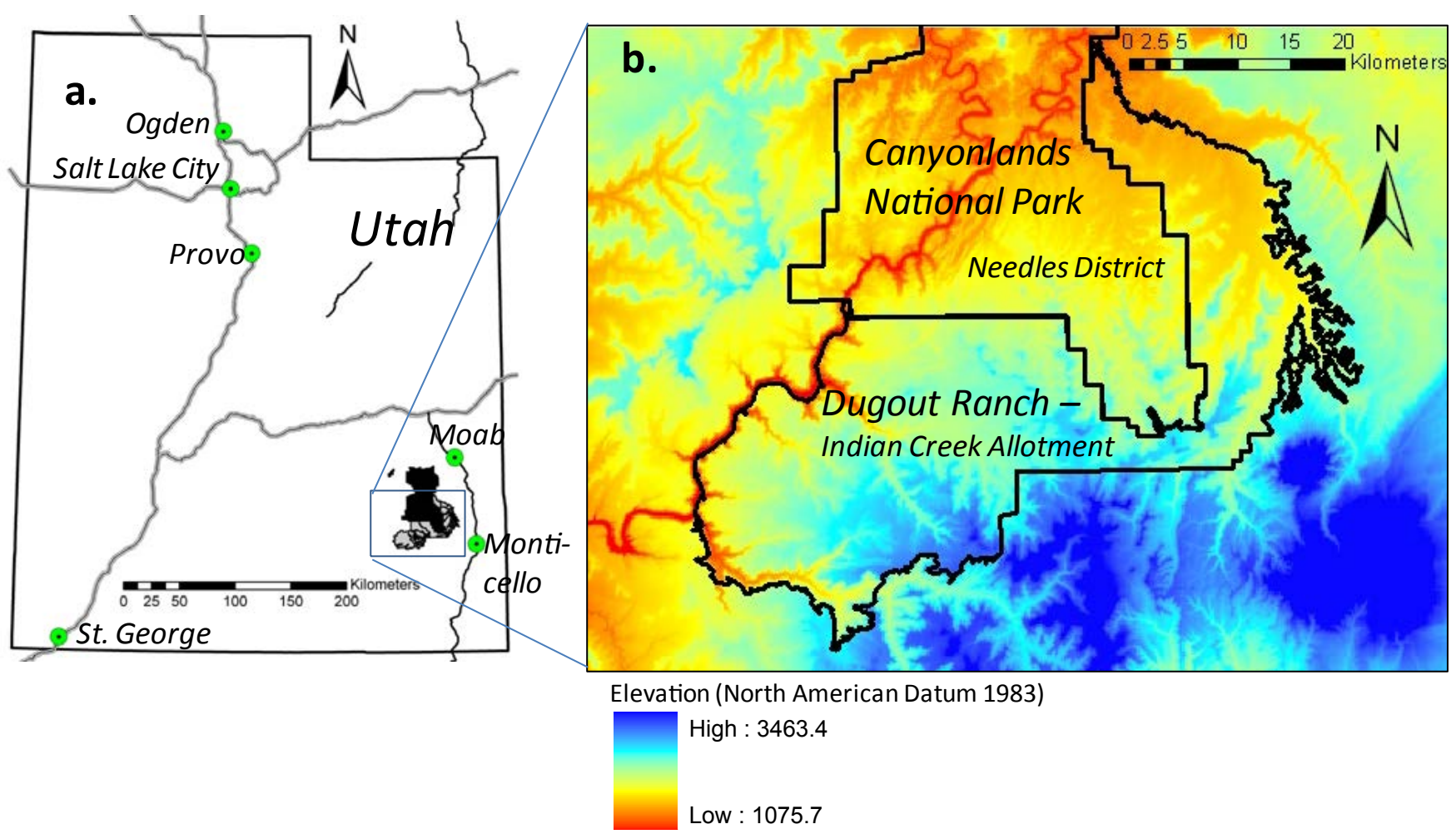

Figure 1. Map of the study area in southeastern Utah. 
SAGEBRUSH BOTTOMS

Loamy Bottom (Basin Big Sagebrush)

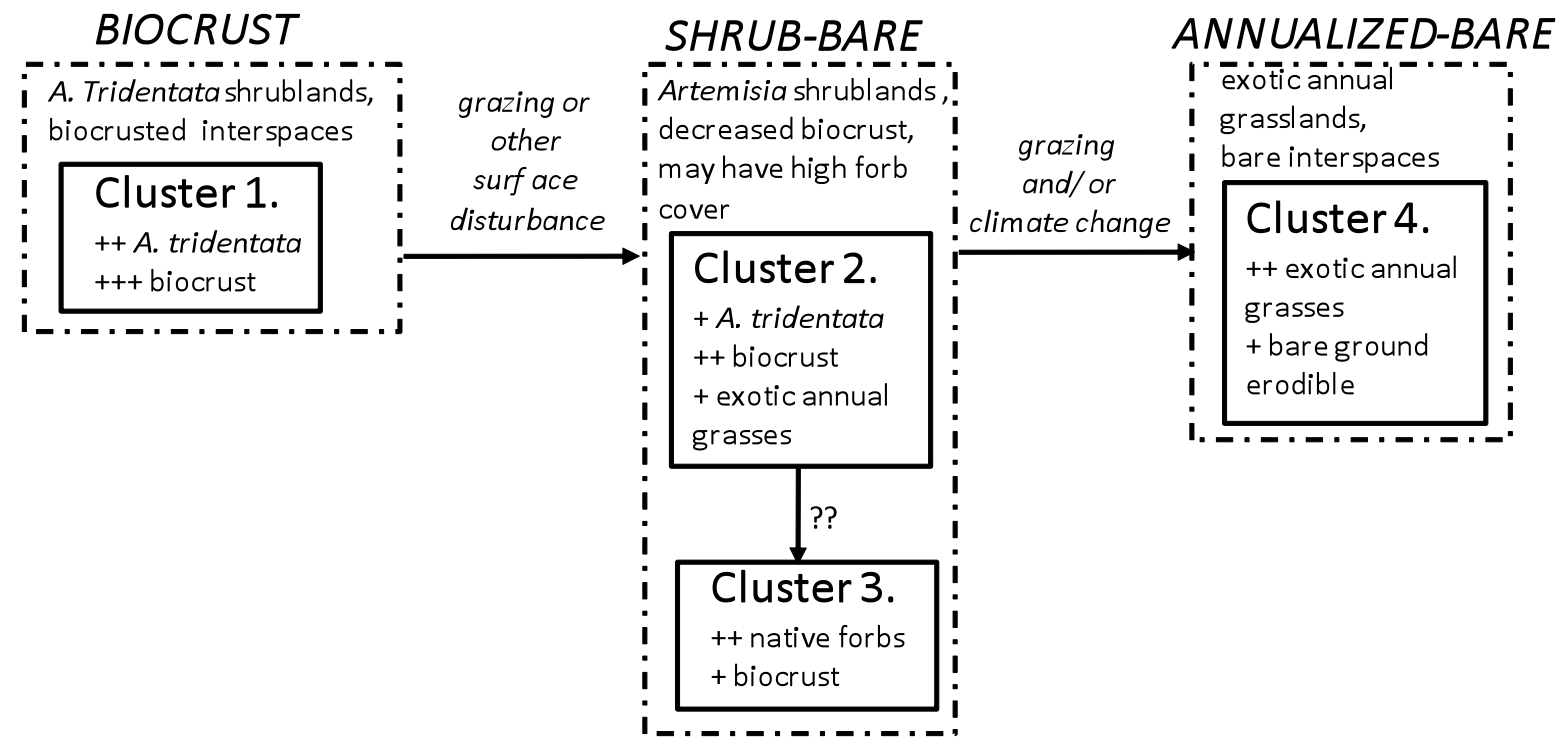

Figure 2. Provisional state-and-transition model illustrating alternate ecosystem states and phases, and hypothesized transitions among them for sagebrush bottom ecosystems.

\section{GREASEWOODECOSYSTEMS} Alkali Flat (Greasewood)

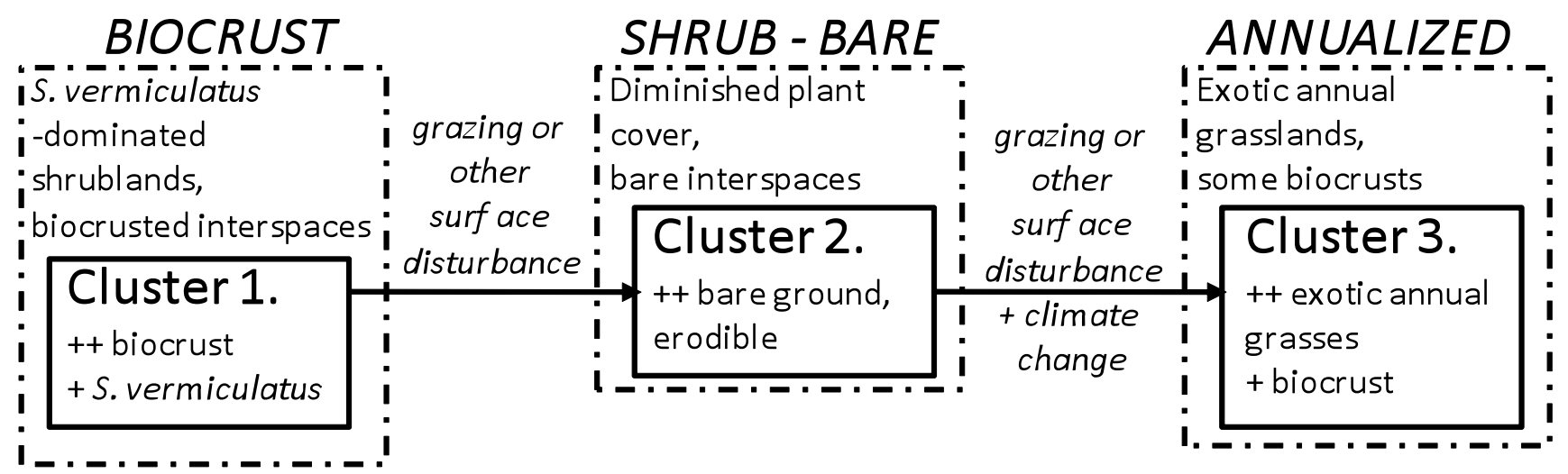

Figure 3. Provisional state-and-transition model illustrating alternate ecosystem states and phases, and hypothesized transitions among them for greasewood ecosystems. 
BLACKBRUSH ECOSYSTEMS

A. Semidesert Shallow Sand (Blackbrush)

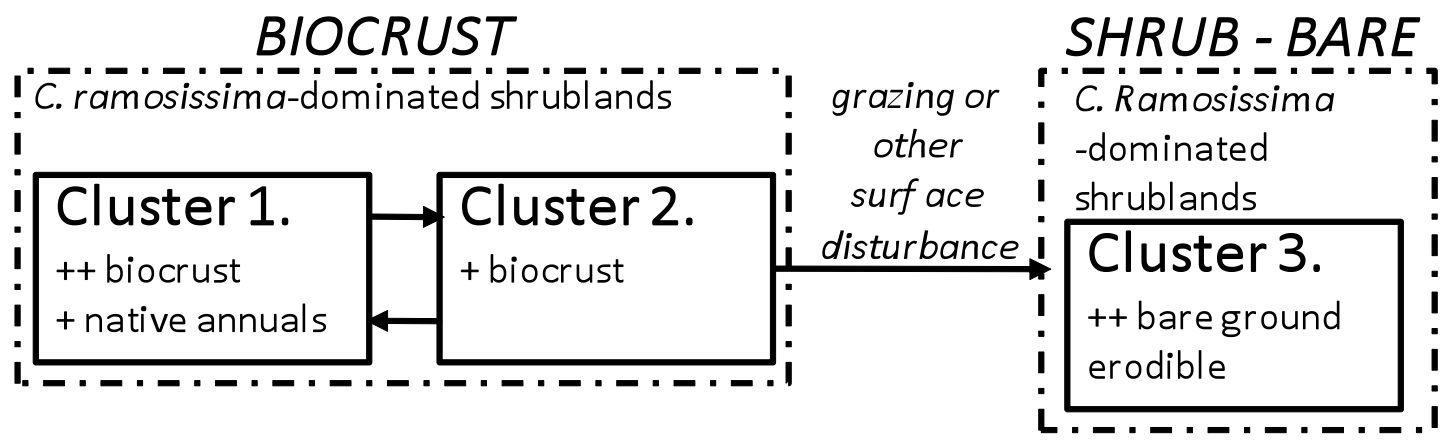

B. Semidesert Shallow Sandy Loam (Utah Juniper - Blackbrush) BIOCRUST

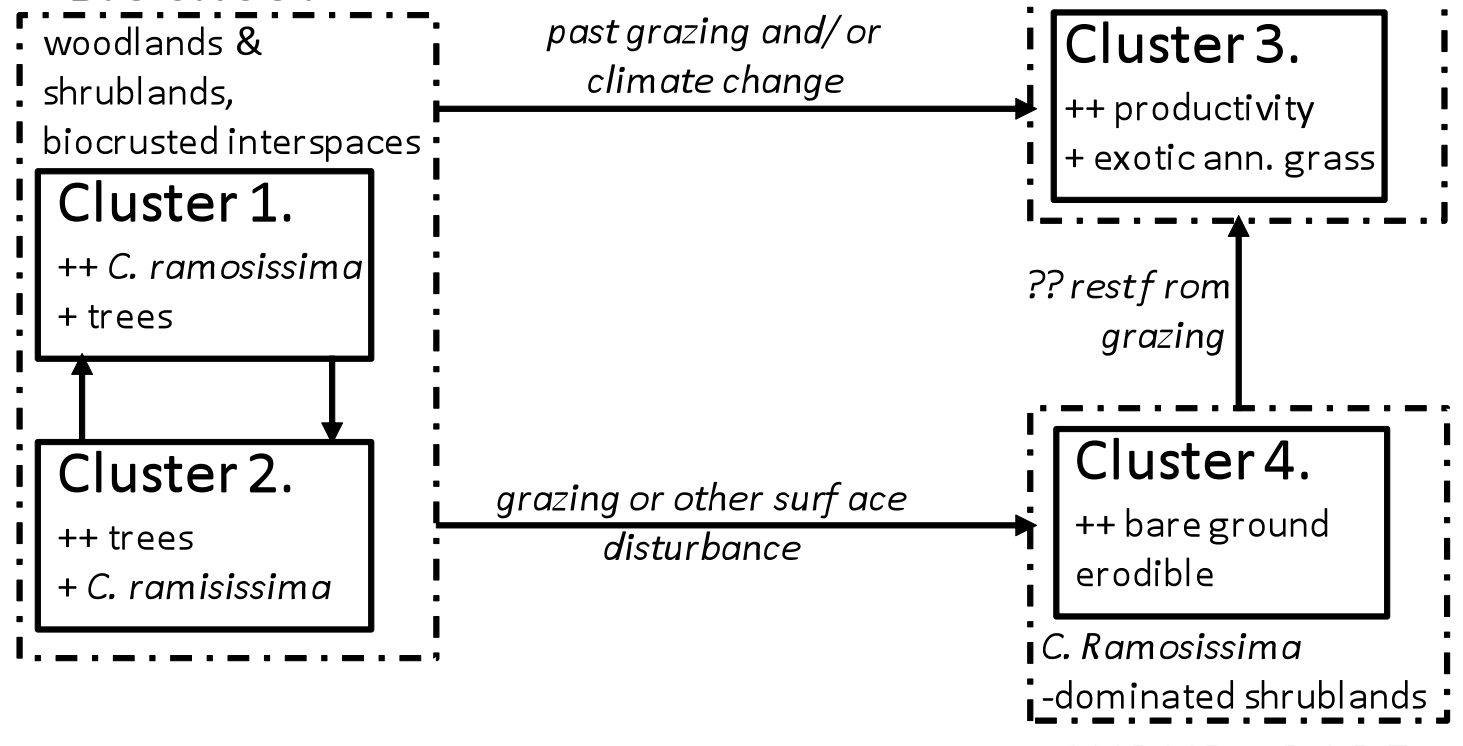

SHRUB - BARE

Figure 4. Provisional state-and-transition model illustrating alternate ecosystem states and phases, and hypothesized transitions among them for blackbrush ecosystems. 


\section{GRASSLAND ECOSYSTEMS}

\section{A. Semidesert sandy loam (Four-wing saltbush)}

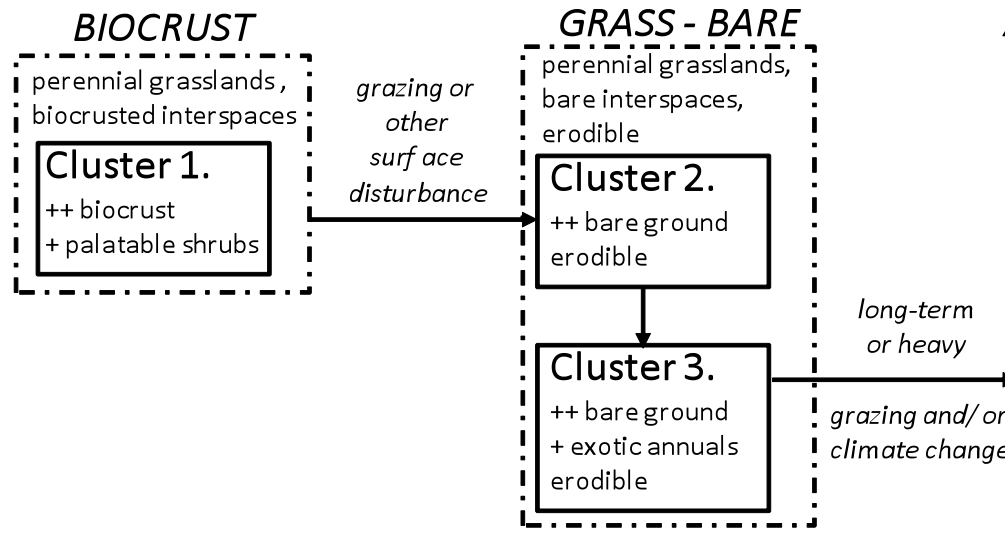

ANNUALIZED-BARE

perennial grasslands

; biocrusted interspaces

Cluster 1

++ biocrust

+ palatable shrubs

ANNUALIZED-BARE,

Annual grass- or

forb-dominated

Cluster 4.

++ exotic annual

grasses

erodible

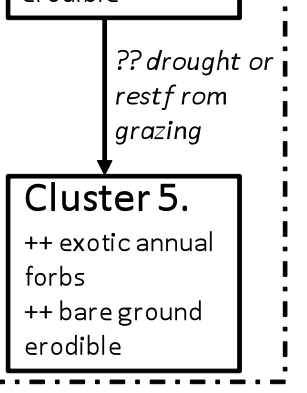

\section{B. Semidesert sand} (Four-wing saltbush)

\section{ANNUALIZED-BARE}

I Annualgrass-or-..

i forb-dominated

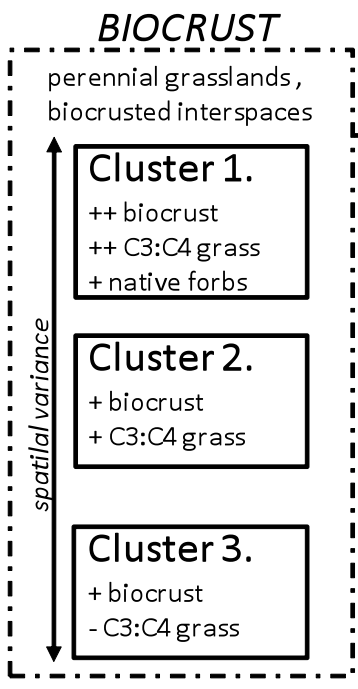

\section{GRASS - BARE}

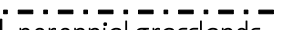
perennial grasslands, i bare interspaces,

erodible

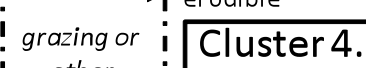

other : Cluster 4.

- surface

++ bare ground

erodible

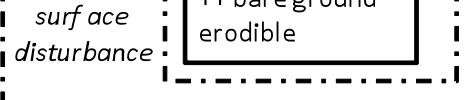

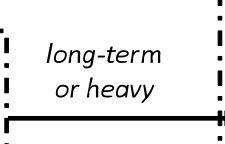

Cluster 5.

+ exotic annual

grasses

+ bare ground highly erodible

igrazing and/or i climate change

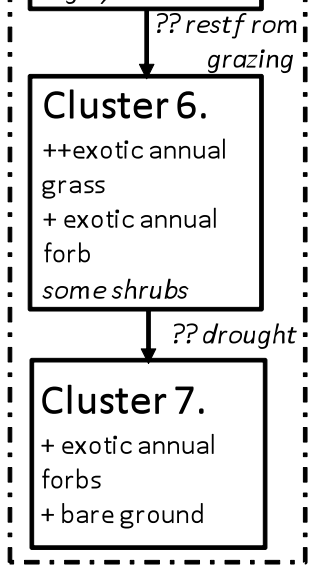

Figure 5. Provisional state-and-transition model illustrating alternate ecosystem states and phases, and hypothesized transitions among them for grassland ecosystems. a. Semidesert sandy loam. b. Semidesert sand. 
UPLAND SAGEBRUSH ECOSYSTEMS

Upland Loam (Basin Big Sagebrush)

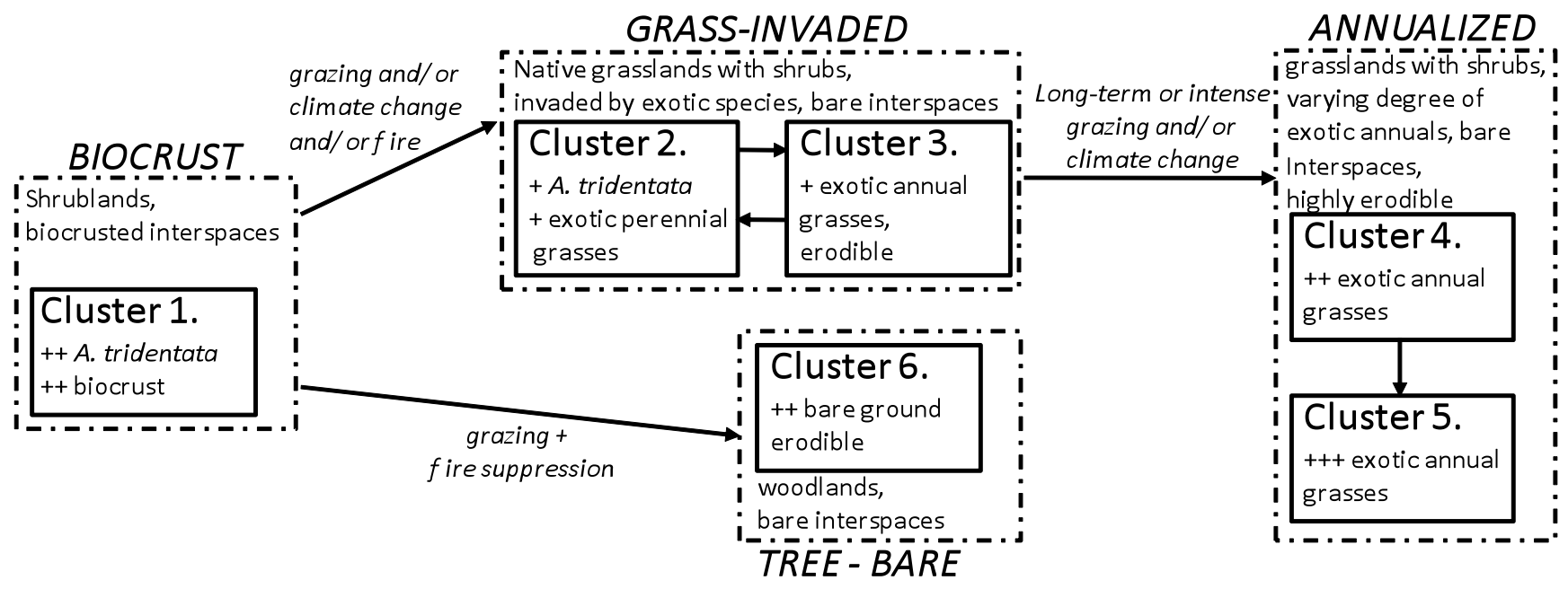

Figure 6. Provisional state-and-transition model illustrating alternate ecosystem states and phases, and hypothesized transitions among them for upland sagebrush ecosystems.

\section{UPLAND PINYON-JUNIPER ECOSYSTEMS Upland Shallow Loam (Pinyon - Utah Juniper)}

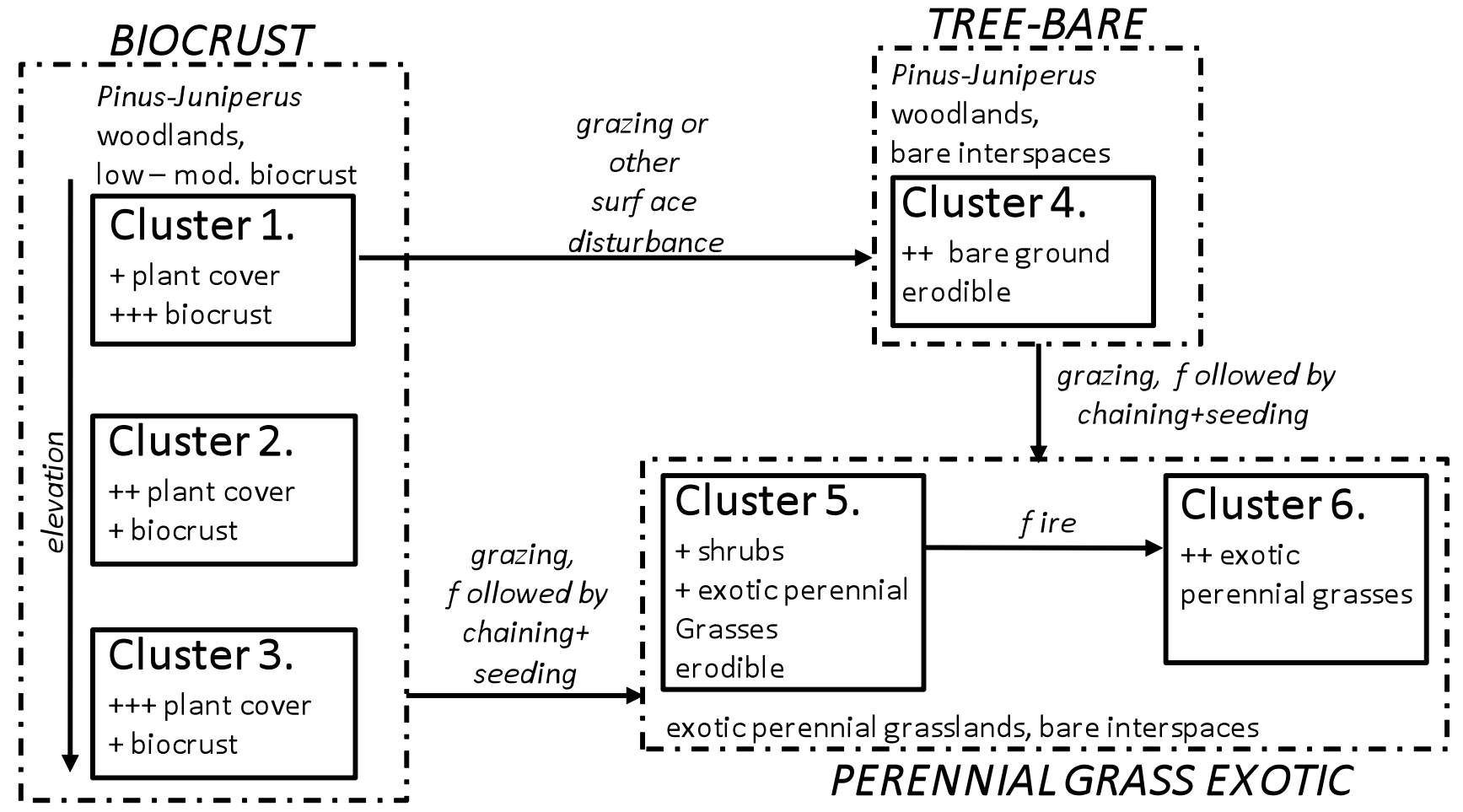

Figure 7. Provisional state-and-transition model illustrating alternate ecosystem states and phases, and hypothesized transitions among them for upland pinyon-juniper ecosystems. 
EXPLANATION

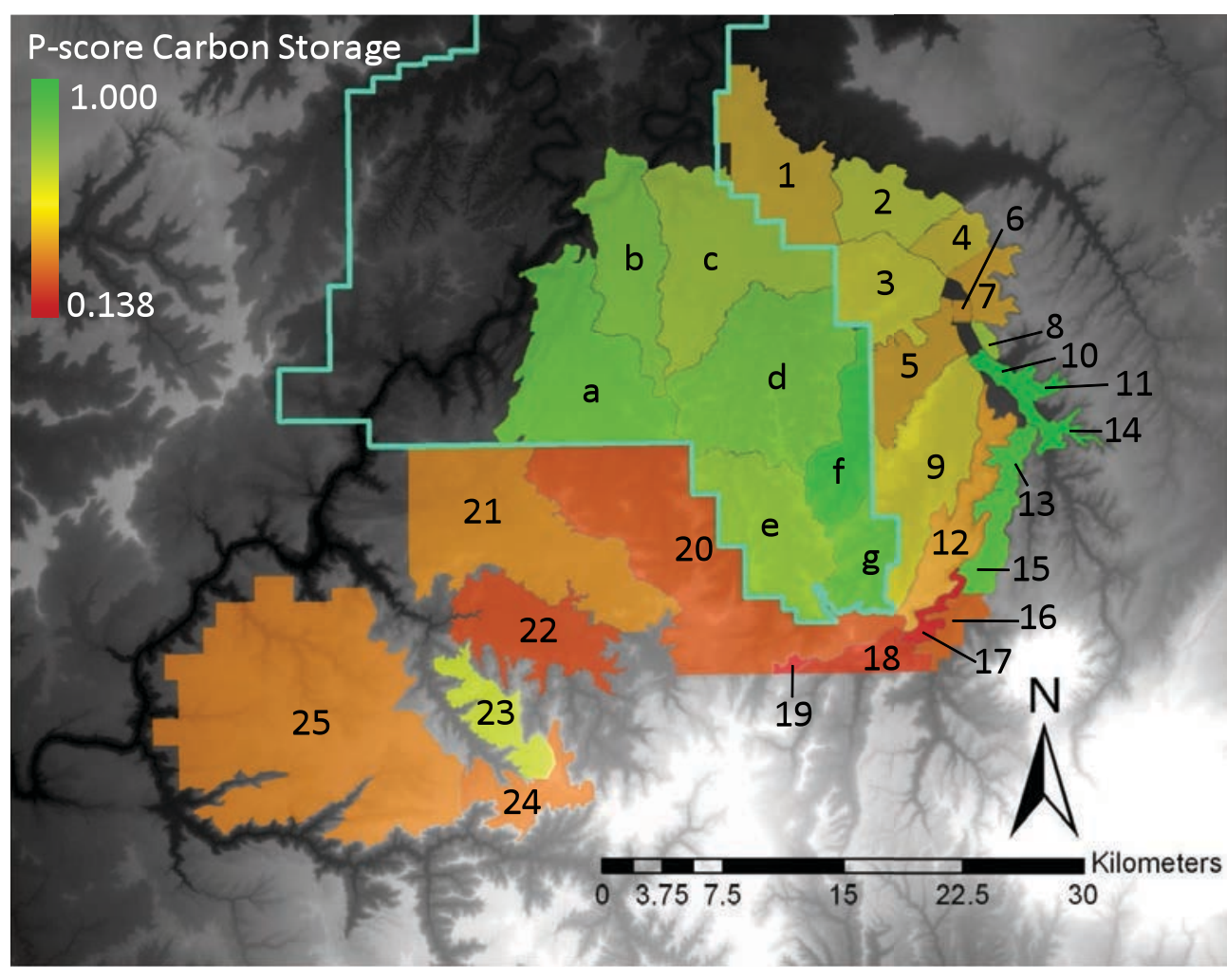

Hydrological units (Canyonlands)

a Butler Wash

b Elephant Wash

Lower Salt Creek

Middle Salt Creek

Upper Salt Creek

Davis Canyon

Lavender Creek

Pastures (Dugout Ranch)

Park Pasture

Middle Pasture

Corral Pocket

Creek Pasture

5 Davis

Lower Ranch

Drill Pasture

8 Bull

9 Lavender

10 Ranch

11 Bull 1

12 Bridger Jack Mesa

13 Cottonwood

14 Upper Ranch

15 Wilson Ranch

16 Upper Cottonwood

17 Slick Bench

18 Steven's Mesa

19 Salt Creek2

20 Salt Creek

21 Ruin Park

22 Beef Basin

23 Wild Cow

24 Sweet Alice

25 Dark Canyon Plateau

Figure 8. Map of C-storage P-scores applied to hydrological units in Canyonlands National Park and pastures in the Dugout Ranch. Key: a. Butler Wash, b. Elephant Wash, c. Lower Salt Creek, d. Middle Salt Creek, e. Upper Salt Creek, f. Davis Canyon, g. Lavender Creek, 1. Park Pasture, 2. Middle Pasture, 3. Corral Pocket, 4. Creek Pasture, 5. Davis, 6. Lower Ranch 2, 7. Drill Pasture, 8. Bull 3, 9. Lavender, 10. Ranch, 11. Bull 1, 12. Bridger Jack Mesa, 13. Cottonwood, 14. Upper Ranch 1, 15. Wilson Ranch, 16. Upper Cottonwood, 17. Slick Bench, 18. Steven's Mesa, 19. Salt Creek 2, 20. Salt Creek, 21. Ruin Park, 22. Beef Basin, 23. Wild Cow, 24. Sweet Alice, 25. Dark Canyon Plateau. 


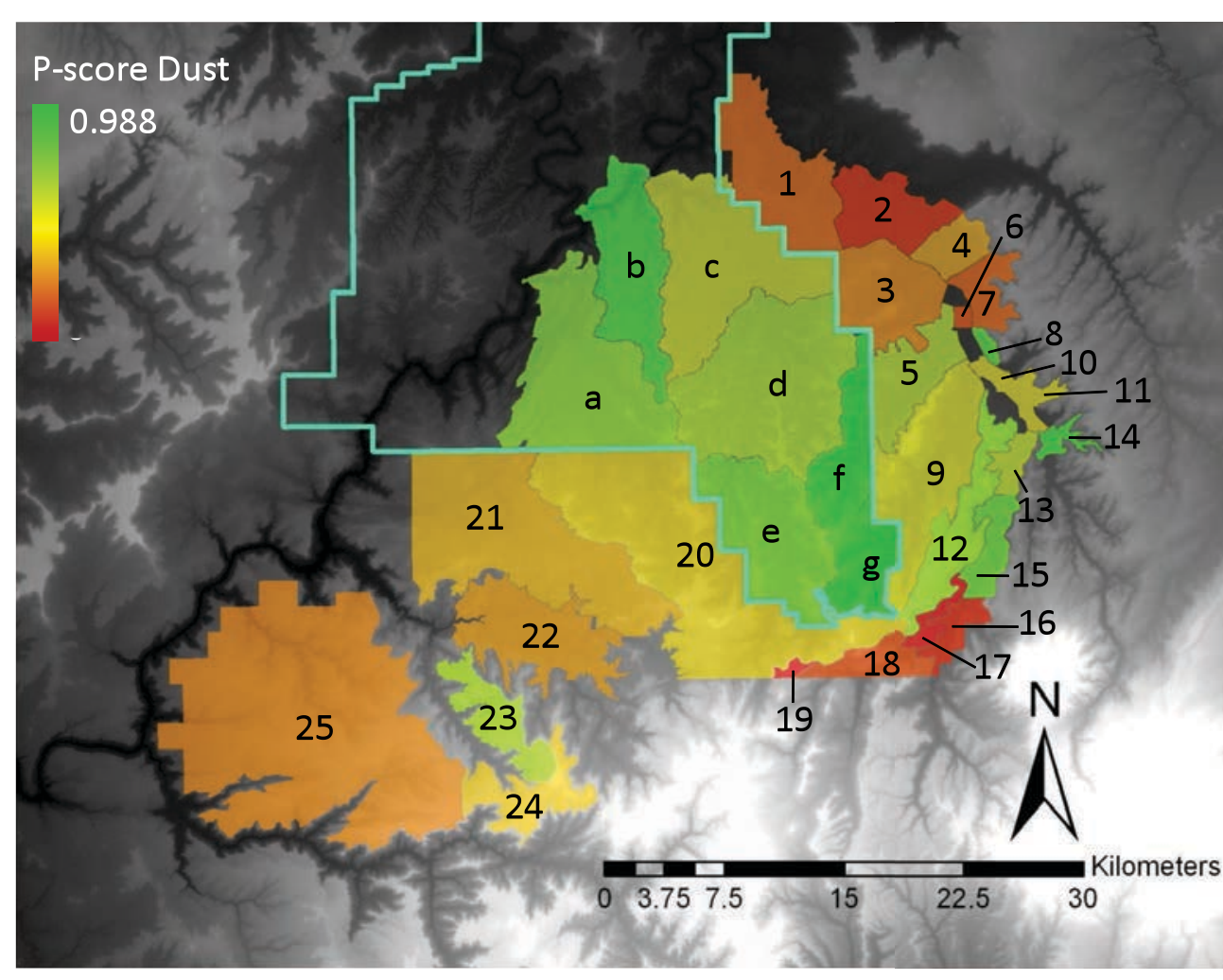

EXPLANATION

Hydrological units (Canyonlands)

a Butler Wash

b Elephant Wash

Lower Salt Creek

d Middle Salt Creek

Upper Salt Creek

Davis Canyon

Lavender Creek

Pastures (Dugout Ranch)

1 Park Pasture

2 Middle Pasture

Corral Pocket

Creek Pasture

5 Davis

6 Lower Ranch

7 Drill Pasture

8 Bull

9 Lavender

10 Ranch

11 Bull 1

12 Bridger Jack Mesa

13 Cottonwood

14 Upper Ranch

15 Wilson Ranch

16 Upper Cottonwood

17 Slick Bench

18 Steven's Mesa

19 Salt Creek2

20 Salt Creek

21 Ruin Park

22 Beef Basin

23 Wild Cow

24 Sweet Alice

25 Dark Canyon Plateau

Figure 9. Map of dust P-scores applied to hydrological units in Canyonlands National Park and pastures in the Dugout Ranch. Key: a. Butler Wash, b. Elephant Wash, c. Lower Salt Creek, d. Middle Salt Creek, e. Upper Salt Creek, f. Davis Canyon, g. Lavender Creek, 1. Park Pasture, 2. Middle Pasture, 3. Corral Pocket, 4. Creek Pasture, 5. Davis, 6. Lower Ranch 2, 7. Drill Pasture, 8. Bull 3, 9. Lavender, 10. Ranch, 11. Bull 1, 12. Bridger Jack Mesa, 13. Cottonwood, 14. Upper Ranch 1, 15. Wilson Ranch, 16. Upper Cottonwood, 17. Slick Bench, 18. Steven's Mesa, 19. Salt Creek 2, 20. Salt Creek, 21. Ruin Park, 22. Beef Basin, 23. Wild Cow, 24. Sweet Alice, 25. Dark Canyon Plateau. 


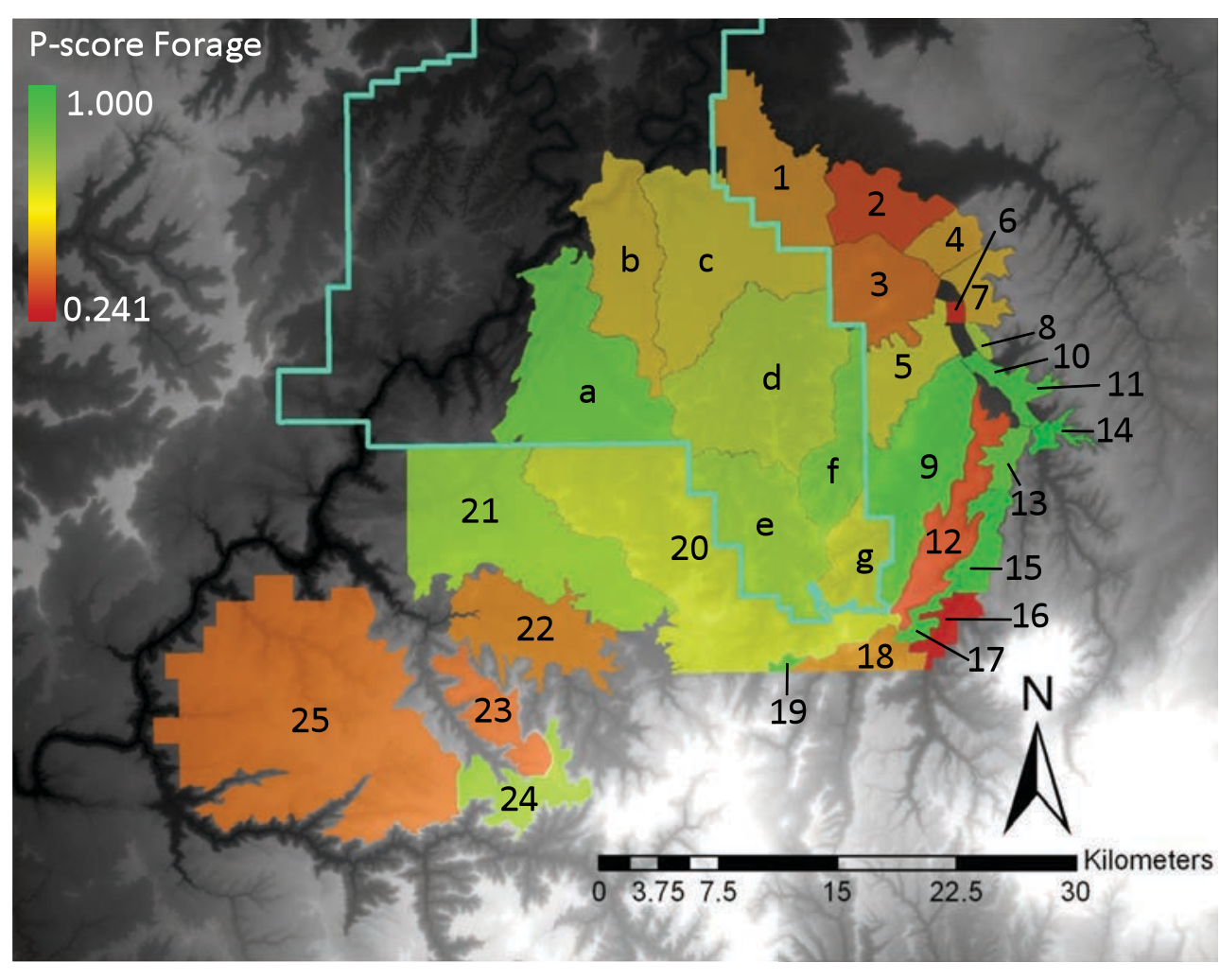

EXPLANATION

Hydrological units (Canyonlands)

a Butler Wash

b Elephant Wash

Lower Salt Creek

d Middle Salt Creek

Upper Salt Creek

Davis Canyon

g Lavender Creek

Pastures (Dugout Ranch)

1 Park Pasture

2 Middle Pasture

Corral Pocket

4 Creek Pasture

Davis

6 Lower Ranch

Drill Pasture

8 Bull

9 Lavender

10 Ranch

11 Bull 1

12 Bridger Jack Mesa

13 Cottonwood

14 Upper Ranch

15 Wilson Ranch

16 Upper Cottonwood

17 Slick Bench

18 Steven's Mesa

19 Salt Creek2

20 Salt Creek

21 Ruin Park

22 Beef Basin

23 Wild Cow

24 Sweet Alice

25 Dark Canyon Plateau

Figure 10. Map of forage P-scores applied to hydrological units in Canyonlands National Park and pastures in the Dugout Ranch. Key: a. Butler Wash, b. Elephant Wash, c. Lower Salt Creek, d. Middle Salt Creek, e. Upper Salt Creek, f. Davis Canyon, g. Lavender Creek, 1. Park Pasture, 2. Middle Pasture, 3. Corral Pocket, 4. Creek Pasture, 5. Davis, 6. Lower Ranch 2, 7. Drill Pasture, 8. Bull 3, 9. Lavender, 10. Ranch, 11. Bull 1, 12. Bridger Jack Mesa, 13. Cottonwood, 14. Upper Ranch 1, 15. Wilson Ranch, 16. Upper Cottonwood, 17. Slick Bench, 18. Steven's Mesa, 19. Salt Creek 2, 20. Salt Creek, 21. Ruin Park, 22. Beef Basin, 23. Wild Cow, 24. Sweet Alice, 25. Dark Canyon Plateau. 


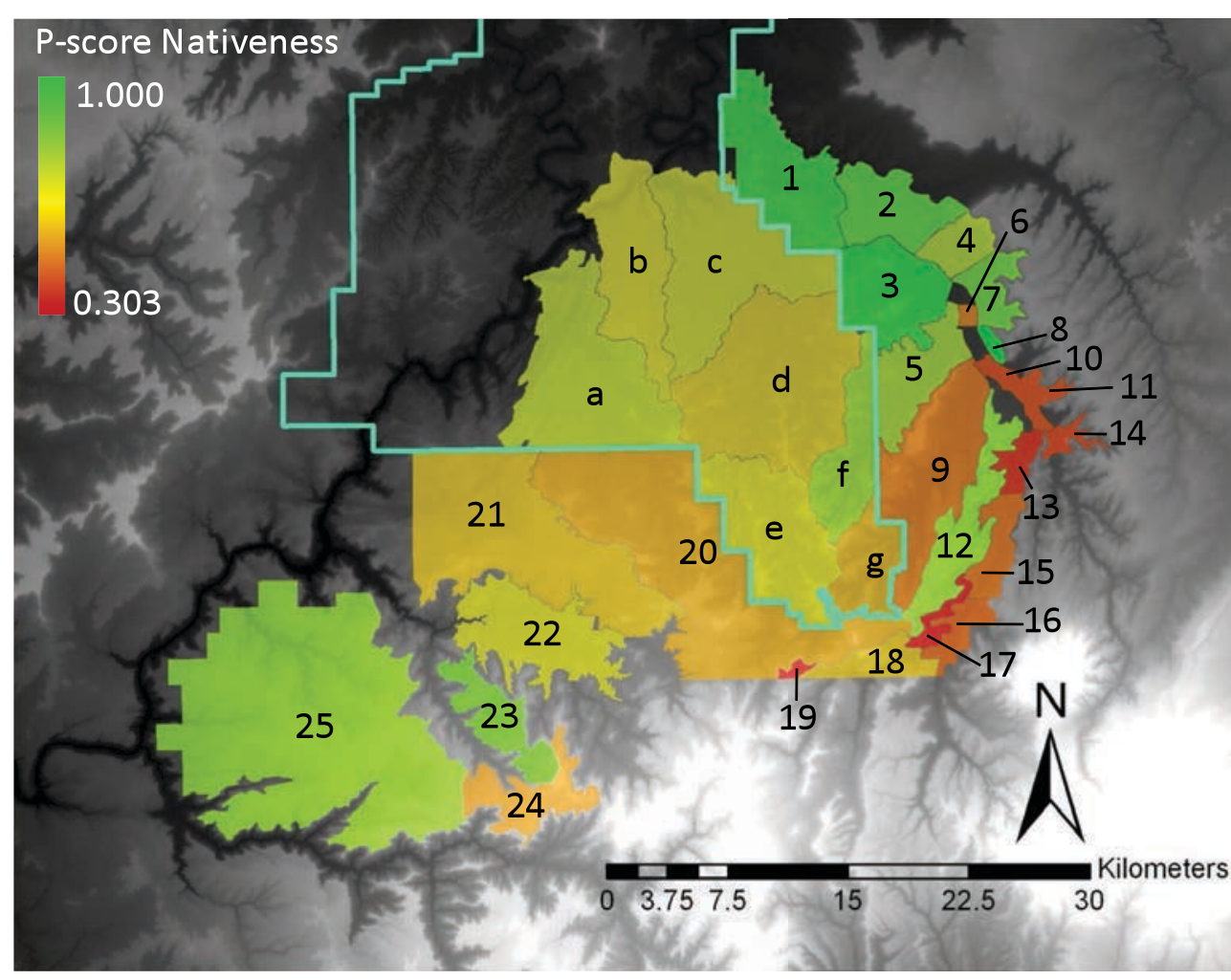

EXPLANATION

Hydrological units (Canyonlands)

a Butler Wash

b Elephant Wash

c Lower Salt Creek

d Middle Salt Creek

Upper Salt Creek

Davis Canyon

g Lavender Creek

Pastures (Dugout Ranch)

1 Park Pasture

2 Middle Pasture

3 Corral Pocket

4 Creek Pasture

5 Davis

6 Lower Ranch

7 Drill Pasture

8 Bull

9 Lavender

10 Ranch

11 Bull 1

12 Bridger Jack Mesa

13 Cottonwood

14 Upper Ranch

15 Wilson Ranch

16 Upper Cottonwood

17 Slick Bench

18 Steven's Mesa

19 Salt Creek2

20 Salt Creek

21 Ruin Park

22 Beef Basin

23 Wild Cow

24 Sweet Alice

25 Dark Canyon Plateau

Figure 11. Map of nativeness P-scores applied to hydrological units in Canyonlands National Park and pastures in the Dugout Ranch. Key: a. Butler Wash, b. Elephant Wash, c. Lower Salt Creek, d. Middle Salt Creek, e. Upper Salt Creek, f. Davis Canyon, g. Lavender Creek, 1. Park Pasture, 2. Middle Pasture, 3. Corral Pocket, 4. Creek Pasture, 5. Davis, 6. Lower Ranch 2, 7. Drill Pasture, 8. Bull 3, 9. Lavender, 10. Ranch, 11. Bull 1, 12. Bridger Jack Mesa, 13. Cottonwood, 14. Upper Ranch 1, 15. Wilson Ranch, 16. Upper Cottonwood, 17. Slick Bench, 18. Steven's Mesa, 19. Salt Creek 2, 20. Salt Creek, 21. Ruin Park, 22. Beef Basin, 23. Wild Cow, 24. Sweet Alice, 25. Dark Canyon Plateau. 


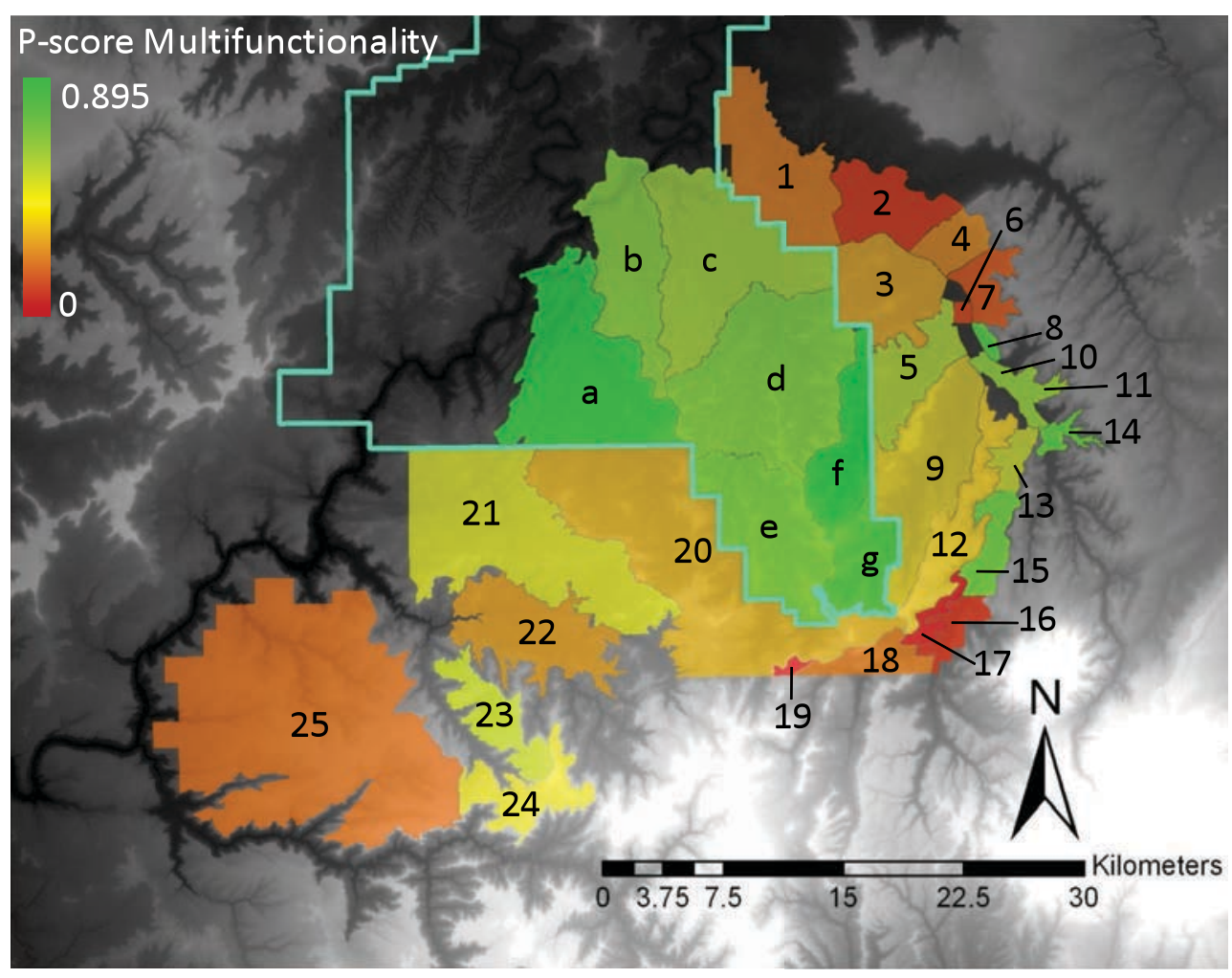

EXPLANATION

Hydrological units (Canyonlands)

a Butler Wash

Elephant Wash

Lower Salt Creek

Middle Salt Creek

Upper Salt Creek

Davis Canyon

Lavender Creek

Pastures (Dugout Ranch)

1 Park Pasture

2 Middle Pasture

3 Corral Pocket

4 Creek Pasture

5 Davis

6 Lower Ranch

7 Drill Pasture

8 Bull

9 Lavender

10 Ranch

11 Bull 1

12 Bridger Jack Mesa

13 Cottonwood

14 Upper Ranch

15 Wilson Ranch

16 Upper Cottonwood

17 Slick Bench

18 Steven's Mesa

19 Salt Creek2

20 Salt Creek

21 Ruin Park

22 Beef Basin

23 Wild Cow

24 Sweet Alice

25 Dark Canyon Plateau

Figure 12. Map of multifunctionality (v. 1) P-scores applied to hydrological units in Canyonlands National Park and pastures in the Dugout Ranch. Key: a. Butler Wash, b. Elephant Wash, c. Lower Salt Creek, d. Middle Salt Creek, e. Upper Salt Creek, f. Davis Canyon, g. Lavender Creek, 1. Park Pasture, 2. Middle Pasture, 3. Corral Pocket, 4. Creek Pasture, 5. Davis, 6. Lower Ranch 2, 7. Drill Pasture, 8. Bull 3, 9. Lavender, 10. Ranch, 11. Bull 1, 12. Bridger Jack Mesa, 13. Cottonwood, 14. Upper Ranch 1, 15. Wilson Ranch, 16. Upper Cottonwood, 17. Slick Bench, 18. Steven's Mesa, 19. Salt Creek 2, 20. Salt Creek, 21. Ruin Park, 22. Beef Basin, 23. Wild Cow, 24. Sweet Alice, 25. Dark Canyon Plateau. 


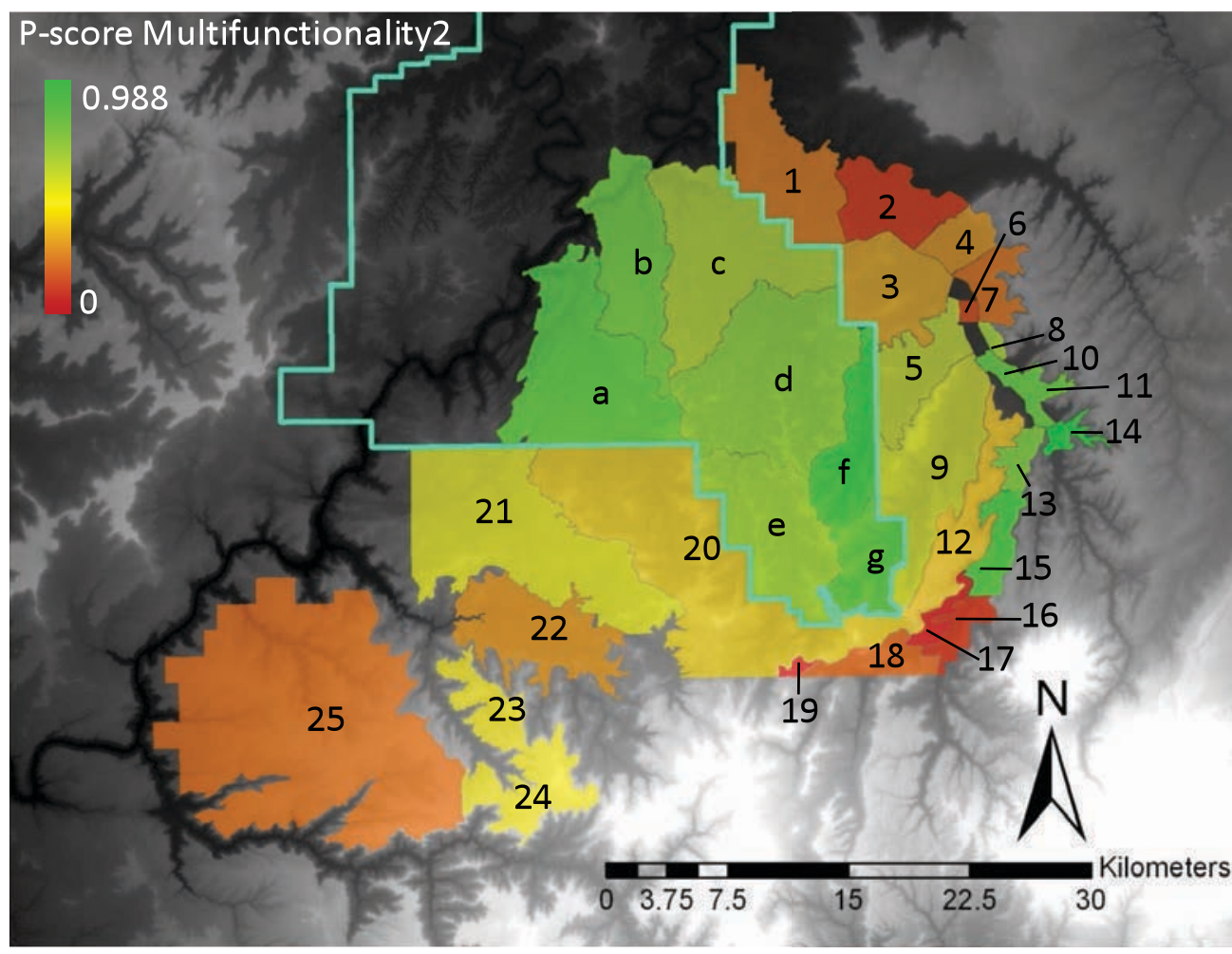

EXPLANATION

Hydrological units (Canyonlands)

a Butler Wash

Elephant Wash

Lower Salt Creek

Middle Salt Creek

Upper Salt Creek

Davis Canyon

Lavender Creek

Pastures (Dugout Ranch)

Park Pasture

Middle Pasture

Corral Pocket

Creek Pasture

Davis

Lower Ranch

Drill Pasture

Bull

Lavender

10 Ranch

1 Bull 1

Bridger Jack Mesa

Cottonwood

Upper Ranch

Wilson Ranch

Upper Cottonwood

Slick Bench

Steven's Mesa

Salt Creek2

Salt Creek

Ruin Park

Beef Basin

Wild Cow

Sweet Alice

Dark Canyon Plateau

Figure 13. Map of mutlifunctionality (v. 2) P-scores applied to hydrological units in Canyonlands National Park and pastures in the Dugout Ranch. Key: a. Butler Wash, b. Elephant Wash, c. Lower Salt Creek, d. Middle Salt Creek, e. Upper Salt Creek, f. Davis Canyon, g. Lavender Creek, 1. Park Pasture, 2. Middle Pasture, 3. Corral Pocket, 4. Creek Pasture, 5. Davis, 6. Lower Ranch 2, 7. Drill Pasture, 8. Bull 3, 9. Lavender, 10. Ranch, 11. Bull 1, 12. Bridger Jack Mesa, 13. Cottonwood, 14. Upper Ranch 1, 15. Wilson Ranch, 16. Upper Cottonwood, 17. Slick Bench, 18. Steven's Mesa, 19. Salt Creek 2, 20. Salt Creek, 21. Ruin Park, 22. Beef Basin, 23. Wild Cow, 24. Sweet Alice, 25. Dark Canyon Plateau. 


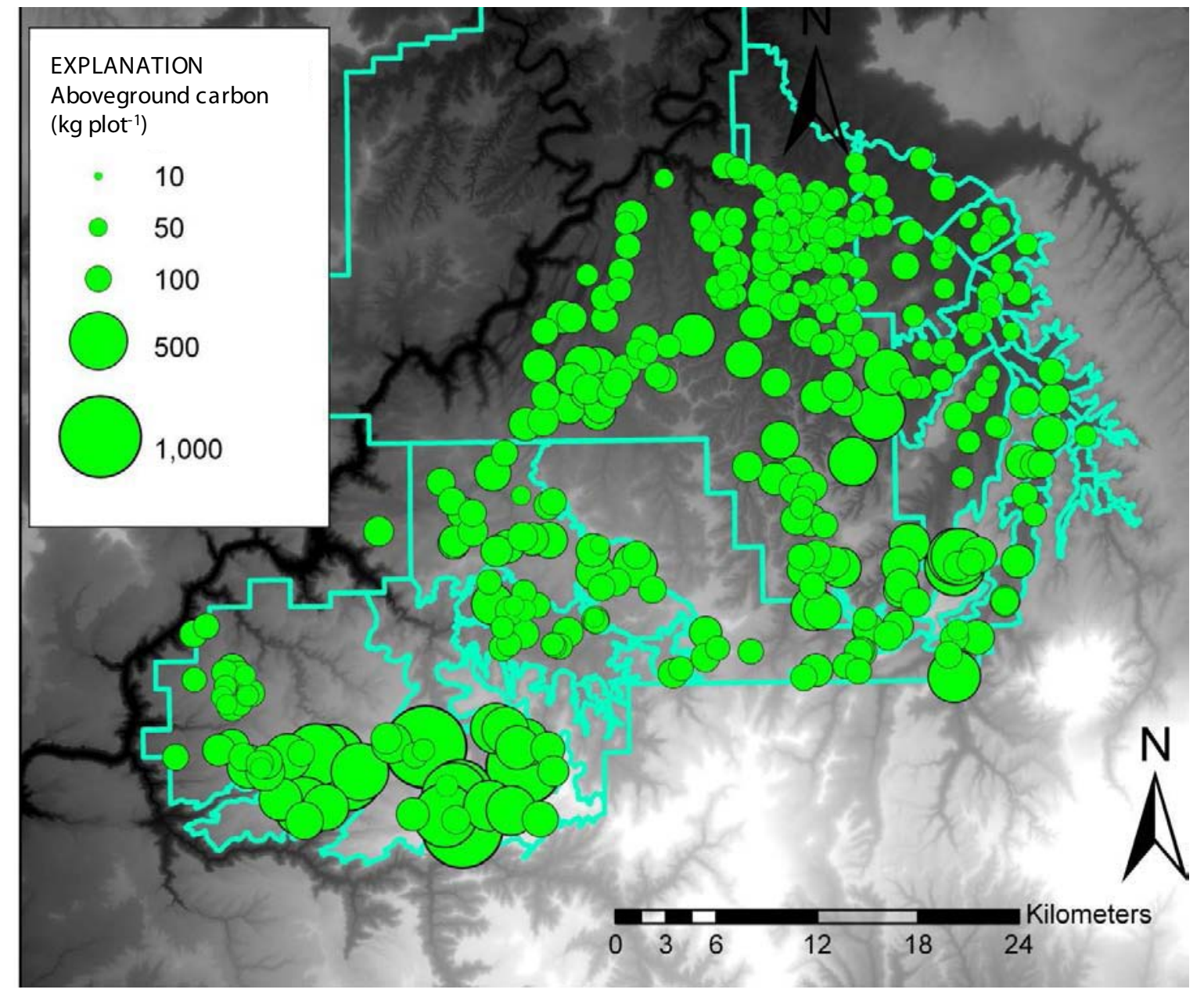

Figure 14. Map of study sites across the study area with points scaled proportionally to absolute values of carbon storage $\left(\mathrm{kg} \mathrm{plot}^{-1}\right)$. 


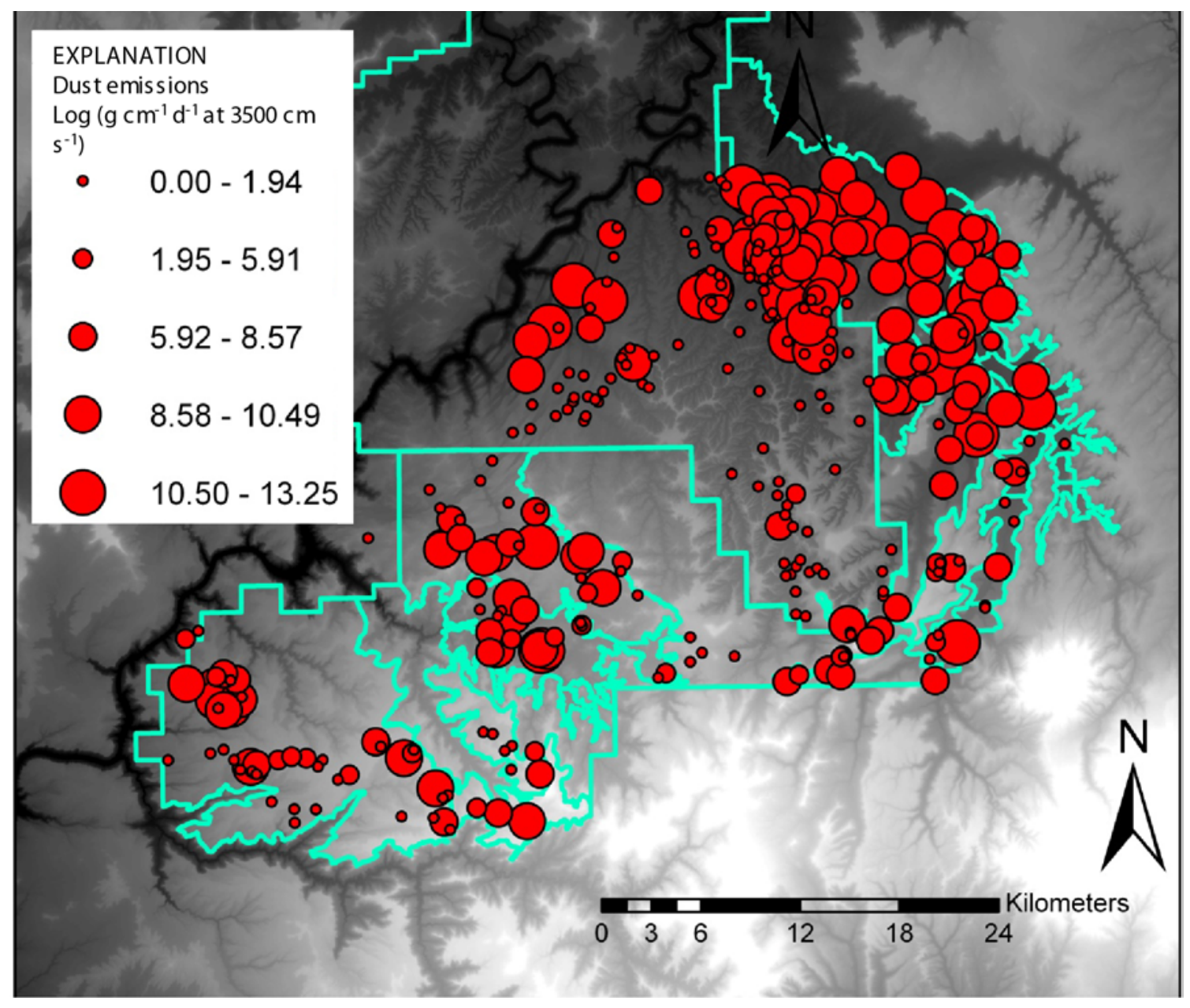

Figure 15. Map of study sites across the study area with points scaled proportionally to absolute values of modeled dust emission $\left(\mathrm{g} \mathrm{cm}^{-1} \mathrm{~d}^{-1}\right.$ at $\left.3500 \mathrm{~cm} \mathrm{~s}^{-1}\right)$. 


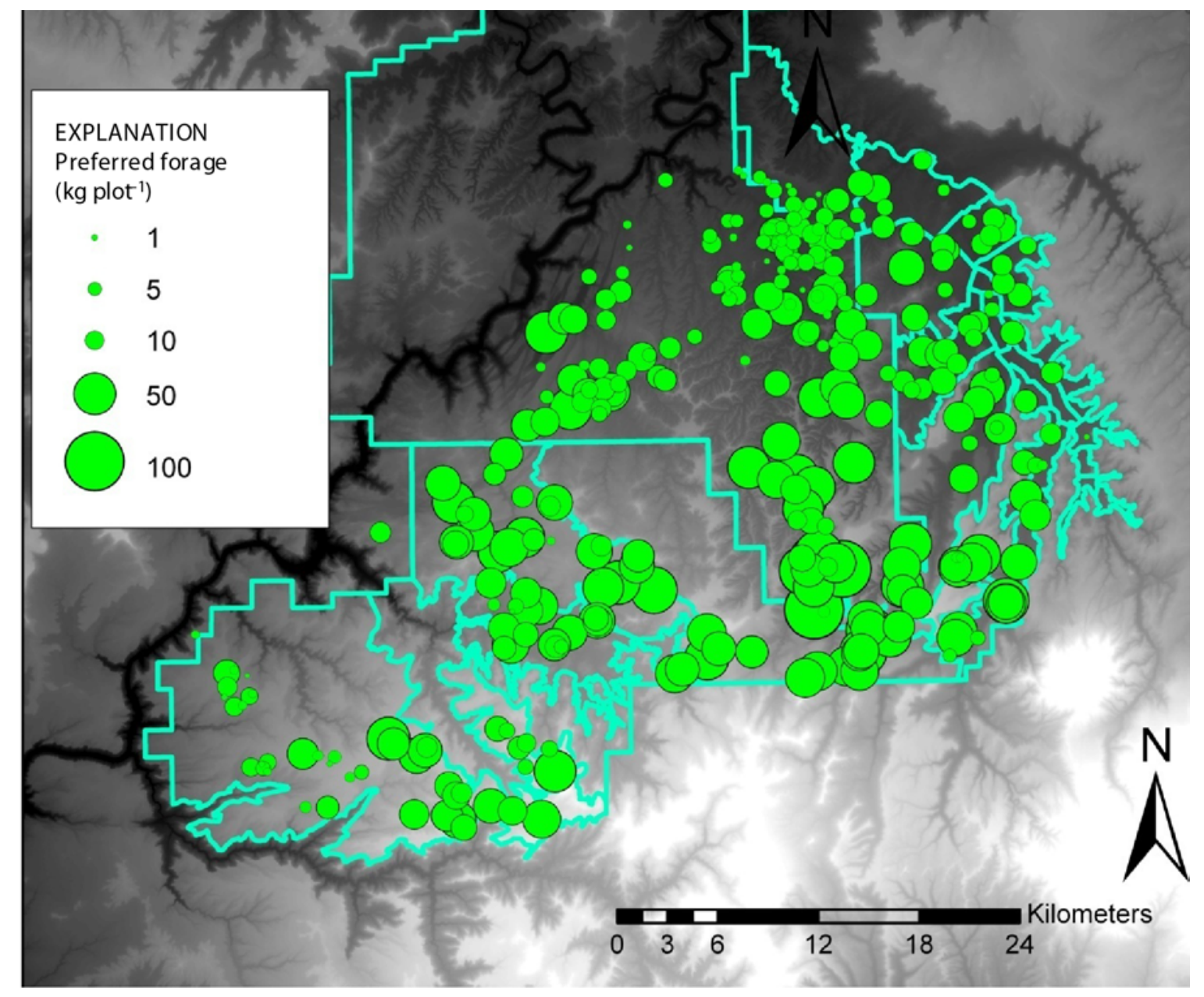

Figure 16. Map of study sites across the study area with points scaled proportionally to absolute values of preferred forage biomass $\left(\mathrm{kg} \mathrm{plot}^{-1}\right)$. 


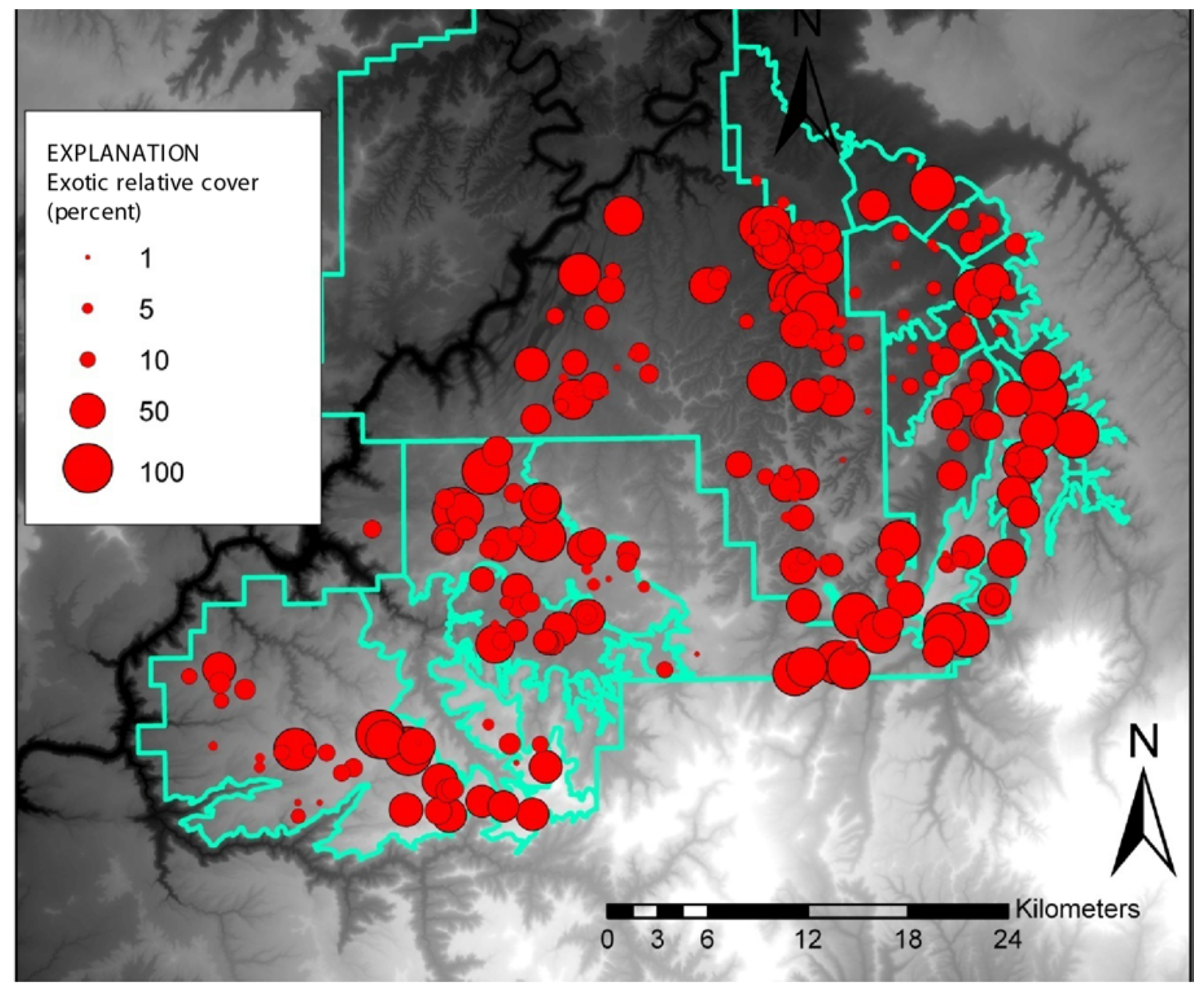

Figure 17. Map of study sites across the study area with points scaled proportionally to absolute values of relative exotic cover (percent). 
Table 1. Ecosystem services and properties estimated, and data sources and models used to estimate them.

\begin{tabular}{|c|c|c|}
\hline $\begin{array}{l}\text { Ecosystem Services \& } \\
\text { Properties Estimated }\end{array}$ & Data & Models Used \\
\hline "Nativeness" & Plant live cover & - \\
\hline \multirow[t]{2}{*}{ Potential Dust Emissions } & Plant gap size distribution & WEMO (Okin 2008) \\
\hline & Ground cover & applied at $3500 \mathrm{~cm} \mathrm{~s}^{-1}$ \\
\hline Aboveground C Storage & Plant live $\&$ dead cover & $\begin{array}{l}\text { various regression equations (Bowker et al. 2006, Clark et al 008, } \\
\text { Williamson 1987, Flombaum and Sala 2007, Huang et al. 2009) }\end{array}$ \\
\hline Preferred Forage Biomass & Plant live cover & regression equations (Williamson 1987, Flombaum and Sala 2007) \\
\hline
\end{tabular}

Table 2. Plots sampled in this study by land ownership, ecosystem type, and year sampled.

Number of plots sampled by general type of potential natural vegetation, specific NRCS ecological site, ownership, and year.

\begin{tabular}{|c|c|c|c|c|c|c|c|c|c|c|c|c|c|c|c|c|c|c|c|c|}
\hline \multirow{4}{*}{$\begin{array}{l}\text { Cluster } \\
\text { analysis }\end{array}$} & \multirow{4}{*}{$\begin{array}{l}\text { General type of potential } \\
\text { natural vegetation and } \\
\text { specific NRCS ecological site }\end{array}$} & \multirow{2}{*}{\multicolumn{18}{|c|}{ No. of plots by ownership and year }} & \multirow{4}{*}{$\begin{array}{l}\text { Grand } \\
\text { Total }\end{array}$} \\
\hline & & & & & & & & & & & & & & & & & & & & \\
\hline & & \multicolumn{4}{|c|}{\begin{tabular}{c|c} 
BLM & \\
\end{tabular}} & \multicolumn{4}{|c|}{ NPS.CANY } & \multirow{2}{*}{\multicolumn{2}{|c|}{\begin{tabular}{|l|} 
NPS.GLCA \\
2008
\end{tabular}}} & \multicolumn{5}{|c|}{ SITLA } & \multicolumn{3}{|c|}{ TNC } & \\
\hline & & 2006 & 2007 & 2008 & Total & 2006 & 2007 & 2008 & Total & & & 200 & & 007 & 2008 & Total & 2007 & 2008 & Total & \\
\hline \multirow[b]{2}{*}{$\mathrm{x}$} & \multicolumn{20}{|c|}{ Sagebrush Bottom } \\
\hline & $\begin{array}{l}\text { Loamy Bottom (Basin Big } \\
\text { Sagebrush) }\end{array}$ & & 1 & & 1 & 7 & 5 & 2 & 14 & & & & & 1 & & 1 & & & & 16 \\
\hline \multirow{4}{*}{$\mathrm{x}$} & \multicolumn{20}{|c|}{ Greasewood } \\
\hline & Alkali Flat (Greasewood) & & 2 & & 2 & 8 & & & 8 & & & & & 1 & & 1 & 1 & 1 & 2 & 13 \\
\hline & \multicolumn{20}{|c|}{ Shadscale } \\
\hline & $\begin{array}{l}\text { Semidesert Shallow Sandy Loam } \\
\text { (Shadscale) }\end{array}$ & & & & & 1 & & & 1 & & & & & & & & & 1 & 1 & 2 \\
\hline \multirow{5}{*}{$\mathrm{x}$} & \multicolumn{20}{|l|}{ 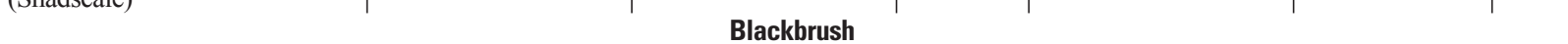 } \\
\hline & Semidesert Sand (Blackbrush) & & & & & 1 & & & 1 & 1 & & & & & & & & & & 2 \\
\hline & $\begin{array}{l}\text { Semidesert Sandy Loam } \\
\text { (Blackbrush) }\end{array}$ & 4 & 1 & 1 & 6 & & & & & 1 & & & & & & & & & & 7 \\
\hline & $\begin{array}{l}\text { Semidesert Shallow Sand } \\
\text { (Blackbrush) }\end{array}$ & 1 & 3 & & 4 & 5 & 2 & & 7 & & & & & 2 & & 2 & & & & 13 \\
\hline & \multicolumn{20}{|c|}{ Blackbrush - Juniper } \\
\hline \multirow[t]{3}{*}{$\mathrm{x}$} & $\begin{array}{l}\text { Semidesert Shallow Sandy Loam } \\
\text { (Utah Juniper - Blackbrush) }\end{array}$ & 2 & 14 & & 16 & 10 & 7 & & 17 & & & & & & & & & & & 33 \\
\hline & \multicolumn{20}{|l|}{ | } \\
\hline & $\begin{array}{l}\text { Sandy Bottom } \\
\text { (Fourwing saltbush) }\end{array}$ & & 1 & 1 & 2 & 2 & 1 & & 3 & & & & & & 1 & 1 & & & & 6 \\
\hline $\mathrm{x}$ & $\begin{array}{l}\text { Semidesert Sand } \\
\text { (Fourwing saltbush) }\end{array}$ & 2 & 7 & 3 & 12 & 10 & 17 & 2 & 29 & 1 & 1 & 2 & & & & 2 & 1 & & 1 & 45 \\
\hline $\mathrm{x}$ & $\begin{array}{l}\text { Semidesert Sandy Loam } \\
\text { (Fourwing saltbush) }\end{array}$ & 5 & 15 & 18 & 38 & 27 & 16 & 9 & 52 & & & 1 & & & 3 & 4 & 6 & 2 & 8 & 102 \\
\hline & $\begin{array}{l}\text { Semidesert Shallow Sandy Loam } \\
\text { (Shadscale) }\end{array}$ & & 1 & & 1 & 2 & & & 2 & & & & & 1 & & 1 & & & & 4 \\
\hline & $\begin{array}{l}\text { Upland Shallow Loam (Black } \\
\text { sagebrush) }\end{array}$ & & 1 & & 1 & & & & & & & & & & & & & & & 1 \\
\hline \multirow{3}{*}{$\mathrm{x}$} & \multicolumn{20}{|c|}{ Upland Sagebrush } \\
\hline & $\begin{array}{l}\text { Upland Loam (Basin Big } \\
\text { Sagebrush) }\end{array}$ & & 30 & 24 & 54 & 2 & & & 3 & & & & & 2 & 2 & 4 & & & & 61 \\
\hline & & & & & & & Pinyo & n-Jun & liper & & & & & & & & & & & \\
\hline \multirow[t]{5}{*}{$\mathrm{x}$} & $\begin{array}{l}\text { Upland Shallow Loam } \\
\text { (Pinyon - Utah Juniper) }\end{array}$ & & 27 & 9 & 36 & & & & & & & & & 2 & 2 & 4 & & & & 40 \\
\hline & $\begin{array}{l}\text { Upland Stony Loam } \\
\text { (Pinyon-Juniper) }\end{array}$ & & 1 & & 1 & & & & & & & & & & & & & & & 1 \\
\hline & \multicolumn{20}{|c|}{ Mixed } \\
\hline & Mixed & & 3 & & 3 & 1 & 2 & & 3 & & & & & & & & & & & 6 \\
\hline & Grand Total & 14 & 107 & 56 & 177 & 76 & 50 & 14 & 140 & 3 & 3 & 3 & & 9 & 8 & 20 & 8 & 4 & 12 & 352 \\
\hline
\end{tabular}


Table 3. Mean values and coefficient of variation $(\times 100)$ describing key attributes of clusters in Loamy Bottoms. Variables underlined in bold indicate those used in cluster analysis.

\begin{tabular}{|c|c|c|c|c|c|c|c|c|}
\hline \multirow{3}{*}{ Variable } & \multicolumn{2}{|c|}{ Cluster 1} & \multicolumn{2}{|c|}{ Cluster 2} & \multicolumn{2}{|c|}{ Cluster 3} & \multicolumn{2}{|c|}{ Cluster 4} \\
\hline & n & 8 & $n$ & 4 & $\mathrm{n}$ & 1 & $\mathrm{n}$ & 3 \\
\hline & Mean & CV & Mean & CV & Mean & CV & Mean & CV \\
\hline Soil Aggregate Stabilty (Avg.) & 5.4 & 8.1 & 5.3 & 10.3 & 5.0 & - & 4.5 & 25.4 \\
\hline Surface Roughness & 10.1 & 60.9 & 5.3 & 50.1 & 2.0 & - & 3.3 & 5.0 \\
\hline Median Canopy Gap (cm) & 76.5 & 18.6 & 128.8 & 24.9 & 207.0 & - & 409.5 & 137.5 \\
\hline Median Basal Gap (cm) & 323.1 & 38.3 & 262.4 & 35.5 & 449.5 & - & 713.2 & 119.6 \\
\hline B. tectorum frequency & 24.6 & 153.2 & 62.1 & 47.4 & 6.7 & - & 100.0 & - \\
\hline Salsola spp. frequency & 0.8 & 282.8 & 35.0 & 105.6 & - & - & 14.4 & 118.4 \\
\hline Species Richness & 21.4 & 41.3 & 28.3 & 21.9 & 14.0 & - & 19.3 & 33.3 \\
\hline$\%$ Bare Ground & 13.6 & 53.2 & 28.0 & 32.8 & 4.7 & - & 8.7 & 76.9 \\
\hline$\%$ Litter \& wood & 57.0 & 24.9 & 52.6 & 15.3 & 64.4 & - & 79.3 & 20.6 \\
\hline$\%$ Biocrust & 37.2 & 26.9 & 10.2 & 56.2 & 6.7 & - & - & - \\
\hline Annual Forbs & 1.8 & 134.5 & 27.0 & 91.8 & 111.5 & - & 12.7 & 94.8 \\
\hline C3 Annual Grass & 4.9 & 230.6 & 10.8 & 50.0 & 0.7 & - & 36.0 & 24.2 \\
\hline C4 Annual Grass & - & - & 1.0 & 128.8 & - & - & 0.4 & 173.2 \\
\hline Total Annuals & 6.7 & 186.8 & 38.8 & 57.3 & 112.2 & - & 49.1 & 27.4 \\
\hline Perennial Forbs & 1.5 & 152.0 & 2.0 & 84.8 & 7.4 & - & 1.8 & 140.9 \\
\hline Per. C3 Bunchgrasses & 1.3 & 261.0 & 1.2 & 125.3 & - & - & 0.2 & 173.2 \\
\hline Per. C4 Bunchgrasses & 1.6 & 222.2 & 0.5 & 125.4 & - & - & 6.7 & 173.2 \\
\hline Per. C4 Rhizomatous grasses & 0.5 & 282.8 & - & - & - & - & - & - \\
\hline Perennial Grasses & 3.3 & 244.3 & 1.7 & 106.0 & - & - & 6.9 & 173.2 \\
\hline Palatable Shrubs & 3.6 & 89.8 & 7.4 & 92.3 & 3.4 & - & 12.0 & 149.4 \\
\hline Unplatable Shrubs & 16.6 & 35.7 & 8.8 & 71.6 & 0.7 & - & 4.0 & 75.3 \\
\hline A. tridentata & 9.8 & 52.8 & 5.8 & 109.3 & 0.7 & - & 2.7 & 151.0 \\
\hline Other shubs (not $A$. tridentata) & 10.5 & 51.7 & 10.4 & 49.8 & 3.4 & & 13.3 & 126.0 \\
\hline Total Perrennials & 25.1 & 47.3 & 19.9 & 20.5 & 11.5 & - & 24.7 & 82.2 \\
\hline Total Plants & 31.7 & 73.9 & 58.7 & 43.8 & 123.7 & - & 73.8 & 38.9 \\
\hline Exotic Annual Forb & 0.1 & 282.8 & 10.7 & 106.4 & 6.1 & - & 6.9 & 93.1 \\
\hline Exotic Annual Grass & 4.1 & 250.8 & 9.8 & 64.7 & 0.7 & - & 36.0 & 24.2 \\
\hline Exotic Annual Relative Cover & 6.1 & 200.6 & 36.4 & 17.3 & 5.5 & - & 63.4 & 32.3 \\
\hline dust flux $\left(1750 \mathrm{~cm} \mathrm{~s}^{-1}\right)$ & - & - & - & - & - & - & - & - \\
\hline dust flux (2625 $\left.\mathrm{cm} \mathrm{s}^{-1}\right)$ & - & - & - & - & - & - & $15,985.6$ & 173.2 \\
\hline dust flux $\left(3500 \mathrm{~cm} \mathrm{~s}^{-1}\right)$ & 0.0 & 282.8 & 34.3 & 200.0 & $2,897.1$ & - & $56,304.0$ & 173.2 \\
\hline Aboveground C ( $\left.\mathrm{kg} \mathrm{plot}^{-1}\right)$ & 157.5 & 26.4 & 132.0 & 16.7 & 139.6 & - & 201.2 & 35.2 \\
\hline Preferred forage mass $\left(\mathrm{kg} \mathrm{plot}^{-1}\right)$ & 15.8 & 94.7 & 25.3 & 77.8 & 10.4 & - & 47.1 & 102.4 \\
\hline $\begin{array}{l}\text { In CANY } \\
\end{array}$ & 8 & & 3 & & 1 & & 2 & \\
\hline Out CANY & 0 & & 1 & & 0 & & 1 & \\
\hline
\end{tabular}


Table 4. Mean values and coefficient of variation ( $\times 100)$ describing key attributes of clusters in Alkali Bottoms. Variables underlined in bold indicate those used in cluster analysis.

\begin{tabular}{|c|c|c|c|c|c|c|}
\hline \multirow{4}{*}{ Variable } & \multirow{2}{*}{\multicolumn{2}{|c|}{ Cluster 1}} & \multirow{2}{*}{\multicolumn{2}{|c|}{ Cluster 2}} & \multirow{2}{*}{\multicolumn{2}{|c|}{ Cluster 3}} \\
\hline & & & & & & \\
\hline & $\mathbf{n}$ & 6 & n & 3 & $\mathbf{n}$ & 4 \\
\hline & Mean & CV & Mean & CV & Mean & CV \\
\hline Soil Aggregate Stabilty (Avg.) & 5.4 & 7.1 & 4.6 & 16.5 & 5.1 & 15.1 \\
\hline Surface Roughness & 11.3 & 22.9 & 4.1 & 66.6 & 6.4 & 45.0 \\
\hline Median Canopy Gap (cm) & 139.6 & 33.9 & 192.5 & 19.2 & 174.9 & 101.4 \\
\hline Median Basal Gap (cm) & 625.8 & 51.6 & 312.3 & 30.6 & 196.8 & 47.7 \\
\hline B. tectorum frequency & 2.2 & 122.5 & 12.2 & 110.2 & 99.2 & 1.7 \\
\hline Salsola spp. frequency & 10.0 & 122.9 & 88.9 & 39.7 & - & - \\
\hline Species Richness & 14.3 & 23.2 & 17.3 & 28.5 & 15.8 & 16.7 \\
\hline$\%$ Bare Ground & 28.4 & 38.8 & 64.3 & 7.6 & 18.5 & 43.1 \\
\hline$\%$ Litter \& wood & 31.9 & 33.7 & 19.7 & 6.6 & 55.2 & 23.3 \\
\hline$\%$ Biocrust & 36.6 & 17.1 & 7.1 & 87.1 & 16.2 & 79.0 \\
\hline Annual Forbs & 0.7 & 125.7 & 8.4 & 98.4 & 5.8 & 128.5 \\
\hline C3 Annual Grass & 0.2 & 154.9 & - & - & 34.3 & 43.7 \\
\hline Total Annuals & 0.9 & 112.2 & 8.4 & 98.4 & 40.3 & 25.1 \\
\hline Perennial Forbs & 0.9 & 130.7 & - & - & 1.2 & 200.0 \\
\hline Per. C3 Bunchgrasses & 0.2 & 244.9 & - & - & 0.5 & 200.0 \\
\hline Per. C4 Bunchgrasses & 0.7 & 244.9 & 2.0 & 100.0 & 0.7 & 78.7 \\
\hline Per. C4 Rhizomatous grasses & 0.1 & 244.9 & 0.7 & 173.2 & 2.9 & 184.0 \\
\hline Perennial Grasses & 1.0 & 188.6 & 2.7 & 86.6 & 4.0 & 165.2 \\
\hline Palatable Shrubs & 3.0 & 131.3 & - & - & 3.4 & 104.1 \\
\hline Unplatable Shrubs & 13.1 & 32.7 & 3.4 & 99.5 & 5.4 & 110.3 \\
\hline S. vermiculatus & 7.4 & 26.5 & 3.1 & 107.6 & 4.2 & 128.4 \\
\hline Other shrubs (not $S$. vermiculatus) & 8.8 & 67.5 & 0.2 & 173.2 & 4.5 & 90.0 \\
\hline Total Perennials & 18.0 & 20.4 & 6.0 & 29.8 & 13.9 & 67.4 \\
\hline Total Plants & 18.9 & 17.9 & 14.5 & 62.2 & 54.3 & 20.3 \\
\hline Exotic Annual Forb & 0.6 & 116.6 & 4.0 & 93.4 & 2.0 & 133.9 \\
\hline Exotic Annual Grass & - & - & - & - & 34.0 & 44.0 \\
\hline Exotic Annual Relative Cover & 3.0 & 119.4 & 27.9 & 119.9 & 66.1 & 31.7 \\
\hline dust flux $\left(1750 \mathrm{~cm} \mathrm{~s}^{-1}\right)$ & - & - & - & - & - & - \\
\hline dust flux $\left(2625 \mathrm{~cm} \mathrm{~s}^{-1}\right)$ & - & - & - & - & - & - \\
\hline dust flux (3500 $\left.\mathrm{cm} \mathrm{s}^{-1}\right)$ & - & - & $25,425.0$ & 164.1 & 894.6 & 200.0 \\
\hline Aboveground C ( $\left.\mathrm{kg} \mathrm{plot}^{-1}\right)$ & 88.0 & 27.0 & 48.3 & 9.1 & 118.1 & 32.4 \\
\hline Preferred forage mass $\left(\mathrm{kg} \mathrm{plot}^{-1}\right)$ & 10.6 & 104.1 & 3.7 & 87.2 & 15.2 & 111.6 \\
\hline In CANY & 6 & & 1 & & 1 & \\
\hline Out CANY & 0 & & 2 & & 3 & \\
\hline
\end{tabular}


Table 5. Mean values and coefficient of variation $(\times 100)$ describing key attributes of clusters in Semidesert Shallow Sand. Variables underlined in bold indicate those used in cluster analysis.

\begin{tabular}{|c|c|c|c|c|c|c|}
\hline \multirow{4}{*}{ Variable } & \multirow{2}{*}{\multicolumn{2}{|c|}{ Cluster 1}} & \multirow{2}{*}{\multicolumn{2}{|c|}{ Cluster 2}} & & \\
\hline & & & & & \multicolumn{2}{|c|}{ Cluster 3} \\
\hline & \multirow{2}{*}{$\begin{array}{c}\mathbf{n} \\
\text { Mean }\end{array}$} & \multirow{2}{*}{$\begin{array}{c}1 \\
C V \\
\end{array}$} & \multirow{2}{*}{$\begin{array}{c}\mathbf{n} \\
\text { Mean }\end{array}$} & \multirow{2}{*}{$\begin{array}{c}6 \\
C V \\
\end{array}$} & \multirow{2}{*}{$\begin{array}{c}\mathrm{n} \\
\text { Mean }\end{array}$} & \multirow{2}{*}{$\begin{array}{c}6 \\
\mathrm{CV} \\
\end{array}$} \\
\hline & & & & & & \\
\hline Soil Aggregate Stabilty (Avg.) & 5.4 & - & 4.2 & 13.9 & 3.0 & 46.8 \\
\hline Surface Roughness & 11.7 & - & 8.4 & 43.6 & 5.4 & 34.3 \\
\hline Median Canopy Gap (cm) & 118.5 & - & 111.4 & 20.0 & 124.0 & 23.3 \\
\hline Median Basal Gap (cm) & 379.0 & - & 232.3 & 28.6 & 189.9 & 37.6 \\
\hline B. tectorum frequency & 30.0 & - & 17.2 & 207.5 & 18.9 & 154.1 \\
\hline Salsola spp. frequency & - & - & 0.6 & 244.9 & - & - \\
\hline Species Richness & 28.0 & - & 15.3 & 25.6 & 22.3 & 40.5 \\
\hline$\%$ Bare Ground & 26.0 & - & 48.6 & 9.7 & 69.2 & 5.1 \\
\hline$\%$ Litter \& wood & 42.7 & - & 18.3 & 20.3 & 11.4 & 29.1 \\
\hline$\%$ Biocrust & 34.0 & - & 20.0 & 24.8 & 4.4 & 52.5 \\
\hline Annual Forbs & 3.4 & - & 0.7 & 168.6 & 0.6 & 90.3 \\
\hline C3 Annual Grass & 5.3 & - & 2.6 & 171.7 & 0.6 & 189.6 \\
\hline Total Annuals & 8.7 & - & 3.2 & 161.3 & 1.1 & 132.3 \\
\hline Perennial Forbs & 2.1 & - & - & - & 0.1 & 244.9 \\
\hline Per. C3 Bunchgrasses & 1.4 & - & 0.3 & 165.0 & - & - \\
\hline Per. C4 Bunchgrasses & - & - & 1.0 & 244.9 & 0.1 & 244.9 \\
\hline Per. C4 Rhizomatous grasses & - & - & 0.2 & 244.9 & 0.8 & 175.5 \\
\hline Perennial Grasses & 1.4 & - & 1.6 & 184.9 & 0.9 & 182.6 \\
\hline Palatable Shrubs & 2.0 & - & 0.3 & 244.9 & 0.1 & 244.9 \\
\hline Unplatable Shrubs & 10.7 & - & 11.9 & 40.8 & 11.4 & 33.0 \\
\hline C. ramosissima & 10.7 & - & 11.0 & 43.6 & 9.5 & 48.0 \\
\hline Other shrubs (not $C$. ramosissima) & 2.0 & & 1.2 & 129.9 & 2.1 & 98.4 \\
\hline Tree & - & - & 0.2 & 244.9 & - & - \\
\hline Total Perennials & 16.2 & - & 14.0 & 35.1 & 12.5 & 26.0 \\
\hline Total Plants & 24.9 & - & 17.2 & 53.3 & 13.6 & 26.8 \\
\hline Exotic Annual Grass & - & - & 0.7 & 244.9 & 0.2 & 244.9 \\
\hline Exotic Annual Relative Cover & - & - & 2.2 & 244.9 & 1.4 & 244.9 \\
\hline dust flux $\left(1750 \mathrm{~cm} \mathrm{~s}^{-1}\right)$ & - & - & - & - & 520.3 & 235.0 \\
\hline dust flux (2625 $\left.\mathrm{cm} \mathrm{s}^{-1}\right)$ & - & - & 27.9 & 244.9 & $5,908.9$ & 115.3 \\
\hline dust flux $\left(3500 \mathrm{~cm} \mathrm{~s}^{-1}\right)$ & - & - & $4,571.9$ & 154.4 & $24,649.4$ & 65.6 \\
\hline Aboveground C ( $\left.\mathrm{kg} \mathrm{plot}^{-1}\right)$ & 123.4 & - & 81.9 & 12.8 & 66.5 & 9.3 \\
\hline Preferred forage mass $\left(\mathrm{kg} \mathrm{plot}^{-1}\right)$ & 8.2 & - & 3.3 & 201.4 & 1.4 & 198.4 \\
\hline \multicolumn{7}{|c|}{ Plot frequency } \\
\hline In CANY & 1 & & 5 & & 1 & \\
\hline Out CANY & 0 & & 1 & & 5 & \\
\hline
\end{tabular}


Table 6. Mean values and coefficient of variation ( $\times 100)$ describing key attributes of clusters in Semidesert Shallow Sandy Loam. Variables underlined in bold indicate those used in cluster analysis.

\begin{tabular}{|c|c|c|c|c|c|c|c|c|}
\hline \multirow{4}{*}{ Variable } & \multirow{2}{*}{\multicolumn{2}{|c|}{ Cluster 1}} & \multirow{2}{*}{\multicolumn{2}{|c|}{ Cluster 2}} & \multirow{2}{*}{\multicolumn{2}{|c|}{ Cluster 3}} & \multirow{2}{*}{\multicolumn{2}{|c|}{ Cluster 4}} \\
\hline & & & & & & & & \\
\hline & $\mathbf{n}$ & 8 & $\mathbf{n}$ & 7 & $\mathbf{n}$ & 2 & $\mathbf{n}$ & 16 \\
\hline & Mean & CV & Mean & CV & Mean & CV & Mean & CV \\
\hline Soil Aggregate Stabilty (Avg.) & 5.1 & 9.3 & 5.2 & 6.3 & 5.3 & 4.4 & 3.4 & 34.4 \\
\hline Surface Roughness & 10.1 & 43.9 & 16.0 & 30.6 & 14.4 & 0.8 & 6.6 & 46.7 \\
\hline Median Canopy Gap (cm) & 127.3 & 39.5 & 115.6 & 30.1 & 130.5 & 4.9 & 152.5 & 39.8 \\
\hline Median Basal Gap (cm) & 220.8 & 72.1 & 249.2 & 46.8 & 353.0 & 5.2 & 294.1 & 57.8 \\
\hline B. tectorum frequency & 0.4 & 282.8 & 4.3 & 204.4 & 43.3 & 10.9 & 21.9 & 126.3 \\
\hline Salsola spp. frequency & - & - & 1.0 & 264.6 & 8.3 & 141.4 & - & - \\
\hline Species Richness & 18.0 & 23.6 & 30.6 & 24.6 & 39.0 & 7.3 & 22.9 & 31.7 \\
\hline$\%$ Bare Ground & 41.7 & 12.2 & 26.7 & 27.0 & 11.7 & 20.2 & 58.3 & 14.5 \\
\hline \% Litter \& wood & 18.9 & 15.8 & 35.2 & 27.1 & 35.0 & 6.7 & 19.3 & 45.8 \\
\hline$\%$ Biocrust & 24.0 & 11.9 & 28.5 & 32.6 & 27.0 & 1.7 & 4.4 & 57.0 \\
\hline Annual Forbs & 0.9 & 282.8 & 2.9 & 111.9 & 5.6 & 10.1 & 0.8 & 102.3 \\
\hline C3 Annual Grass & 0.3 & 282.8 & 1.1 & 167.3 & 12.3 & 11.5 & 1.1 & 171.4 \\
\hline Total Annuals & 1.2 & 282.8 & 3.9 & 120.5 & 17.9 & 4.7 & 1.9 & 120.8 \\
\hline Perennial Forbs & 0.9 & 125.5 & 2.3 & 72.3 & 1.0 & 42.4 & 0.6 & 109.1 \\
\hline Per. C3 Bunchgrasses & 0.4 & 116.5 & 1.0 & 66.6 & 2.0 & 141.4 & 0.5 & 164.1 \\
\hline Per. C4 Bunchgrasses & - & - & 0.3 & 181.2 & - & - & 0.3 & 273.3 \\
\hline Per. C4 Rhizomatous grasses & 0.5 & 154.6 & 1.2 & 105.2 & 1.0 & 42.4 & 0.5 & 229.1 \\
\hline Perennial Grasses & 0.9 & 132.4 & 2.5 & 68.5 & 3.0 & 108.4 & 1.4 & 169.1 \\
\hline Palatable Shrubs & 0.2 & 185.2 & 1.3 & 91.8 & 0.4 & 141.4 & 0.5 & 164.8 \\
\hline Unplatable Shrubs & 7.5 & 29.5 & 5.1 & 62.6 & 11.1 & 97.9 & 6.5 & 75.4 \\
\hline C. ramosissima & 4.4 & 108.6 & 0.5 & 176.1 & 8.7 & 97.5 & 4.6 & 109.3 \\
\hline Other shrubs (not $C$. ramosissima) & 3.3 & 86.7 & 6.0 & 62.3 & 2.7 & 68.1 & 2.5 & 64.5 \\
\hline Trees & 1.8 & 109.4 & 6.0 & 59.5 & 11.7 & 36.3 & 3.9 & 106.1 \\
\hline Total Perennials & 11.3 & 24.9 & 17.2 & 20.1 & 27.1 & 67.3 & 12.9 & 37.9 \\
\hline Total Plants & 12.5 & 39.5 & 21.1 & 32.6 & 45.0 & 42.4 & 14.9 & 40.3 \\
\hline Exotic Annual Forb & - & - & - & - & 0.7 & 141.4 & - & - \\
\hline Exotic Annual Grass & - & - & - & - & 3.7 & 141.4 & 0.5 & 249.6 \\
\hline Exotic Annual Relative Cover & - & - & - & - & 13.7 & 141.4 & 2.5 & 202.9 \\
\hline dust flux $\left(1750 \mathrm{~cm} \mathrm{~s}^{-1}\right)$ & - & - & - & - & - & - & 180.8 & 304.4 \\
\hline dust flux $\left(2625 \mathrm{~cm} \mathrm{~s}^{-1}\right)$ & - & - & - & - & - & - & $1,994.5$ & 216.3 \\
\hline dust flux (3500 $\left.\mathrm{cm} \mathrm{s}^{-1}\right)$ & 453.2 & 282.8 & - & - & - & - & $9,132.0$ & 162.3 \\
\hline Aboveground C $\left(\mathrm{kg} \mathrm{plot}^{-1}\right)$ & 120.4 & 47.5 & 83.0 & 24.2 & 259.3 & 34.8 & 107.6 & 55.8 \\
\hline Preferred forage mass $\left(\mathrm{kg} \mathrm{plot}^{-1}\right)$ & 9.4 & 51.7 & 1.7 & 122.2 & 5.2 & 61.4 & 3.4 & 117.3 \\
\hline \multicolumn{9}{|c|}{ Plot frequency } \\
\hline In CANY & 8 & & 7 & & 2 & & 0 & \\
\hline Out CANY & 0 & & 0 & & 0 & & 16 & \\
\hline
\end{tabular}


Table 7. Mean values and coefficient of variation ( $\times 100)$ describing key attributes of clusters in Semidesert Sandy Loam. Variables underlined in bold indicate those used in cluster analysis.

\begin{tabular}{|c|c|c|c|c|c|c|c|c|c|c|}
\hline \multirow{3}{*}{ Variable } & \multirow{2}{*}{\multicolumn{2}{|c|}{ Cluster 1}} & \multirow{2}{*}{\multicolumn{2}{|c|}{ Cluster 2}} & \multirow{2}{*}{\multicolumn{2}{|c|}{ Cluster 3}} & \multirow{2}{*}{\multicolumn{2}{|c|}{ Cluster 4}} & \multirow{2}{*}{\multicolumn{2}{|c|}{ Cluster 5}} \\
\hline & & & & & & & & & & \\
\hline & $n$ & 23 & $n$ & 40 & $n$ & 16 & $n$ & 12 & $n$ & 11 \\
\hline & Mean & CV & Mean & cV & Mean & cV & Mean & CV & Mean & CV \\
\hline Elevation (m) & 1635.7 & 0.1 & 1564.5 & 0.1 & 1669.3 & 0.1 & 1726.46 & 0.08 & 1518.1 & 0.0 \\
\hline Soil Aggregate Stabilty (Avg.) & 5.4 & 7.8 & 4.0 & 28.5 & 4.4 & 22.8 & 4.5 & 25.8 & 3.7 & 26.8 \\
\hline Surface Roughness & 11.7 & 32.2 & 5.3 & 45.6 & 6.2 & 39.4 & 6.8 & 52.9 & 2.1 & 95.7 \\
\hline Median Canopy Gap (cm) & 166.3 & 121.5 & 68.2 & 30.8 & 80.8 & 40.2 & 84.5 & 55.4 & 743.0 & 121.9 \\
\hline Median Basal Gap (cm) & 224.3 & 117.3 & 101.1 & 47.3 & 108.9 & 46.7 & 151.3 & 105.6 & $1,311.4$ & 135.8 \\
\hline B. tectorum frequency & 42.9 & 68.2 & 16.0 & 159.2 & 76.9 & 46.1 & 98.3 & 3.4 & 2.7 & 331.7 \\
\hline Salsola spp. frequency & 29.0 & 147.8 & 18.0 & 171.9 & 42.6 & 125.9 & 4.4 & 154.5 & 91.2 & 27.2 \\
\hline Species Richness & 23.6 & 31.9 & 19.7 & 32.3 & 19.7 & 31.1 & 18.5 & 29.4 & 13.7 & 34.0 \\
\hline$\%$ Bare Ground & 19.9 & 39.7 & 49.0 & 19.2 & 42.1 & 32.6 & 19.9 & 47.3 & 50.5 & 21.1 \\
\hline \% Litter \& wood & 49.0 & 23.5 & 26.1 & 32.2 & 32.9 & 30.6 & 57.7 & 25.8 & 32.5 & 30.4 \\
\hline$\%$ Biocrust & 29.4 & 48.8 & 8.3 & 106.2 & 9.0 & 80.9 & 8.7 & 178.0 & 1.8 & 118.3 \\
\hline Annual Forbs & 24.0 & 41.0 & 3.6 & 106.6 & 5.3 & 62.8 & 4.5 & 153.3 & 20.2 & 22.7 \\
\hline C3 Annual Grass & 5.9 & 95.6 & 1.5 & 124.0 & 9.8 & 72.2 & 31.1 & 37.6 & 0.1 & 331.7 \\
\hline Total Annuals & 29.8 & 41.2 & 5.1 & 98.1 & 15.1 & 41.6 & 35.7 & 27.5 & 20.2 & 22.4 \\
\hline Perennial Forbs & 1.6 & 175.0 & 1.2 & 217.8 & 0.7 & 133.0 & 0.5 & 160.0 & 0.2 & 182.5 \\
\hline Per. C3 Bunchgrasses & 2.4 & 124.2 & 2.4 & 152.6 & 0.9 & 142.8 & 1.6 & 166.1 & - & - \\
\hline Per. C4 Bunchgrasses & 2.0 & 162.7 & 2.9 & 192.5 & 4.7 & 86.5 & 8.9 & 86.8 & 2.0 & 100.2 \\
\hline Per. C4 Rhizomatous grasses & 5.1 & 87.5 & 5.0 & 83.9 & 6.1 & 97.5 & 3.9 & 157.6 & 0.7 & 175.9 \\
\hline Perennial Grasses & 9.5 & 90.8 & 10.3 & 76.0 & 11.7 & 57.5 & 14.3 & 70.8 & 2.7 & 92.9 \\
\hline Palatable Shrubs & 4.4 & 111.0 & 1.2 & 169.3 & 1.9 & 168.4 & 1.5 & 100.4 & 0.4 & 189.0 \\
\hline Unpalatable Shrubs & 1.7 & 180.5 & 2.9 & 109.2 & 2.2 & 146.3 & 1.9 & 118.0 & 0.1 & 222.5 \\
\hline Total Perennials & 17.4 & 66.7 & 15.8 & 55.9 & 16.4 & 53.9 & 18.1 & 69.4 & 3.4 & 76.5 \\
\hline Total Plants & 47.2 & 34.0 & 21.0 & 54.4 & 31.5 & 45.2 & 53.8 & 24.5 & 23.7 & 24.1 \\
\hline Exotic Annual Forb & 3.6 & 207.0 & 0.4 & 233.6 & 1.8 & 110.9 & 2.7 & 226.7 & 17.4 & 23.3 \\
\hline Exotic Annual Grass & 3.2 & 130.9 & 0.4 & 172.6 & 9.5 & 74.9 & 30.9 & 37.7 & 0.1 & 331.7 \\
\hline Exotic Annual Relative Cover & 12.6 & 81.6 & 3.9 & 121.6 & 34.9 & 22.3 & 64.5 & 30.9 & 75.0 & 19.0 \\
\hline dust flux (1750 $\left.\mathrm{cm} \mathrm{s}^{-1}\right)$ & - & - & 222.1 & 380.9 & - & - & $6,000.0$ & 335.3 & $1,686.1$ & 252.9 \\
\hline dust flux $\left(2625 \mathrm{~cm} \mathrm{~s}^{-1}\right)$ & - & - & $2,873.2$ & 217.0 & $1,843.7$ & 181.8 & $22,585.1$ & 303.2 & $33,235.3$ & 149.2 \\
\hline dust flux (3500 $\left.\mathrm{cm} \mathrm{s}^{-1}\right)$ & 4978.0 & 96.3 & $16,328.9$ & 132.1 & $21,974.2$ & 131.1 & $56,420.3$ & 288.0 & $132,877.5$ & 87.3 \\
\hline Aboveground C ( $\left.\mathrm{kg} \mathrm{plot}^{-1}\right)$ & 122.6 & 28.6 & 83.5 & 28.3 & 74.7 & 25.7 & 133.6 & 24.2 & 69.5 & 23.4 \\
\hline Preferred forage mass $\left(\mathrm{kg} \mathrm{plot}^{-1}\right)$ & 25.5 & 67.0 & 20.8 & 62.0 & 17.1 & 74.7 & 24.3 & 68.8 & 4.8 & 72.2 \\
\hline \multicolumn{11}{|c|}{ Plot frequency } \\
\hline In CANY & 21 & & 21 & & 4 & & 2 & & 10 & \\
\hline Out of CANY & 2 & & 19 & & 12 & & 10 & & 1 & \\
\hline
\end{tabular}


Table 8. Mean values and coefficient of variation ( $\times 100)$ describing key attributes of clusters in Semidesert Sand. Variables underlined in bold indicate those used in cluster analysis.

\begin{tabular}{|c|c|c|c|c|c|c|c|c|c|c|c|c|c|c|}
\hline \multirow{4}{*}{ Variable } & \multirow{2}{*}{\multicolumn{2}{|c|}{ Cluster 1}} & \multirow{2}{*}{\multicolumn{2}{|c|}{ Cluster 2}} & \multirow{2}{*}{\multicolumn{2}{|c|}{ Cluster 3}} & \multirow{2}{*}{\multicolumn{2}{|c|}{ Cluster 4}} & \multirow{2}{*}{\multicolumn{2}{|c|}{ Cluster 5}} & \multirow{2}{*}{\multicolumn{2}{|c|}{ Cluster 6}} & \multirow{2}{*}{\multicolumn{2}{|c|}{ Cluster 7}} \\
\hline & & & & & & & & & & & & & & \\
\hline & n & 4 & $\mathbf{n}$ & 8 & $\mathbf{n}$ & 9 & \begin{tabular}{l|l}
$\mathbf{n}$ & \\
\end{tabular} & 16 & \begin{tabular}{l|l}
$\mathbf{n}$ & \\
\end{tabular} & 2 & n & 3 & $\mathbf{n}$ & 3 \\
\hline & Mean & CV & Mean & CV & Mean & CV & Mean & CV & Mean & CV & Mean & CV & Mean & CV \\
\hline Elevation (m) & 1708.4 & 1.5 & 1653.8 & 8.3 & 1660.3 & 7.1 & 1511.2 & 2.3 & 1552.4 & 7.9 & 1624.3 & 6.3 & 1610.6 & 3.6 \\
\hline Soil Aggregate Stabilty (Avg.) & 5.6 & 1.5 & 5.1 & 11.7 & 5.1 & 15.4 & 3.2 & 35.9 & 4.4 & 32.9 & 5.1 & 2.7 & 5.1 & 6.0 \\
\hline Surface Roughness & 14.2 & 40.6 & 7.9 & 49.9 & 7.8 & 45.8 & 3.3 & 44.8 & 6.6 & 48.3 & 6.2 & 57.7 & 7.3 & 21.9 \\
\hline Median Canopy Gap (cm) & 65.6 & 8.7 & 69.7 & 35.3 & 75.7 & 24.0 & 92.4 & 31.6 & 165.0 & 91.7 & 1342.5 & 160.5 & 212.3 & 89.8 \\
\hline Median Basal Gap (cm) & 110.6 & 18.4 & 134.7 & 44.0 & 104.8 & 30.5 & 162.1 & 55.3 & 287.0 & 110.4 & 1730.0 & 163.7 & 367.7 & 112.0 \\
\hline B. tectorum frequency & 38.3 & 59.9 & 30.4 & 112.3 & 26.7 & 147.8 & 23.5 & 128.2 & 100.0 & 0.0 & 96.7 & 0.0 & 12.2 & 150.2 \\
\hline Salsola spp. frequency & 14.2 & 156.5 & 30.0 & 145.6 & 8.1 & 207.7 & 17.1 & 160.1 & 46.7 & 141.4 & 28.9 & 153.2 & 86.7 & 3.8 \\
\hline Species Richness & 21.3 & 14.6 & 27.0 & 30.0 & 22.4 & 20.2 & 25.9 & 22.5 & 23.5 & 21.1 & 17.3 & 20.3 & 22.7 & 15.5 \\
\hline$\%$ Bare Ground & 11.5 & 22.9 & 18.3 & 27.8 & 36.3 & 17.5 & 55.8 & 14.4 & 30.7 & 79.9 & 6.0 & 58.8 & 25.3 & 19.0 \\
\hline$\%$ Litter \& wood & 52.7 & 19.4 & 55.9 & 19.6 & 29.0 & 30.1 & 25.5 & 29.6 & 59.3 & 33.4 & 78.4 & 14.8 & 47.3 & 30.3 \\
\hline$\%$ Biocrust & 38.0 & 22.6 & 20.7 & 50.5 & 20.5 & 36.9 & 3.9 & 106.2 & 0.3 & 141.4 & 8.4 & 128.4 & 15.8 & 6.5 \\
\hline Annual Forbs & 19.7 & 43.5 & 5.5 & 101.5 & 6.9 & 81.5 & 1.9 & 72.0 & 4.3 & 98.7 & 31.3 & 33.1 & 46.7 & 16.1 \\
\hline C3 Annual Grass & 6.3 & 87.7 & 5.1 & 135.8 & 1.9 & 105.5 & 1.4 & 185.9 & 17.7 & 13.2 & 43.3 & 18.8 & 1.1 & 123.6 \\
\hline C4 Annual Grass & 0.2 & 200.0 & 0.0 & 0.0 & 0.4 & 158.1 & 0.0 & 0.0 & 0.0 & 0.0 & 0.0 & 0.0 & 0.2 & 173.2 \\
\hline Total Annuals & 26.2 & 55.0 & 10.6 & 91.2 & 9.2 & 83.8 & 3.3 & 101.8 & 22.0 & 30.0 & 74.6 & 5.6 & 48.0 & 17.6 \\
\hline Perennial Forbs & 4.0 & 81.4 & 3.4 & 59.0 & 1.8 & 135.8 & 2.4 & 77.9 & 0.7 & 0.0 & 0.5 & 86.6 & 2.9 & 133.6 \\
\hline Per. C3 Bunchgrasses & 11.9 & 21.9 & 15.1 & 54.1 & 3.8 & 90.3 & 3.0 & 64.7 & 0.0 & 0.0 & 0.2 & 173.2 & 1.8 & 86.6 \\
\hline Per. C4 Bunchgrasses & 1.7 & 132.9 & 5.3 & 132.6 & 4.3 & 126.0 & 2.8 & 70.2 & 5.7 & 74.4 & 1.6 & 173.2 & 1.1 & 92.3 \\
\hline Per. C4 Rhizomatous grasses & 1.9 & 112.0 & 1.8 & 124.3 & 6.8 & 125.3 & 1.6 & 116.0 & 0.0 & 0.0 & 0.2 & 173.2 & 2.9 & 93.4 \\
\hline Perennial Grasses & 15.4 & 35.0 & 22.2 & 73.0 & 14.8 & 104.4 & 7.4 & 48.5 & 5.7 & 74.4 & 2.0 & 144.4 & 5.8 & 67.1 \\
\hline Palatable Shrubs & 1.5 & 116.6 & 4.1 & 95.0 & 2.1 & 109.3 & 1.4 & 239.0 & 0.0 & 0.0 & 6.0 & 120.2 & 3.3 & 91.7 \\
\hline Unpalatable Shrubs & 0.5 & 200.0 & 1.9 & 135.4 & 2.5 & 86.1 & 3.8 & 97.1 & 2.4 & 141.4 & 3.1 & 154.3 & 0.0 & 0.0 \\
\hline Trees & 0.0 & 0.0 & 2.6 & 168.9 & 0.0 & 0.0 & 0.0 & 0.0 & 0.0 & 0.0 & 0.0 & 0.0 & 0.0 & 0.0 \\
\hline Total Perennials & 21.4 & 45.1 & 34.2 & 51.0 & 21.2 & 81.3 & 15.0 & 38.9 & 8.8 & 86.5 & 11.6 & 130.5 & 12.0 & 19.6 \\
\hline Total Plants & 47.6 & 46.3 & 44.8 & 50.6 & 30.4 & 80.0 & 18.3 & 41.1 & 30.7 & 46.1 & 86.3 & 13.9 & 60.0 & 18.0 \\
\hline Exotic Annual Forbs & 3.0 & 172.3 & 1.2 & 144.3 & 0.6 & 206.0 & 0.6 & 161.3 & 3.3 & 85.7 & 15.1 & 100.3 & 11.3 & 73.4 \\
\hline Exotic Annual Grasses & 3.3 & 116.6 & 3.3 & 195.7 & 0.8 & 180.9 & 0.7 & 212.6 & 17.7 & 13.2 & 42.4 & 15.5 & 0.2 & 173.2 \\
\hline Total Exotics & 6.3 & 126.8 & 4.5 & 147.1 & 1.4 & 161.2 & 1.2 & 139.3 & 21.0 & 24.6 & 57.5 & 19.7 & 11.6 & 68.8 \\
\hline Exotic Relative Cover & 11.9 & 143.4 & 8.4 & 97.6 & 3.7 & 184.6 & 6.7 & 133.4 & 72.0 & 22.7 & 66.4 & 5.5 & 20.3 & 68.1 \\
\hline Exotic Annual Relative Cover & 11.9 & 143.4 & 8.4 & 97.6 & 3.7 & 184.6 & 6.7 & 133.4 & 72.0 & 22.7 & 66.4 & 5.5 & 20.3 & 68.1 \\
\hline dust flux $\left(1750 \mathrm{~cm} \mathrm{~s}^{-1}\right)$ & 0.0 & 0.0 & 0.0 & 0.0 & 0.0 & 0.0 & 588.1 & 205.1 & 0.0 & 0.0 & 0.0 & 0.0 & 0.0 & 0.0 \\
\hline dust flux $\left(2625 \mathrm{~cm} \mathrm{~s}^{-1}\right)$ & 0.0 & 0.0 & 35.8 & 282.8 & 92.0 & 300.0 & 8806.9 & 151.3 & 21436.0 & 141.4 & 0.0 & 0.0 & 0.0 & 0.0 \\
\hline dust flux (3500 $\left.\mathrm{cm} \mathrm{s}^{-1}\right)$ & 0.0 & 0.0 & 5315.7 & 282.8 & 5789.7 & 233.4 & 37824.0 & 97.5 & 88200.5 & 141.4 & 0.0 & 0.0 & 21174.6 & 169.9 \\
\hline Aboveground C ( $\left.\mathrm{kg} \mathrm{plot}^{-1}\right)$ & 134.3 & 61.4 & 187.3 & 40.0 & 93.4 & 18.7 & 78.9 & 16.1 & 138.6 & 41.7 & 201.8 & 22.7 & 119.6 & 29.0 \\
\hline Preferred forage mass $\left(\mathrm{kg} \mathrm{plot}^{-1}\right)$ & 16.2 & 65.7 & 45.0 & 58.3 & 25.9 & 98.0 & 14.7 & 78.4 & 8.5 & 74.4 & 21.3 & 124.1 & 17.7 & 52.6 \\
\hline \multicolumn{15}{|c|}{ Frequency } \\
\hline In CANY & 4 & & 7 & & 7 & & 5 & & 0 & & 3 & & 3 & \\
\hline Out of CANY & 0 & & 1 & & 2 & & 11 & & 2 & & 0 & & 0 & \\
\hline
\end{tabular}


Table 9. Mean values and coefficient of variation $(\times 100)$ describing key attributes of clusters in Upland Loam. Variables underlined in bold indicate those used in cluster analysis.

\begin{tabular}{|c|c|c|c|c|c|c|c|c|c|c|c|c|}
\hline \multirow{3}{*}{ Variable } & \multicolumn{2}{|c|}{ Cluster 1} & \multicolumn{2}{|c|}{ Cluster 2} & \multicolumn{2}{|c|}{ Cluster 3} & \multicolumn{2}{|c|}{ Cluster 4} & \multicolumn{2}{|c|}{ Cluster 5} & \multicolumn{2}{|c|}{ Cluster 6} \\
\hline & $\mathbf{n}$ & 7 & $\mathbf{n}$ & 14 & n & 12 & $\mathbf{n}$ & 14 & \begin{tabular}{l|l}
$\mathbf{n}$ \\
\end{tabular} & 8 & $\mathbf{n}$ & 6 \\
\hline & Mean & CV & Mean & CV & Mean & CV & Mean & CV & Mean & CV & Mean & CV \\
\hline Soil Aggregate Stabilty (Avg.) & 4.8 & 15.2 & 4.3 & 24.6 & 3.5 & 32.2 & 3.5 & 31.7 & 3.2 & 39.8 & 3.6 & 18.9 \\
\hline Surface Roughness & 7.2 & 63.6 & 6.0 & 37.6 & 6.3 & 46.3 & 5.4 & 70.8 & 4.5 & 41.0 & 5.8 & 40.7 \\
\hline Median Canopy Gap (cm) & 43.9 & 21.9 & 40.1 & 22.6 & 89.2 & 57.9 & 46.7 & 21.1 & 53.8 & 18.7 & 105.4 & 78.4 \\
\hline Median Basal Gap (cm) & 48.9 & 30.5 & 49.0 & 19.7 & 166.9 & 93.2 & 62.8 & 47.5 & 84.1 & 33.4 & 273.1 & 104.2 \\
\hline A. cristatum frequency & - & - & 14.0 & 254.2 & 24.7 & 180.9 & - & - & - & - & 15.6 & 234.6 \\
\hline B. tectorum frequency & 18.6 & 113.9 & 17.4 & 84.5 & 45.6 & 84.4 & 67.1 & 32.1 & 92.9 & 9.1 & 20.0 & 95.5 \\
\hline Salsola spp. frequency & - & - & - & - & 0.3 & 346.4 & 3.6 & 224.1 & 0.4 & 282.8 & - & - \\
\hline Species Richness & 18.3 & 29.7 & 22.1 & 19.1 & 21.8 & 20.9 & 20.0 & 25.9 & 20.3 & 19.9 & 22.2 & 24.9 \\
\hline$\%$ Bare Ground & 35.8 & 20.3 & 22.2 & 25.0 & 46.2 & 16.2 & 21.3 & 19.2 & 18.7 & 52.2 & 34.9 & 18.4 \\
\hline$\%$ Litter \& wood & 31.6 & 24.8 & 47.6 & 17.3 & 30.4 & 31.4 & 53.2 & 20.3 & 62.3 & 25.8 & 53.3 & 14.2 \\
\hline$\%$ Biocrust & 14.6 & 47.3 & 5.1 & 93.0 & 4.3 & 96.3 & 1.9 & 162.4 & 2.6 & 162.3 & 6.3 & 66.8 \\
\hline Annual Forbs & 1.2 & 202.7 & 1.9 & 166.3 & 2.5 & 128.4 & 8.9 & 83.5 & 5.3 & 124.2 & 1.0 & 108.4 \\
\hline C3 Annual Grass & 1.3 & 161.9 & 1.0 & 112.0 & 4.1 & 97.4 & 8.5 & 49.3 & 23.8 & 21.9 & 1.3 & 104.4 \\
\hline Total Annuals & 2.6 & 122.8 & 2.9 & 138.9 & 6.6 & 84.0 & 17.5 & 56.8 & 29.1 & 29.8 & 2.4 & 98.3 \\
\hline Perennial Forbs & 0.9 & 115.8 & 0.4 & 113.1 & 0.7 & 126.4 & 1.1 & 102.0 & 0.6 & 166.6 & 0.2 & 154.9 \\
\hline Per. C3 Bunchgrasses & 3.7 & 54.9 & 24.8 & 25.7 & 6.1 & 101.5 & 13.5 & 46.2 & 15.6 & 49.0 & 5.6 & 112.9 \\
\hline Per. C4 Bunchgrasses & 0.2 & 264.6 & 1.1 & 230.2 & 1.6 & 205.4 & 1.5 & 142.4 & 1.7 & 141.2 & - & - \\
\hline Per. C3 Rhizomatous grasses & 1.5 & 264.6 & 0.4 & 374.2 & - & - & - & - & - & - & - & - \\
\hline Per. C4 Rhizomatous grasses & 14.2 & 56.9 & 8.0 & 96.2 & 4.2 & 151.8 & 8.5 & 79.5 & 4.0 & 188.3 & 1.4 & 161.1 \\
\hline Perennial Grasses & 19.7 & 45.1 & 34.4 & 24.5 & 11.9 & 81.8 & 23.4 & 34.3 & 21.3 & 26.6 & 7.0 & 93.5 \\
\hline Palatable Shrubs & 1.0 & 233.9 & 0.7 & 198.9 & 0.6 & 150.0 & 1.8 & 149.7 & 1.8 & 90.1 & 0.4 & 167.3 \\
\hline Unplatable Shrubs & 11.4 & 38.0 & 5.9 & 109.6 & 3.7 & 114.6 & 1.7 & 128.0 & 2.8 & 172.1 & 3.8 & 46.7 \\
\hline A. tridentata ${ }^{\mathrm{a}}$ & 11.4 & 38.0 & 5.9 & 109.6 & 3.7 & 114.6 & 1.7 & 128.0 & 2.8 & 172.1 & 3.8 & 46.7 \\
\hline Trees & 2.8 & 179.8 & 0.4 & 255.7 & 3.4 & 140.3 & 2.7 & 242.5 & 0.3 & 196.0 & 28.1 & 31.0 \\
\hline Total Perennials & 36.6 & 24.6 & 44.0 & 27.2 & 22.8 & 40.3 & 32.3 & 36.5 & 27.0 & 19.5 & 40.1 & 22.8 \\
\hline Total Plants & 39.2 & 17.6 & 46.9 & 23.9 & 29.4 & 36.1 & 49.8 & 10.9 & 56.1 & 16.5 & 42.4 & 18.5 \\
\hline Exotic Annual Forb & 0.1 & 264.6 & 0.3 & 217.2 & 0.3 & 286.7 & 0.9 & 246.6 & 1.9 & 114.2 & 0.2 & 244.9 \\
\hline Exotic Annual Grass & 1.1 & 208.5 & 0.7 & 116.9 & 2.9 & 123.0 & 7.0 & 42.1 & 23.1 & 24.8 & 1.0 & 123.0 \\
\hline Exotic Perrennial Grass & - & - & 5.9 & 202.4 & 3.1 & 211.8 & - & - & 2.3 & 260.3 & 2.5 & 231.2 \\
\hline Exotic Relative Cover & 2.9 & 171.8 & 19.1 & 182.8 & 19.5 & 76.7 & 16.1 & 36.1 & 49.0 & 23.5 & 7.9 & 140.0 \\
\hline Exotic Annual Relative Cover & 2.9 & 171.8 & 2.2 & 128.2 & 10.2 & 89.1 & 16.1 & 36.1 & 44.2 & 13.8 & 3.2 & 109.4 \\
\hline dust flux $\left(1750 \mathrm{~cm} \mathrm{~s}^{-1}\right)$ & - & - & 0.0 & 374.2 & 204.4 & 346.4 & 11.2 & 343.4 & 255.6 & 247.7 & - & - \\
\hline dust flux $\left(2625 \mathrm{~cm} \mathrm{~s}^{-1}\right)$ & - & - & 134.5 & 318.9 & $1,159.1$ & 343.9 & $2,148.2$ & 157.6 & $3,186.5$ & 151.0 & - & - \\
\hline dust flux (3500 $\left.\mathrm{cm} \mathrm{s}^{-1}\right)$ & 1.9 & 263.8 & $2,149.2$ & 179.2 & $4,053.5$ & 285.7 & $9,838.5$ & 148.2 & $12,594.9$ & 116.4 & 61.2 & 244.9 \\
\hline Aboveground $\mathrm{C}\left(\mathrm{kg} \mathrm{plot}^{-1}\right)$ & 125.3 & 62.7 & 123.3 & 12.3 & 115.4 & 60.2 & 158.2 & 74.4 & 140.2 & 25.6 & 629.9 & 35.3 \\
\hline Preferred forage mass $\left(\mathrm{kg} \mathrm{plot}^{-1}\right)$ & 26.1 & 38.8 & 50.1 & 19.8 & 17.8 & 75.9 & 37.0 & 32.0 & 35.5 & 23.8 & 11.0 & 96.0 \\
\hline \multicolumn{13}{|c|}{ Frequency } \\
\hline In CANY & 1 & & 2 & & 0 & & 0 & & 0 & & 0 & \\
\hline Out of CANY & 6 & & 12 & & 12 & & 14 & & 8 & & 6 & \\
\hline
\end{tabular}


Table 10. Mean values and coefficient of variation ( $\times 100)$ describing key attributes of clusters in Upland Shallow Loam. Variables underlined in bold indicate those used in cluster analysis.

\begin{tabular}{|c|c|c|c|c|c|c|c|c|c|c|c|c|}
\hline \multirow{4}{*}{ Variable } & \multirow{2}{*}{\multicolumn{2}{|c|}{ Cluster 1}} & \multirow{2}{*}{\multicolumn{2}{|c|}{ Cluster 2}} & \multirow{2}{*}{\multicolumn{2}{|c|}{ Cluster 3}} & \multirow{2}{*}{\multicolumn{2}{|c|}{ Cluster 4}} & \multirow{2}{*}{\multicolumn{2}{|c|}{ Cluster 5}} & \multirow{2}{*}{\multicolumn{2}{|c|}{ Cluster 6}} \\
\hline & & & & & & & & & & & & \\
\hline & $\mathbf{n}$ & 5 & $\mathbf{n}$ & 8 & $\mathbf{n}$ & 3 & \begin{tabular}{l|l}
$\mathbf{n}$ & \\
\end{tabular} & 8 & $\mathbf{n}$ & 5 & \begin{tabular}{l|l}
$\mathbf{n}$ & \\
\end{tabular} & 11 \\
\hline & Mean & CV & Mean & CV & Mean & CV & Mean & CV & Mean & CV & Mean & CV \\
\hline Elevation (m) & $1,851.3$ & 0.8 & $2,171.4$ & 3.6 & $2,312.7$ & 1.5 & $1,978.1$ & 8.4 & $2,326.6$ & 2.6 & $2,137.1$ & 5.5 \\
\hline Mean Annual Precipitation (mm) & 286.8 & 1.7 & 334.6 & 4.8 & 353.3 & 1.0 & 302.0 & 9.0 & 359.8 & 5.3 & 332.1 & 3.1 \\
\hline Precip./ Potential Evapotranspiration & 0.24 & 3.5 & 0.4 & 22.4 & 0.4 & 4.2 & 0.29 & 21.2 & 0.39 & 7.2 & 0.39 & 17.6 \\
\hline Soil Aggregate Stabilty (Avg.) & 4.7 & 13.3 & 3.6 & 19.3 & 4.4 & 26.9 & 3.0 & 24.8 & 3.2 & 45.8 & 3.4 & 24.5 \\
\hline Surface Roughness & 11.0 & 11.1 & 5.2 & 28.4 & 4.4 & 13.3 & 7.1 & 16.4 & 3.5 & 59.0 & 3.4 & 48.7 \\
\hline Median Canopy Gap (cm) & 209.7 & 38.1 & 141.1 & 34.7 & 85.8 & 34.8 & 137.9 & 45.1 & 58.5 & 17.2 & 51.3 & 19.2 \\
\hline Median Basal Gap (cm) & 407.4 & 40.4 & 315.1 & 67.8 & 111.0 & 17.4 & 403.9 & 75.4 & 70.4 & 12.5 & 65.7 & 26.2 \\
\hline A. cristatum frequency & - & - & 5.4 & 282.8 & 33.3 & 173.2 & 2.1 & 282.8 & 86.7 & 18.2 & 88.5 & 33.4 \\
\hline B. tectorum frequency & 10.0 & 187.1 & 42.1 & 96.0 & 2.2 & 173.2 & 17.9 & 100.4 & 3.3 & 173.2 & 15.5 & 136.8 \\
\hline Species Richness & 25.8 & 16.8 & 21.9 & 16.1 & 25.3 & 34.5 & 23.5 & 20.3 & 20.2 & 26.1 & 24.3 & 30.9 \\
\hline \%Bare Ground & 43.9 & 9.0 & 28.3 & 18.1 & 22.7 & 45.9 & 50.8 & 11.1 & 31.1 & 14.1 & 35.3 & 23.2 \\
\hline$\%$ Litter \& wood & 23.3 & 29.5 & 54.3 & 12.6 & 58.7 & 23.6 & 32.0 & 17.9 & 49.1 & 15.5 & 37.3 & 29.8 \\
\hline$\%$ Biocrust & 19.2 & 21.3 & 6.2 & 55.4 & 8.2 & 9.4 & 6.3 & 60.3 & 1.3 & 61.2 & 1.1 & 129.0 \\
\hline Annual Forbs & 1.4 & 77.9 & 0.4 & 119.0 & 0.2 & 173.2 & 1.4 & 90.5 & 1.1 & 118.3 & 0.6 & 151.6 \\
\hline C3 Annual Grass & - & - & 3.3 & 93.2 & - & - & 0.5 & 185.2 & - & - & 1.6 & 165.8 \\
\hline Perennial Forbs & 1.1 & 31.0 & 1.3 & 131.4 & 1.8 & 94.9 & 2.3 & 85.1 & 1.1 & 144.4 & 2.4 & 95.3 \\
\hline Per. C3 Bunchgrasses & 0.4 & 146.8 & 3.0 & 90.8 & 7.8 & 63.0 & 0.6 & 282.8 & 17.1 & 27.6 & 23.4 & 20.2 \\
\hline Per. C4 Bunchgrasses & - & - & - & - & - & - & - & - & - & - & - & - \\
\hline Per. C4 Rhizomatous grasses & 0.7 & 171.9 & - & - & - & - & 0.3 & 138.0 & 0.4 & 223.6 & 0.9 & 174.8 \\
\hline Perennial Grasses & 1.1 & 154.6 & 3.0 & 90.8 & 8.0 & 57.9 & 0.9 & 219.5 & 17.5 & 30.2 & 24.3 & 19.2 \\
\hline Palatable Shrubs & 0.4 & 149.1 & 0.5 & 135.4 & 1.3 & 130.4 & 0.8 & 163.1 & 0.7 & 142.0 & 0.3 & 178.9 \\
\hline Unplatable Shrubs & 1.0 & 155.5 & 1.4 & 99.7 & 7.6 & 62.0 & 1.9 & 84.7 & 10.1 & 51.0 & 2.4 & 94.3 \\
\hline Total shrubs & 1.4 & 92.0 & 1.9 & 68.3 & 8.9 & 71.1 & 2.8 & 91.8 & 10.8 & 53.7 & 2.7 & 84.9 \\
\hline A. tridentata & 0.3 & 223.6 & 0.8 & 171.0 & 2.0 & 58.7 & 0.9 & 103.0 & 8.7 & 75.3 & 0.6 & 133.3 \\
\hline Trees & 5.9 & 86.2 & 22.8 & 25.9 & 33.8 & 19.9 & 8.3 & 78.5 & 10.3 & 51.4 & 2.2 & 135.0 \\
\hline Total Perenials & 9.4 & 40.9 & 29.0 & 18.7 & 52.5 & 17.0 & 14.2 & 31.0 & 39.6 & 18.2 & 31.6 & 13.4 \\
\hline Total Plants & 11.1 & 30.8 & 32.7 & 25.2 & 52.7 & 16.6 & 16.3 & 23.2 & 40.7 & 19.4 & 33.8 & 14.7 \\
\hline Exotic Annual Grass & - & - & 2.7 & 101.4 & - & - & 0.4 & 190.6 & - & - & 1.3 & 203.6 \\
\hline Exotic Perrennial Grass & - & - & 0.3 & 282.8 & 4.0 & 158.3 & 0.1 & 282.8 & 16.1 & 38.9 & 22.5 & 22.6 \\
\hline Exotic Relative Cover & 1.5 & 223.6 & 7.5 & 103.9 & 8.2 & 157.7 & 4.3 & 159.5 & 38.7 & 29.6 & 71.0 & 18.8 \\
\hline Exotic Annual Relative Cover & 1.5 & 223.6 & 6.8 & 98.6 & - & - & 3.9 & 165.0 & - & - & 3.7 & 185.1 \\
\hline dust flux $\left(1750 \mathrm{~cm} \mathrm{~s}^{-1}\right)$ & - & - & - & - & - & - & 0.0 & 282.8 & 0.2 & 223.6 & - & - \\
\hline dust flux (2625 $\left.\mathrm{cm} \mathrm{s}^{-1}\right)$ & - & - & - & - & - & - & 265.5 & 236.8 & 71.2 & 213.1 & 581.5 & 212.4 \\
\hline dust flux $\left(3500 \mathrm{~cm} \mathrm{~s}^{-1}\right)$ & $3,470.3$ & 223.6 & 12.4 & 246.2 & - & - & $3,075.0$ & 130.2 & $2,235.3$ & 210.3 & $4,980.4$ & 153.9 \\
\hline Aboveground C $\left(\mathrm{kg} \mathrm{plot}^{-1}\right)$ & 121.0 & 58.4 & 496.8 & 28.3 & 787.1 & 24.0 & 175.8 & 63.3 & 255.4 & 36.5 & 109.1 & 43.7 \\
\hline Preferred forage mass $\left(\mathrm{kg} \mathrm{plot}^{-1}\right)$ & 4.9 & 125.6 & 6.1 & 58.2 & 15.9 & 50.8 & 3.7 & 113.5 & 27.9 & 36.6 & 36.8 & 19.3 \\
\hline \multicolumn{13}{|c|}{ Treatment type } \\
\hline None & 5 & & 8 & & 2 & & 7 & & 1 & & 0 & \\
\hline Chain Seed & 0 & & 0 & & 1 & & 1 & & 4 & & 1 & \\
\hline Chain Seed Burn & 0 & & 0 & & 0 & & 0 & & 0 & & 10 & \\
\hline \multicolumn{13}{|c|}{ Frequency } \\
\hline In CANY & 0 & & 0 & & 0 & & 0 & & 0 & & 0 & \\
\hline Out of CANY & 5 & & 8 & & 3 & & 8 & & 5 & & 11 & \\
\hline
\end{tabular}


Table 11. Summary of P-scores for hydrological units of the Needles District of Canyonlands, and pastures of the Indian Creek Allotment of the Dugout Ranch.

\begin{tabular}{|c|c|c|c|c|c|c|c|c|c|}
\hline Watershed/Pasture & $\begin{array}{c}\text { samples } \\
\text { per } \mathrm{m}^{2} X \\
10^{6} \\
\end{array}$ & $\begin{array}{c}\text { Area } \\
\mathrm{m}^{2} \times 10^{6} \\
\end{array}$ & $n=$ & $\mathbf{P}_{\mathrm{c}}$ & $\mathbf{P}_{\text {dust }}$ & $\mathbf{P}_{\text {forage }}$ & $\mathbf{P}_{\text {native }}$ & $\mathbf{P}_{\mathrm{m} \times 1}$ & $\mathbf{P}_{\mathrm{m} \times \mathbf{2}}$ \\
\hline Butler Wash & 0.11 & 243.7 & 26 & 0.787 & 0.819 & 0.803 & 0.885 & 0.817 & 0.826 \\
\hline Davis Cyn. & 0.38 & 29.3 & 11 & 0.976 & 0.970 & 0.775 & 0.907 & 0.895 & 0.950 \\
\hline Elephant cyn & 0.14 & 48.9 & 7 & 0.668 & 0.883 & 0.488 & 0.842 & 0.687 & 0.784 \\
\hline Lavender & 0.13 & 23.1 & 3 & 0.926 & 0.988 & 0.603 & 0.751 & 0.772 & 0.861 \\
\hline Lower salt Creek & 0.55 & 76.7 & 42 & 0.592 & 0.682 & 0.506 & 0.873 & 0.642 & 0.702 \\
\hline Middle Salt Creek & 0.35 & 94.5 & 33 & 0.751 & 0.740 & 0.663 & 0.785 & 0.722 & 0.754 \\
\hline Upper Salt Creek & 0.38 & 55.2 & 21 & 0.637 & 0.832 & 0.691 & 0.842 & 0.730 & 0.748 \\
\hline Beef Basin & 0.40 & 43.0 & 17 & 0.245 & 0.456 & 0.408 & 0.842 & 0.415 & 0.343 \\
\hline Bridger Jack & 0.20 & 29.9 & 6 & 0.452 & 0.824 & 0.279 & 0.915 & 0.518 & 0.429 \\
\hline Bull1 & 0.32 & 3.1 & 1 & 1.000 & 0.575 & 0.952 & 0.370 & 0.671 & 0.818 \\
\hline Bull3 & 0.49 & 2.1 & 1 & 0.598 & 0.877 & 0.671 & 1.000 & 0.770 & 0.706 \\
\hline Corral Pocket & 0.20 & 35.6 & 7 & 0.548 & 0.411 & 0.366 & 0.981 & 0.438 & 0.367 \\
\hline Cottonwood & 0.45 & 6.6 & 3 & 0.938 & 0.694 & 0.828 & 0.342 & 0.591 & 0.757 \\
\hline Creek Pasture & 0.42 & 11.8 & 5 & 0.494 & 0.457 & 0.440 & 0.886 & 0.405 & 0.363 \\
\hline Dark Canyon & 0.21 & 204.5 & 43 & 0.419 & 0.409 & 0.330 & 0.912 & 0.343 & 0.287 \\
\hline Davis Cyn. & 0.08 & 26.6 & 2 & 0.632 & 0.703 & 0.549 & 0.898 & 0.610 & 0.573 \\
\hline Drill Pasture & 0.35 & 11.5 & 4 & 0.491 & 0.380 & 0.481 & 0.928 & 0.340 & 0.315 \\
\hline Lavender & 0.16 & 55.0 & 9 & 0.517 & 0.596 & 0.844 & 0.606 & 0.538 & 0.545 \\
\hline Lower Ranch 2 & 1.40 & 1.4 & 2 & 0.466 & 0.286 & 0.258 & 0.614 & 0.261 & 0.212 \\
\hline Middle Pasture & 0.26 & 26.8 & 7 & 0.578 & 0.202 & 0.285 & 0.936 & 0.178 & 0.163 \\
\hline Park Pasture & 0.31 & 47.6 & 15 & 0.492 & 0.407 & 0.418 & 0.966 & 0.359 & 0.318 \\
\hline Ranch & 0.17 & 6.0 & 1 & 1.000 & 0.575 & 0.952 & 0.370 & 0.671 & 0.818 \\
\hline Ruin Park & 0.21 & 103.3 & 22 & 0.445 & 0.518 & 0.727 & 0.758 & 0.563 & 0.532 \\
\hline Salt Creek & 0.09 & 133.1 & 12 & 0.253 & 0.562 & 0.609 & 0.736 & 0.496 & 0.439 \\
\hline Salt Creek 2 & 1.29 & 1.6 & 2 & 0.138 & 0.000 & 1.000 & 0.303 & 0.000 & 0.000 \\
\hline Slick Bench & 0.38 & 5.2 & 2 & 0.138 & 0.000 & 1.000 & 0.303 & 0.000 & 0.000 \\
\hline Steven's Mesa & 0.15 & 13.0 & 2 & 0.193 & 0.250 & 0.414 & 0.758 & 0.351 & 0.271 \\
\hline Sweet Alice & 0.14 & 21.2 & 3 & 0.336 & 0.551 & 0.759 & 0.641 & 0.548 & 0.520 \\
\hline Upper Cottonwood & 0.23 & 8.8 & 2 & 0.322 & 0.082 & 0.241 & 0.372 & 0.096 & 0.117 \\
\hline Upper Ranch & 0.27 & 3.7 & 1 & 1.000 & 0.965 & 1.000 & 0.350 & 0.762 & 0.988 \\
\hline Wild Cow & 0.39 & 20.8 & 8 & 0.584 & 0.811 & 0.305 & 0.938 & 0.602 & 0.520 \\
\hline Wilson Ranch & 0.24 & 12.3 & 3 & 0.928 & 0.861 & 0.954 & 0.419 & 0.745 & 0.913 \\
\hline
\end{tabular}


Table 12. Summary of E-scores for major ecological sites within hydrological units of the Needles District of Canyonlands, and pastures of the Indian Creek Allotment of the Dugout Ranch.

\begin{tabular}{|c|c|c|c|c|c|c|c|c|c|}
\hline Watershed/Pasture & Ecological site & & $n=$ & $\mathrm{E}_{\mathrm{c}}$ & & $E_{\text {forage }}$ & $\mathbf{E}_{\text {native }}$ & $\mathbf{E}_{\mathrm{m} \times 1}$ & $1 \times 2$ \\
\hline \multirow[t]{4}{*}{ Butler Wash } & Semidesert Sand (Fourwing Saltbush) & & 8 & 0.75 & 0.78 & 0.53 & 0.79 & 0.71 & 0.77 \\
\hline & Semidesert Sandy Loam (Fourwing Saltbush) & & 12 & 0.90 & 0.96 & 0.97 & 0.92 & 0.94 & 0.93 \\
\hline & Semidesert Shallow Sand (Blackbrush) & & 1 & 1.00 & 1.00 & 1.00 & 1.00 & 1.00 & 1.00 \\
\hline & Semidesert Shallow Sandy Loam (Utah Juniper & Blackbrush) & 6 & 0.57 & 0.56 & 0.79 & 0.93 & 0.69 & 0.67 \\
\hline \multirow[t]{4}{*}{ Elephant Cyn. } & Semidesert Sand (Fourwing Saltbush) & & 4 & 0.67 & 0.86 & 0.46 & 0.75 & 0.67 & 0.76 \\
\hline & Semidesert Sandy Loam (Fourwing Saltbush) & & 1 & 0.93 & 0.96 & 1.00 & 0.91 & 0.95 & 0.93 \\
\hline & Semidesert Shallow Sand (Blackbrush) & & 1 & 0.71 & 0.81 & 0.40 & 0.98 & 0.69 & 0.83 \\
\hline & Semidesert Shallow Sandy Loam (Utah Juniper & Blackbrush) & 1 & 0.36 & 0.95 & 0.18 & 1.00 & 0.50 & 0.70 \\
\hline \multirow[t]{6}{*}{ Lower Salt Creek } & Alkali Flat (Greasewood) & & 3 & 0.69 & 0.67 & 0.55 & 0.91 & 0.69 & 0.75 \\
\hline & Loamy Bottom (Basin Big Sagebrush) & & 3 & 0.85 & 1.00 & 0.34 & 0.99 & 0.73 & 0.94 \\
\hline & Semidesert Sand (Fourwing Saltbush) & & 4 & 0.43 & 0.66 & 0.39 & 0.98 & 0.57 & 0.65 \\
\hline & Semidesert Sandy Loam (Fourwing Saltbush) & & 25 & 0.62 & 0.67 & 0.61 & 0.79 & 0.67 & 0.69 \\
\hline & Semidesert Shallow Sand (Blackbrush) & & 4 & 0.67 & 0.61 & 0.34 & 0.98 & 0.61 & 0.74 \\
\hline & Semidesert Shallow Sandy Loam (Utah Juniper & Blackbrush) & 8 & 0.40 & 0.64 & 0.38 & 0.98 & 0.56 & 0.63 \\
\hline \multirow[t]{6}{*}{ Middle Salt Creek } & Alkali Flat (Greasewood) & & 4 & 0.87 & 0.99 & 0.78 & 0.84 & 0.87 & 0.90 \\
\hline & Loamy Bottom (Basin Big Sagebrush) & & 3 & 0.85 & 1.00 & 0.34 & 0.99 & 0.73 & 0.94 \\
\hline & Semidesert Sand (Fourwing Saltbush) & & 4 & 0.70 & 0.85 & 0.73 & 0.97 & 0.80 & 0.83 \\
\hline & Semidesert Sandy Loam (Fourwing Saltbush) & & 14 & 0.73 & 0.60 & 0.68 & 0.65 & 0.66 & 0.66 \\
\hline & Semidesert Shallow Sand (Blackbrush) & & 1 & 0.71 & 0.81 & 0.40 & 0.98 & 0.69 & 0.83 \\
\hline & Semidesert Shallow Sandy Loam (Utah Juniper & Blackbrush) & 1 & 0.51 & 0.35 & 1.00 & 0.93 & 0.64 & 0.55 \\
\hline \multirow[t]{4}{*}{ Upper Salt Creek } & Loamy Bottom (Basin Big Sagebrush) & & 7 & 0.78 & 0.71 & 0.60 & 0.68 & 0.69 & 0.72 \\
\hline & Semidesert Sand (Fourwing Saltbush) & & 7 & 0.65 & 0.90 & 0.67 & 0.95 & 0.78 & 0.82 \\
\hline & Semidesert Sandy Loam (Fourwing Saltbush) & & 4 & 0.69 & 0.89 & 0.79 & 0.90 & 0.81 & 0.82 \\
\hline & Upland Loam (Basin Big Sagebrush) & & 3 & 0.20 & 0.89 & 0.84 & 0.89 & 0.60 & 0.54 \\
\hline \multirow[t]{2}{*}{ Davis Cyn. } & Semidesert Sand (Fourwing Saltbush) & & 1 & 0.95 & 0.94 & 1.00 & 0.95 & 0.96 & 0.95 \\
\hline & Semidesert Shallow Sandy Loam (Utah Juniper & Blackbrush) & 1 & 1.00 & 1.00 & 0.55 & 0.86 & 0.83 & 0.95 \\
\hline \multirow[t]{3}{*}{ Lavender Creek } & Loamy Bottom (Basin Big Sagebrush) & & 1 & 0.85 & 1.00 & 0.34 & 0.99 & 0.73 & 0.94 \\
\hline & Semidesert Sand (Fourwing Saltbush) & & 1 & 1.00 & 1.00 & 0.47 & 0.35 & 0.64 & 0.70 \\
\hline & Semidesert Sandy Loam (Fourwing Saltbush) & & 1 & 0.93 & 0.96 & 1.00 & 0.91 & 0.95 & 0.93 \\
\hline \multirow[t]{3}{*}{ Beef Basin } & Semidesert Sandy Loam (Fourwing Saltbush) & & 2 & 0.82 & 0.71 & 0.88 & 0.52 & 0.72 & 0.80 \\
\hline & Upland Loam (Basin Big Sagebrush) & & 10 & 0.22 & 0.46 & 0.56 & 0.83 & 0.46 & 0.38 \\
\hline & Upland Shallow Loam (Pinyon Utah Juniper) & & 3 & 0.15 & 0.40 & 0.13 & 0.93 & 0.29 & 0.20 \\
\hline \multirow[t]{2}{*}{ Bridger Jack } & Upland Loam (Basin Big Sagebrush) & & 4 & 0.20 & 0.56 & 0.45 & 0.84 & 0.45 & 0.37 \\
\hline & Upland Shallow Loam (Pinyon Utah Juniper) & & 2 & 0.62 & 1.00 & 0.16 & 0.97 & 0.56 & 0.47 \\
\hline Bull1 & Semidesert Sandy Loam (Fourwing Saltbush) & & 1 & 1.00 & 0.58 & 0.95 & 0.37 & 0.67 & 0.82 \\
\hline Bull3 & Semidesert Sandy Loam (Fourwing Saltbush) & & 1 & 0.60 & 0.88 & 0.67 & 1.00 & 0.77 & 0.71 \\
\hline \multirow[t]{3}{*}{ Dark Canyon } & Semidesert Shallow Sandy Loam (Utah Juniper & Blackbrush) & 11 & 0.43 & 0.00 & 0.36 & 0.97 & 0.00 & 0.00 \\
\hline & Upland Loam (Basin Big Sagebrush) & & 15 & 0.46 & 0.78 & 0.43 & 0.86 & 0.60 & 0.54 \\
\hline & Upland Shallow Loam (Pinyon Utah Juniper) & & 17 & 0.40 & 0.56 & 0.28 & 0.89 & 0.49 & 0.40 \\
\hline \multirow[t]{2}{*}{ Lower Ranch 2} & Semidesert Sand (Fourwing Saltbush) & & 1 & 0.41 & 0.57 & 0.33 & 0.97 & 0.52 & 0.42 \\
\hline & Semidesert Sandy Loam (Fourwing Saltbush) & & 1 & 0.52 & 0.00 & 0.19 & 0.26 & 0.00 & 0.00 \\
\hline Ranch & Semidesert Sandy Loam (Fourwing Saltbush) & & 1 & 1.00 & 0.58 & 0.95 & 0.37 & 0.67 & 0.82 \\
\hline \multirow[t]{3}{*}{ Ruin Park } & Semidesert Sandy Loam (Fourwing Saltbush) & & 9 & 0.82 & 0.78 & 0.89 & 0.66 & 0.78 & 0.83 \\
\hline & Upland Loam (Basin Big Sagebrush) & & 12 & 0.22 & 0.36 & 0.76 & 0.77 & 0.46 & 0.39 \\
\hline & Upland Shallow Loam (Pinyon Utah Juniper) & & 1 & 0.22 & 0.38 & 0.10 & 1.00 & 0.30 & 0.21 \\
\hline
\end{tabular}




\begin{tabular}{|c|c|c|c|c|c|c|c|c|c|}
\hline Watershed/Pasture & Ecological site & & $n=$ & $E_{c}$ & $\mathbf{E}_{\text {dust }}$ & $E_{\text {forage }}$ & $\mathbf{E}_{\text {native }}$ & $E_{m \mid x 1}$ & $E_{m \mid x 2}$ \\
\hline Salt Creek 2 & Upland Shallow Loam (Pinyon Utah Juniper) & & 1 & 0.14 & 0.00 & 1.00 & 0.30 & 0.00 & 0.00 \\
\hline Slick Bench & Upland Shallow Loam (Pinyon Utah Juniper) & & 2 & 0.14 & 0.00 & 1.00 & 0.30 & 0.00 & 0.00 \\
\hline Steven's Mesa & Upland Shallow Loam (Pinyon Utah Juniper) & & 2 & 0.19 & 0.25 & 0.41 & 0.76 & 0.35 & 0.27 \\
\hline Sweet Alice & Upland Shallow Loam (Pinyon Utah Juniper) & & 3 & 0.34 & 0.55 & 0.76 & 0.64 & 0.55 & 0.52 \\
\hline \multirow[t]{3}{*}{ Upper Cottonwood } & Loamy Bottom (Basin Big Sagebrush) & & 2 & 0.21 & 0.00 & 0.12 & 0.37 & 0.00 & 0.00 \\
\hline & Semidesert Sandy Loam (Fourwing Saltbush) & & 1 & 1.00 & 0.58 & 0.95 & 0.37 & 0.67 & 0.82 \\
\hline & Upland Loam (Basin Big Sagebrush) & & 0 & 0.23 & 0.61 & 0.63 & 0.93 & 0.53 & 0.44 \\
\hline Upper Ranch & Alkali Flat (Greasewood) & & 1 & 1.00 & 0.96 & 1.00 & 0.35 & 0.76 & 0.99 \\
\hline \multirow[t]{2}{*}{ Wild Cow } & Upland Loam (Basin Big Sagebrush) & & 2 & 0.60 & 0.91 & 0.61 & 0.89 & 0.74 & 0.69 \\
\hline & Upland Shallow Loam (Pinyon Utah Juniper) & & 5 & 0.58 & 0.80 & 0.26 & 0.94 & 0.58 & 0.50 \\
\hline \multirow[t]{2}{*}{ Wilson Ranch } & Alkali Flat (Greasewood) & & 1 & 1.00 & 0.96 & 1.00 & 0.35 & 0.76 & 0.99 \\
\hline & Semidesert Sandy Loam (Fourwing Saltbush) & & 2 & 0.82 & 0.71 & 0.88 & 0.52 & 0.72 & 0.80 \\
\hline \multirow[t]{4}{*}{ Corral Pocket } & Semidesert Sand (Fourwing Saltbush) & & 2 & 0.41 & 0.57 & 0.33 & 0.97 & 0.52 & 0.42 \\
\hline & Semidesert Sandy Loam (Fourwing Saltbush) & & 2 & 0.60 & 0.88 & 0.67 & 1.00 & 0.77 & 0.71 \\
\hline & Semidesert Shallow Sand (Blackbrush) & & 2 & 0.64 & 0.41 & 0.28 & 0.98 & 0.52 & 0.42 \\
\hline & Semidesert Shallow Sandy Loam (Utah Juniper & Blackbrush) & 1 & 0.43 & 0.00 & 0.36 & 0.97 & 0.00 & 0.00 \\
\hline \multirow[t]{3}{*}{ Cottonwood } & Alkali Flat (Greasewood) & & 1 & 1.00 & 0.96 & 1.00 & 0.35 & 0.76 & 0.99 \\
\hline & Semidesert Sand (Fourwing Saltbush) & & 1 & 0.69 & 0.00 & 0.19 & 0.29 & 0.00 & 0.00 \\
\hline & Semidesert Sandy Loam (Fourwing Saltbush) & & 1 & 1.00 & 0.58 & 0.95 & 0.37 & 0.67 & 0.82 \\
\hline \multirow[t]{3}{*}{ Creek Pasture } & Alkali Flat (Greasewood) & & 1 & 0.42 & 0.00 & 0.25 & 0.74 & 0.00 & 0.00 \\
\hline & Semidesert Sand (Fourwing Saltbush) & & 1 & 0.41 & 0.57 & 0.33 & 0.97 & 0.52 & 0.42 \\
\hline & Semidesert Sandy Loam (Fourwing Saltbush) & & 3 & 0.60 & 0.88 & 0.67 & 1.00 & 0.77 & 0.71 \\
\hline \multirow[t]{4}{*}{ Davis } & Alkali Flat (Greasewood) & & 1 & 0.42 & 0.00 & 0.25 & 0.74 & 0.00 & 0.00 \\
\hline & Semidesert Sand (Fourwing Saltbush) & & 1 & 0.41 & 0.57 & 0.33 & 0.97 & 0.52 & 0.42 \\
\hline & Semidesert Sandy Loam (Fourwing Saltbush) & & 8 & 0.60 & 0.87 & 0.69 & 0.96 & 0.77 & 0.71 \\
\hline & Semidesert Shallow Sandy Loam (Utah Juniper & Blackbrush) & 1 & 1.00 & 1.00 & 0.55 & 0.86 & 0.83 & 0.82 \\
\hline \multirow[t]{3}{*}{ Drill Pasture } & Semidesert Sand (Fourwing Saltbush) & & 1 & 0.41 & 0.57 & 0.33 & 0.97 & 0.52 & 0.42 \\
\hline & Semidesert Sandy Loam (Fourwing Saltbush) & & 2 & 0.62 & 0.86 & 0.74 & 0.84 & 0.76 & 0.73 \\
\hline & Semidesert Shallow Sandy Loam (Utah Juniper & Blackbrush) & 1 & 0.43 & 0.00 & 0.36 & 0.97 & 0.00 & 0.00 \\
\hline GLCA & Semidesert Sand (Fourwing Saltbush) & & 1 & 0.95 & 0.94 & 1.00 & 0.95 & 0.96 & 0.96 \\
\hline \multirow[t]{3}{*}{ Lavender } & Semidesert Sand (Fourwing Saltbush) & & 1 & 0.48 & 0.93 & 0.58 & 1.00 & 0.71 & 0.64 \\
\hline & Semidesert Sandy Loam (Fourwing Saltbush) & & 7 & 0.68 & 0.80 & 0.82 & 0.68 & 0.74 & 0.77 \\
\hline & Upland Shallow Loam (Pinyon Utah Juniper) & & 1 & 0.14 & 0.00 & 1.00 & 0.30 & 0.00 & 0.00 \\
\hline \multirow[t]{3}{*}{ Middle Pasture } & Semidesert Sand (Fourwing Saltbush) & & 1 & 0.69 & 0.00 & 0.19 & 0.29 & 0.00 & 0.00 \\
\hline & Semidesert Sandy Loam (Fourwing Saltbush) & & 3 & 0.60 & 0.88 & 0.67 & 1.00 & 0.77 & 0.71 \\
\hline & Semidesert Shallow Sand (Blackbrush) & & 3 & 0.56 & 0.00 & 0.17 & 0.99 & 0.00 & 0.00 \\
\hline \multirow[t]{4}{*}{ Park Pasture } & Semidesert Sand (Fourwing Saltbush) & & 6 & 0.42 & 0.63 & 0.37 & 0.97 & 0.56 & 0.46 \\
\hline & Semidesert Sandy Loam (Fourwing Saltbush) & & 5 & 0.61 & 0.87 & 0.70 & 0.94 & 0.77 & 0.72 \\
\hline & Semidesert Shallow Sand (Blackbrush) & & 1 & 0.56 & 0.00 & 0.17 & 0.99 & 0.00 & 0.00 \\
\hline & Semidesert Shallow Sandy Loam (Utah Juniper & Blackbrush) & 2 & 0.43 & 0.00 & 0.36 & 0.97 & 0.00 & 0.00 \\
\hline \multirow[t]{2}{*}{ Salt Creek } & Upland Loam (Basin Big Sagebrush) & & 9 & 0.20 & 0.57 & 0.51 & 0.80 & 0.46 & 0.38 \\
\hline & Upland Shallow Loam (Pinyon Utah Juniper) & & 2 & 0.34 & 0.55 & 0.76 & 0.64 & 0.55 & 0.52 \\
\hline
\end{tabular}

